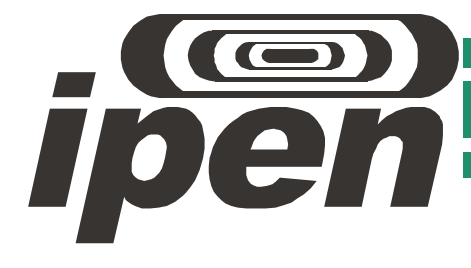

AUTARQUIA ASSOCIADA À UNIVERSIDADE DE SÃO PAULO

\title{
APLICAÇÃO DA ESPECTROSCOPIA DE CORRELAÇÃO ANGULAR PERTURBADA NA INVESTIGAÇÃO DE INTERAÇÕES HIPERFINAS EM COMPOSTOS DE HÁFNIO, INDIO E CÁDMIO COM OS LIGANTES F1-, OH1- e EDTA
}

\author{
Antonio Acleto Amaral
}

Dissertação apresentada como parte dos requisitos para obtenção do Grau de Mestre em Ciências na Área de Tecnologia Nuclear - Aplicações

Orientador:

Prof. Dr. André Luis Lapolli 


\section{INSTITUTO DE PESQUISAS ENERGÉTICAS E NUCLEARES} Autarquia Associada à Universidade de São Paulo

\footnotetext{
Aplicação da Espectroscopia de Correlação Angular Perturbada na Investigação de Interações Hiperfinas em Compostos de Háfnio, Índio e Cádmio com os Ligantes $\mathrm{F}^{1-}, \mathrm{OH}^{1-}$ e EDTA
}

\section{ANTONIO ACLETO AMARAL}

Dissertação apresentada como parte dos requisitos para obtenção do Grau de Mestre em Ciências na Área de Tecnologia Nuclear - Aplicações

Orientador:

Dr. André Luis Lapolli

São Paulo

2011 
Comissão Examinadora:

Dr. André Luis Lapolli (orientador)

Dr. Artur Wilson Carbonari

Dr. Marcos Brown Gonçalves 


\section{AGRADECIMENTOS}

A todos, que direta ou indiretamente participaram na construção desse trabalho. Em especial agradeço:

- A Deus, "porque nEle vivemos, e nos movemos, e existimos" (At.17:28);

- Ao Dr. André Luis Lapolli, pela orientação competente e sempre presente, pelos conselhos e oportunidade de realização desse trabalho;

- Ao Dr. Artur Wilson Carbonari, pela sempre pronta e gentil assessoria e esclarecimentos;

- Ao Dr. Rajandra Narain Saxena, pelas várias discussões e esclarecimentos na área da "química nuclear".

- Ao Dr. José Mestnik Filho, pelas discussões e incentivo.

- A Ms Andréia dos Santos Silva pela parceria.

- Aos amigos Dr Gabriel, Dr Messias, Ms Luciano, Ms Moacir, Ms Briana, Ms Renilson, Daniel, Juliana e Tiago pelo carinho e pelas conversas esclarecedoras que permitiram a compreensão de diversos conceitos fundamentais para a conclusão desse trabalho.

- À minha esposa Iris e a meus filhos Rafael e Caroline, por todo amor, carinho e paciência durante a realização desse trabalho;

- Aos meus pais Hernane e Maria (em memória) pela base moral e por incutirem em mim a importância da perseverança. 


\title{
APLICAÇÃO DA ESPECTROSCOPIA DE CORRELAÇÃO ANGULAR PERTURBADA NA INVESTIGAÇÃO DE INTERAÇÕES HIPERFINAS EM COMPOSTOS DE HÁFNIO, INDIO E CÁDMIO COM OS LIGANTES $\mathrm{F}^{1-}$, OH $^{1-}$ e EDTA.
}

\author{
Antonio Acleto Amaral
}

\section{RESUMO}

O presente trabalho realiza a investigação dos parâmetros hiperfinos, incluindo a sua natureza dinâmica, em compostos ligantes em solução a temperatura ambiente (295 K) e resfriada (77K) através da espectroscopia de Correlação Angular $\gamma-\gamma$ Perturbada (CAP). Para a realização das medidas experimentais, utilizou-se núcleos de prova radioativos de ${ }^{111} \mathrm{In} \rightarrow{ }^{111} \mathrm{Cd},{ }^{181} \mathrm{Hf} \rightarrow{ }^{181} \mathrm{Ta}$ e ${ }^{111 \mathrm{~m}} \mathrm{Cd} \rightarrow{ }^{111} \mathrm{Cd}$, que decaem através de cascata gama. As amostras foram preparadas diluindo-se soluções com os núcleos radioativos em água, quando se investigou a interação do núcleo de prova com o ligante água; adicionando-se soluções com os núcleos radioativos em solução tampão, quando se investigou a interação do núcleo de

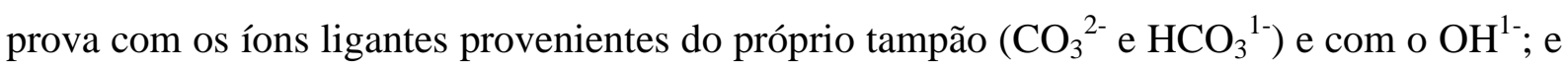
adicionando-se soluções com os núcleos radioativos em soluções do ligante ácido etilenodiaminotetracético (EDTA), este em pH entre 4,0 e 5,0, (que corresponde ao pH da própria solução saturada do EDTA) e em solução tampão de pH entre 9 e 10. Assim foi possível investigar os efeitos gerados por cada um desses métodos de preparação de amostras nas medidas CAP. Finalmente foi feita uma análise comparativa para os vários métodos de inserção dos núcleos de prova na amostra, considerando-se aspectos químicos e nucleares. A inexistência de medidas para esse tipo de amostra, justifica a importância dos resultados obtidos. 


\section{APPLICATION OF THE PERTURBED ANGULAR CORRELATION IN THE INESTIGATION OF HYPERFINE INTERACTIONS IN COMPOUNDS OF HAFNIUM, INDIUM AND CADMIUM WITH $\mathbf{F}^{1-}, \mathrm{OH}^{1-}$ AND EDTA LIGANDS.}

Antonio Acleto Amaral

\section{ABSTRACT}

In this study the hyperfine parameters, including the dynamical nature, Perturbed Angular Correlation (PAC) spectroscopy was used to measure the hyperfine parameters in molecules of ligand compounds in solutions. The measurements were carried out at $295 \mathrm{~K}$ and $77 \mathrm{~K}$ using ${ }^{111} \mathrm{In} \rightarrow{ }^{111} \mathrm{Cd},{ }^{181} \mathrm{Hf} \rightarrow{ }^{181} \mathrm{Ta}$ and ${ }^{111 \mathrm{~m}} \mathrm{Cd} \rightarrow{ }^{111} \mathrm{Cd}$, as probe nuclei. Samples were prepared by adding a small volume of radioactive solution containing the probe nuclei in aqueous solution, buffer solution and ethylenediaminetetraacetic acid (EDTA) used as a ligand with $\mathrm{pH} 4.3$ which correspond to the $\mathrm{pH}$ of the saturated EDTA solution and in buffer solution with $\mathrm{pH}$ between 9 and 10. The results made possible to understand the impact of each method for PAC measurements. Finally a comparative analysis for the several methods of inserting of the probe nuclei in the sample was made, considering chemical and nuclear aspects. The lack of measurements in this kind of samples justifies the importance of the obtained results. 


\section{SUMÁRIO}

1 Introdução …............................................................................................................................................1

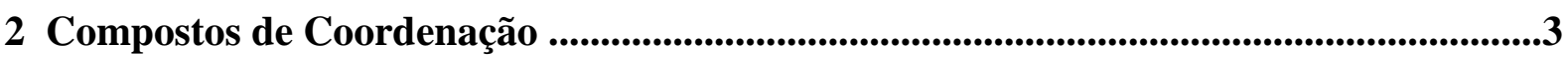

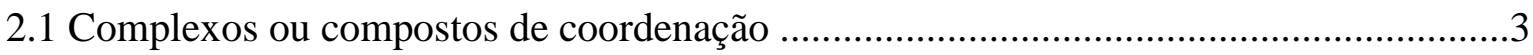

2.2 Como ocorrem as ligações entre o metal e os ligantes ...............................................

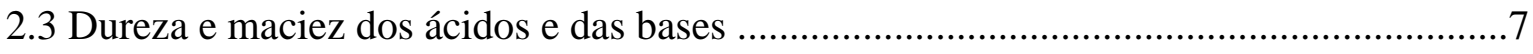

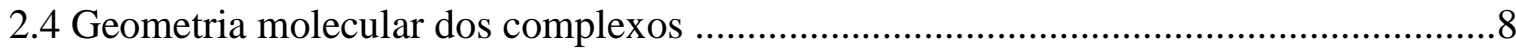

2.5 Reatividade do íon metálico dentro de sua esfera de coordenação numa

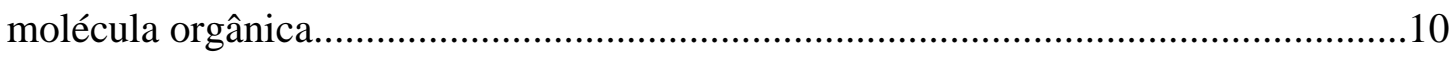

2.6 Importância dos equilíbrios envolvendo complexos.................................................11

2.7 Efeito do pH sobre o equilíbrio metal-complexo .......................................................12

2.8 Alguns aspectos da química do EDTA e a influencia do pH no seu equilíbrio

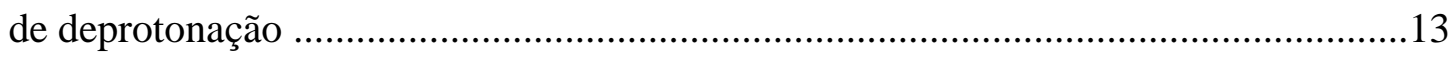

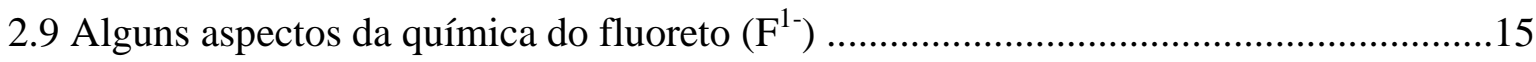

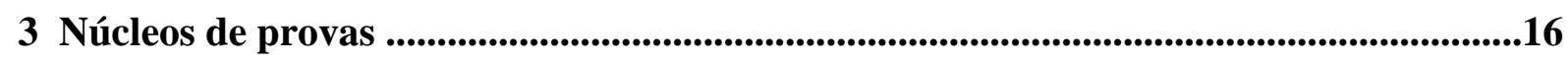

3.1 Núcleos de prova radioativos e suas propriedades .................................................16

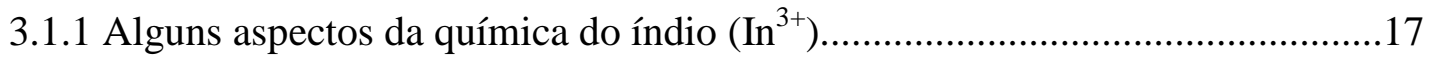


3.1.2 Alguns aspectos da química do cádmio $\left(\mathrm{Cd}^{2+}\right)$

3.4.3 Alguns aspectos da química do Háfnio $\left(\mathrm{Hf}^{4+}\right)$ 18

4. Interações hiperfinas

4.1 Correlação angular $\gamma-\gamma$

4.1.1 Correlação angular $\gamma-\gamma$ não perturbada .24

4.1.2 Correlação angular $\gamma-\gamma$ perturbada .25

4.2 Interação Elétrica.

4.3 Interação Dinâmica. 30

4.4. O Índio e o "after-effects"

4.5 Núcleos de prova radioativos - algumas propriedades nucleares 32

5 Arranjo Experimental e Procedimentos.

5.1.1.1 Confecção das amostras contendo ${ }^{111}$ In .38

5.1.1.2 Confecção da amostra de ${ }^{111 \mathrm{~m}} \mathrm{Cd}$ : 39

5.1.1.3 Confecção da amostra contendo ${ }^{181} \mathrm{Hf}$ :

5.1.1.3.1 Confecção da amostra contendo ${ }^{181} \mathrm{Hf}$ a partir do ${ }^{181} \mathrm{Hf}$ metálico .40

5.1.1.3.2 Confecção das amostras contendo ${ }^{181} \mathrm{Hf}$ a proveniente do oxicloreto de háfnio. 
5.3 Tratamento dos dados

6 Resultados Discussões

6.1 Amostras com adição de ${ }^{111} \mathrm{In} \rightarrow{ }^{111} \mathrm{Cd}$ como núcleo de prova..............................46

6.2 Amostras com adição de ${ }^{111 \mathrm{~m}} \mathrm{Cd} \rightarrow{ }^{111} \mathrm{Cd}$ como núcleo de prova............................50

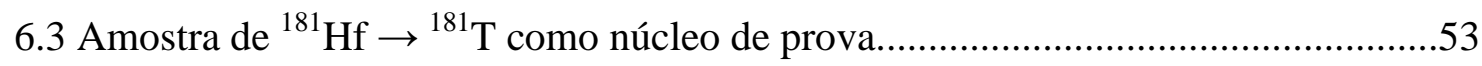

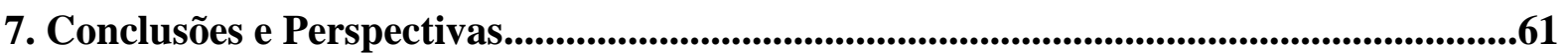

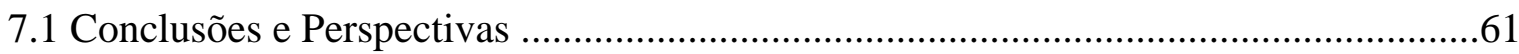

7.1.1 Amostras com ${ }^{111} \mathrm{In} \mathrm{e}^{111 \mathrm{~m}} \mathrm{Cd}$ como pontas de prova .....................................62

7.1.2 Amostras com ${ }^{181}$ Hf como ponta de prova .................................................63

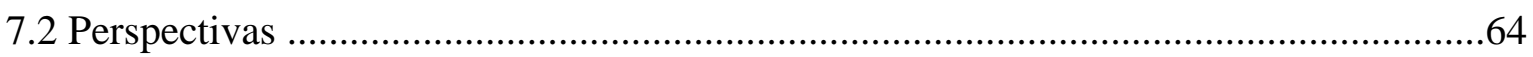

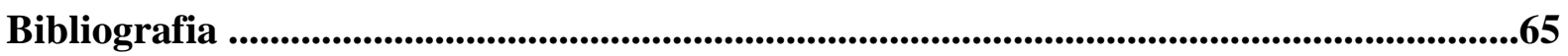




\section{LISTA DE TABELAS}

Tabela 1 - Ácidos e bases duros e moles

Tabela 2 - Algumas características dos elementos zircônio e háfnio 20

Tabela 3 - Espécies de zircônio em solução na ausência de ligantes.

Tabela 4 - Parâmetros Hiperfinos obtidos do núcleo de prova ${ }^{111} \mathrm{Cd}$ em solução aquosa, com EDTA em pH entre 4 e 5 e EDTA e em pH entre 9 e 10.

Tabela 5 - Parâmetros Hiperfinos obtidos do núcleo de prova ${ }^{111 \mathrm{~m}} \mathrm{Cd}$ em solução aquosa e com solução saturada de EDTA em pH entre 9 e 10.

Tabela 6. Parâmetros Hiperfinos obtidos do núcleo de prova ${ }^{181}$ Ta em solução aquosa, em solução tampão com EDTA em pH entre 4 e 5 e com EDTA em pH entre 9 e 10 


\section{LISTA DE FIGURAS}

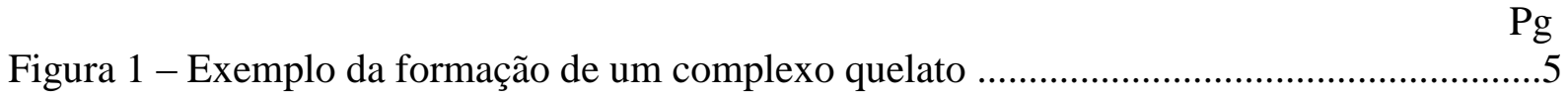

Figura 2 - Exemplo de uma ligação em ponte ….............................................................

Figura 3 - Porção da hemoglobina responsável pelo transporte de oxigênio ..........................12

Figura 4 - Diagrama para a distribuição de espécies para o EDTA em solução aquosa em

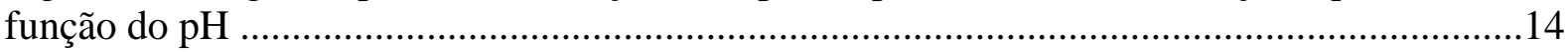

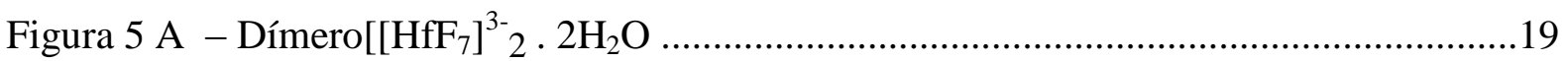

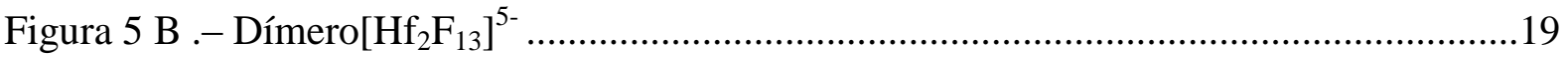

Figura 6 - Núcleo de prova no interior do cristal .........................................................26

Figura 7 - Esquema simplificado de decaimento gama em cascata ...................................26

Figura 8 - Desdobramento de um estado nuclear causado por um gradiente de campo

elétrico

Figura 9 - Decaimento do ${ }^{111}$ In e ${ }^{111 \mathrm{~m}} \mathrm{Cd}$. A ampliação mostra os três possíveis níveis de energia do estado intermediário de spin $5 / 2$ devido à influencia de gradientes de campo elétricos extranucleares

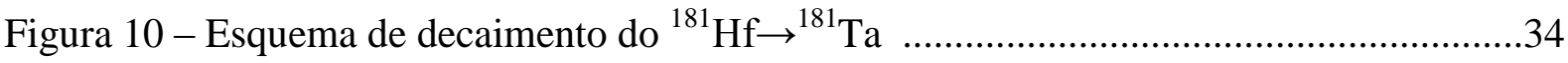

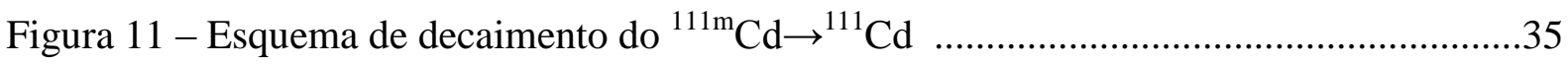

Figura 12 - Esquema simplificado do espectrômetro com quatro detectores ........................42

Figura 13- Espectro de correlação angular perturbada do ${ }^{111} \mathrm{Cd}$ em solução aquosa: a $295 \mathrm{~K}$ e B) a $77 \mathrm{~K}$.

Figuras 14 - Espectro de correlação angular perturbada do ${ }^{111} \mathrm{Cd}$ com EDTA em pH entre4 e 5 (da própria solução saturada de EDTA): 14 - A a 295K e $14-\mathrm{B}$ a $77 \mathrm{~K}$ 
Figuras 15 - Espectro de correlação angular perturbada do ${ }^{111} \mathrm{Cd}$ com EDTA em pH entre 9 e 10 (Ajustada com solução de $\mathrm{NaOH}$ ): 15 - A a 295K e 14 - B a $77 \mathrm{~K}$

Figuras 16 - Espectro de correlação angular perturbada do ${ }^{111 \mathrm{~m}} \mathrm{Cd}$ em solução aquosa: 17 - A a $295 \mathrm{~K}$ e 17 - B a $77 \mathrm{~K}$

Figuras 17 - Espectro de correlação angular perturbada do ${ }^{111 \mathrm{~m}} \mathrm{Cd}$ com solução saturada de EDTA em pH entre 4 e 5 (pH da própria solução saturada de EDTA) a $295 \mathrm{~K}(\mathrm{~A})$ e $77 \mathrm{~K}(\mathrm{~B})$

Figuras 18 - Espectro de correlação angular perturbada do ${ }^{111 \mathrm{~m}} \mathrm{Cd}$ com EDTA em pH entre 9 e 10 (EDTA em solução tampão) a 295K (A) e 77K (B)...

Figura 19 - Espectro de correlação angular perturbada para solução aquosa do ${ }^{181} \mathrm{Hf}$ .54

Figura 20 - Espectro de correlação angular perturbada para o ${ }^{181} \mathrm{Hf}$ a mais solução saturada de EDTA: A) a 295 e B) a $77 \mathrm{~K}$

Figura 21 - Espectro de correlação angular perturbada para o ${ }^{181} \mathrm{Hf}$ mais solução saturada de EDTA (cristalizado): A) a 295 e B) a $77 \mathrm{~K}$

Figura 22 - Espectros de correlação angular perturbada para a amostra de $\mathrm{HfOCl}_{2} \mathrm{em}$ solução aquosa a) a 295 e B) a $77 \mathrm{~K}$

Figura 23 - Espectros de correlação angular perturbada para as amostras de $\mathrm{HfOCl}_{2}$ em solução tampão a pH 10 a $77 \mathrm{~K}$

Figura 24 - Espectro de correlação angular perturbada para a solução de $\mathrm{HfOCl}_{2}$ mais EDTA em tampão pH 10: A) a 295K e B) a77K

Figura $25 \mathrm{~A}$ - Monômero $\left[\mathrm{HfF}_{6}\right]^{2-}$ .58

Figura $25 \mathrm{~B}$ - Monômero $\left[\mathrm{Hf}_{4} \mathrm{~F}_{12}\right]^{4-}$ .58

Figura $25 \mathrm{C}$ - Monômero $\left[\mathrm{HfF}_{6}\right]^{2-}$ 59

Figura $25 \mathrm{D}$ - Dímero $\left[\mathrm{Hf}_{2} \mathrm{~F}_{14}\right]^{2-}$ .59

Figura 26 - Estrutura da molécula de trietilenotetramina ligada ao dímero $\left[\mathrm{Hf}_{2} \mathrm{~F}_{12}\right]^{4-}$ .59 


\section{CAPÍTULO 1}

\section{INTRODUÇÃO}

O conhecimento do comportamento das biomoléculas é de fundamental importância para a compreensão dos fenômenos relacionados com a dinâmica metabólica dos sistemas biológicos, processos imunológicos, processos terapêuticos, etc. Outra questão importante, ainda pouco conhecida, é como os íons metálicos, essenciais ou não, entram nas células já que são muito reativos com diferentes alvos presentes no conteúdo celular [1].

Na bioquímica, um dos problemas chaves do estudo de proteínas compostas com um metal é a compreensão da sua estrutura, dinâmica molecular e a posição de ligação do metal, entre outras questões fundamentais. Neste sentido, muitos estudos são realizados visando a compreensão de todo este processo, mas de maneira geral, as melhores interpretações são do ponto de vista ainda macroscópico (em nível celular) [1].

De certa forma, para se compreender melhor o sistema biológico há a necessi dade de se compreender o que ocorre microscopicamente, investigando as interações loc ais (em nível molecular). Umas das formas de se investigar tais interações é através do estudo de interações hiperfinas em biomoléculas que pode ser realizado por meio de div ersas técnicas. As interações hiperfinas fornecem informações sobre a vizinhança atômi ca em torno de um núcleo de prova numa escala nanométrica por meio das interações en 
tre os momentos deste núcleo e as cargas e spins na sua vizinhança. A espectroscopia de Ressonância Magnética Nuclear (RMN) é reconhecidamente a técnica mais importante para a investigação a nível molecular, permitindo obter informação estrutural e dinâmic a para qualquer estado da matéria. Em particular é um método decisivo na determinação de estruturas tridimensionais de moléculas no estado líquido, mas é incapaz de observar dinâmicas locais. Neste sentido a técnica de Correlação Angular Perturbada (CAP) perm ite a obtenção dos parâmetros hiperfinos tanto estáticos quanto dinâmicos que correspon dem a vários fenômenos que podem ocorrer em diversos materiais ou em uma única mo lécula. A técnica CAP têm sido aplicada com sucesso para o estudo das interações entre átomos metálicos radioativos inseridos num determinado material (ponta de prova) e su a vizinhança [1-3].

O propósito do presente trabalho é o de estabelecer uma metodologia de preparação de amostras para materiais em solução, bem como de tratamento dos dados adquiridos na investigação desse tipo de amostra. Após o que, pode-se utilizá-lo para o estudo das interações hiperfinas num sítio específico de biomoléculas tais como aminoácidos, polipeptídios, proteínas entre outras, contribuindo significativamente para a compreensão das estruturas moleculares de tais compostos e dos mecanismos químicos dos quais participam no meio biológico.

A presente dissertação começa apresentando alguns fundamentos da química de coordenação, da química dos ligantes $\mathrm{F}^{1-}$, das espécies provenientes do Etilenodiaminotetracetato de sódio - EDTA dissódico $\left(\mathrm{C}_{10} \mathrm{H}_{14} \mathrm{~N}_{2} \mathrm{O}_{8} \mathrm{Na}_{2} \cdot 2 \mathrm{H}_{2} \mathrm{O}\right)$ (Capítulo 2) e dos elementos utilizados como pontas de prova (Capítulo 3). Em seguida, apresenta-se a teoria que envolve as Interações Hiperfinas de natureza elétricas e também de natureza dinâmica. Com base nesses conceitos, apresenta-se a técnica de Correlação Angular $\gamma-\gamma$ Perturbada (Capítulo 4), seguida da descrição breve do aparato experimental para a realização das medidas e tratamento dos dados (Capítulo 5). Na sequência são descritos os materiais e procedimentos utilizados na preparação das amostras (Capítulo 6). Após a apresentação da metodologia experimental, os resultados obtidos são apresentados e discutidos sistematicamente possibilitando a interpretação física e química dos dados experimentais (Capítulo 6). Por fim são apresentadas as conclusões do trabalho, ressaltando-se suas contribuições e apresentando as perspectivas para futuros trabalhos nessa mesma área (Capítulo 7). 


\section{CAPÍTULO 2}

\section{COMPOSTOS DE COORDENAÇÃO}

A seguir serão apresentados alguns fundamentos teóricos da química de coordenação. Destacam-se também algumas das propriedades químicas dos ligantes fluoreto e EDTA considerados neste trabalho.

\subsection{Complexos ou Compostos de Coordenação}

Uma propriedade importante dos metais é a sua propensão em perder elétrons com facilidade e formar íons positivos o que possibilita a sua solubilidade nos fluidos biológicos. Esta característica faz dos metais importantes componentes funcionais e estruturais dos seres vivos. É na forma de cátions que os metais desempenham suas principais funções biológicas [4]. No entanto, os íons metálicos simples, muitas vezes, não possuem as características necessárias para exercerem as funções biológicas correspondentes. Nesses casos, a espécie metálica envolvida, deverá estar combinada através de ligações covalentes coordenadas a um composto orgânico 
complexo, e é o composto de coordenação resultante que possui a necessária atividade biológica [5].

Na forma de cátions, os metais apresentam-se deficientes de elétrons, (agem quimicamente como ácidos de Lewis), o que faz com que se liguem com facilidade a moléculas ricas em elétrons (bases de Lewis). A atração entre estas oposições de cargas leva a tendência geral dos íons metálicos interagirem com moléculas biológicas que, geralmente apresentam grupos doadores de elétrons. O composto resultante é chamado de complexo ou composto de coordenação [4].

Os íons ou moléculas ligadas ao átomo metálico por coordenação são denominados de ligantes e devem possuir pares de elétrons não compartilhados para que estabeleçam as ligações coordenativas (ligantes = espécies doadoras de pares de elétrons). Um ligante pode ser um simples ânion, como por exemplo, $\mathrm{Cl}^{1-}, \mathrm{F}^{1-}$, ou moléculas neutras tais como $\mathrm{H}_{2} \mathrm{O}, \mathrm{NH}_{3}$, ou ainda espécies carregadas, tais como $\mathrm{CN}^{1-}$ [6].

A coordenação de ligantes neutros pode ser entendida em termos de ligações dativas, enquanto a coordenação entre o íon metálico e os ligantes carregados negativamente pode ser entendida em termos de ligação iônica levando-se em conta os quesitos de tamanho e neutralidade de carga.

O número de ligações formadas entre o íon metálico e o ligante corresponde ao número de coordenação do metal.

Três fatores governam o número de coordenação de um complexo [6]:

a) O tamanho do átomo ou íon central;

b) As interações espaciais entre os ligantes;

c) As interações eletrônicas entre o átomo ou íon central e os ligantes.

Se a natureza da ligação entre o metal e os ligantes for covalente, então os números de coordenação, dependem dos orbitais atômicos vazios do metal. Vários complexos de coordenação de metais de transição covalentes se encaixam na chamada regra dos 18 elétrons, segundo a qual a coordenação de um íon metálico encontra-se 
saturada quando cada um dos orbitais de valência do metal está ocupado por um par de elétrons $\left(d^{10} s^{2} p^{6}\right)[6]$.

Os ligantes podem apresentar mais de um átomo com disponibilidade eletrônica para efetuar ligações coordenadas. Assim, eles são classificados em: monodentados, quando possuem apenas um átomo doador, ou polidentados, quando possuem mais de um átomo doador. Quando dois ou mais átomos do ligante efetuam ligação coordenada para um mesmo átomo metálico, a molécula ligante é denominada quelante e o complexo formado pode ser chamado de quelato, conforme exemplo da figura $1[4]$.

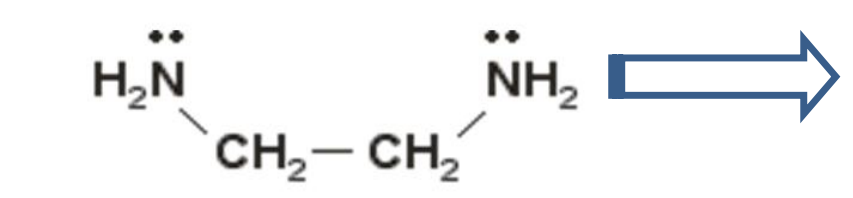

ligante bidentado (etilenodiamina)

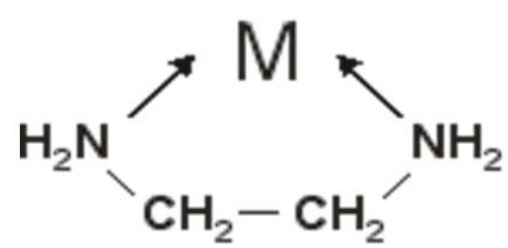

quelato

Figura 1 - Exemplo da formação de um complexo quelato

Quando cada um dos átomos do ligante efetua uma ligação coordenada para um átomo metálico distinto (estes metais podem ser iguais ou diferentes), a ligação é dita em ponte, conforme exemplo da figura 2.

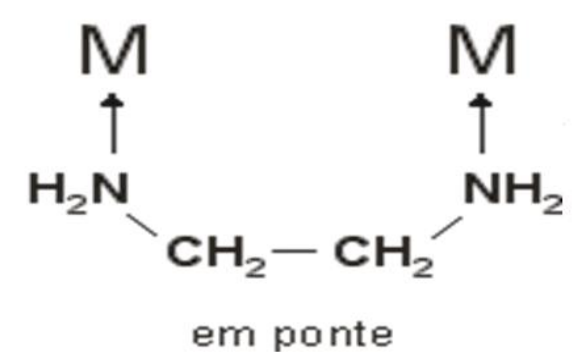

Figura 2 - Exemplo de uma ligação em ponte.

Os compostos de coordenação formados a partir destas interações são extremamente estáveis devido ao denominado efeito quelato. Termodinamicamente, o efeito quelato deve-se principalmente ao aumento de entropia associada à formação 
desses compostos. Isso ocorre por que, na reação de formação, cada ligante polidentado substitui pelo menos dois ligantes monodentados, o que leva a um aumento do número de espécies químicas (íons, moléculas, radicais livres) no sistema, como pode ser observado nas reações equacionadas a seguir [7].

$$
\begin{aligned}
& {\left[\mathrm{Ni}\left(\mathrm{NH}^{3}\right)_{6}\right]^{2+}+3 \mathrm{en} \leftrightarrow\left[\mathrm{Ni}(\mathrm{en})^{3}\right]^{2+}+6 \mathrm{NH}_{3} ; \quad \Delta \mathrm{S}^{0}=121 \mathrm{~J} \cdot \mathrm{K}^{-1} \cdot \mathrm{mol}^{-1}} \\
& \Delta \mathrm{H}^{0}=-17 \mathrm{~kJ} \cdot \mathrm{mol}^{-1}
\end{aligned}
$$

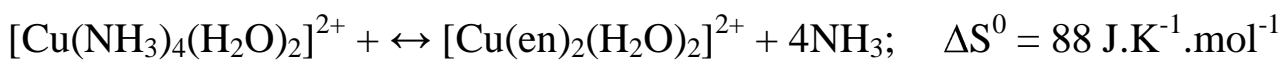

$$
\begin{aligned}
& \Delta \mathrm{H}^{0}=-15 \mathrm{~kJ} \cdot \mathrm{mol}^{-1}
\end{aligned}
$$

Como a água é uma base de Lewis, ela forma complexo com a maioria dos metais do bloco $d$. Soluções aquosas de íons dos metais $d$ são normalmente soluções de complexos com água [8]. Considerando que haja afinidade química entre o íon metálico e a molécula-ligante, para que ocorra a formação de um complexo metálico, primeiramente é necessário que tanto o íon metálico quanto a molécula-ligante sofram desovatação, ou seja, se "separem” das moléculas de água. Depois da desovatação o íon e a molécula-ligante se ligam (complexação) e posteriormente, o complexo formado volta a sofrer solvatação [4].

Os complexos podem ser caracterizados como moléculas simples, por forças de ligação, comprimento de ligação e ângulos de ligação. No entanto diferem da maioria das moléculas simples pela facilidade com que as ligações metal-ligante se formam e se quebram. Em meio aquoso, os íons complexos devem ser imaginados como espécies dinâmicas, em que os ligantes estão sempre abandonando e voltando ao complexo. Deste modo, se tem composição e geometria médias para um dado complexo em meio aquoso. Entretanto, ainda é útil descrever estas espécies pelos mesmos métodos básicos usados para as moléculas mais "permanentes" [5]. 


\subsection{Como ocorrem as ligações entre o metal e os ligantes}

A primeira teoria formulada para explicar as ligações existentes nos compostos de coordenação foi elaborada por Alfred Werner que postulou [9]:

1) A maior parte dos elementos possuem dois tipos de valência: a valência primária (número de oxidação) e a valência secundária (número de coordenação);

2) Todo elemento tende a satisfazer tanto suas valências primárias quanto as valências secundárias;

3) A valência secundária apresenta direções fixas no espaço.

A teoria de Werner propõe que as ligações coordenadas são formadas por meio da doação de um par de elétrons por parte do ligante ao íon metálico central do complexo.

A formação de compostos de coordenação pode ocorrer com facilidade com os metais de transição já que estes apresentam orbitais $\boldsymbol{d}$ disponíveis para receberem os pares de elétrons doados pelo ligante. O número de ligações coordenadas formadas depende, sobretudo, do número de orbitais vazios de energia adequada.

\subsection{Dureza e maciez dos ácidos e das bases}

Os íons metálicos e os ligantes podem ser classificados como duros e moles ou macios. Estabeleceu-se empiricamente que ácidos duros coordenam-se preferencialmente a bases duras e os ácidos moles, a bases moles [10,11]. Nos sistemas bioinorgânicos, esse conceito de ácidos e bases duros e moles é aplicado. Um exemplo clássico é o da metalotioneína na qual, grupos tióis da cisteína, após a desprotonação, 


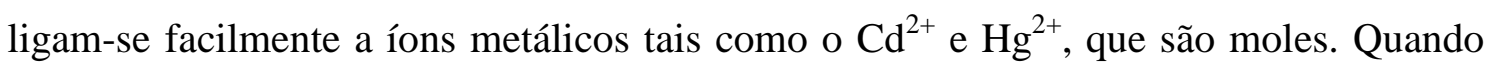
acontece uma contaminação dos organismos por metais moles, acontece um aumento na produção da metalotioneína pelo fígado sugerindo uma função protetora do organismo contra esses metais tóxicos $[10,11]$.

Ligantes duros formam ligações através de átomos de oxigênio e nitrogênio e se ligam preferencialmente a metais "duros" enquanto os ligantes moles formam ligações preferencialmente através S e P e se ligam a metais "moles" [4]. As espécies duras tendem a ser pequenas e com elevadas cargas enquanto as moles tendem a ser maiores com cargas menores. Na tabela 1 estão mostrados alguns ácidos e bases moles e duros.

Tabela 1. Ácidos e bases duros e moles [11,12]

\begin{tabular}{|c|c|c|}
\hline & Ácidos & Bases \\
\hline Duros & $\begin{array}{l}\mathrm{H}^{+}, \mathrm{Eu}^{3+}, \mathrm{Ca}^{2+}, \mathrm{Na}^{+}, \mathrm{Mg}^{2+}, \mathrm{In}^{3+} \mathrm{Sc}^{3+}, \mathrm{La}^{3+}, \\
\mathrm{Ce}^{4+}, \mathrm{K}^{+}, \mathrm{Co}^{3+}, \mathrm{Ti}^{4+}, \mathrm{Cr}^{3+}, \mathrm{Fe}^{3+}, \mathrm{Li}^{+}, \mathrm{Be}^{2+}, \\
\mathrm{Sr}^{2+}, \mathrm{Zr}^{4+}, \mathrm{Hf}^{4+}, \mathrm{Cr}^{6+}, \mathrm{Mn}^{2+}, \mathrm{Mn}^{7+}, \mathrm{Sn}^{4+}, \\
\mathrm{Si}^{4+}, \mathrm{As}^{3+}, \mathrm{Ga}^{3+}, \mathrm{N}^{3+}, \mathrm{Cl}^{3+}, \mathrm{Cl}^{7+}, \mathrm{I}^{5+}, \mathrm{I}^{7+}, \\
\text { etc. }\end{array}$ & $\begin{array}{l}\mathrm{F}^{-}, \mathrm{NH}_{3}, \mathrm{O}^{2-}, \mathrm{H}_{2} \mathrm{O}, \mathrm{SO}_{4}{ }^{2-}, \\
\mathrm{NO}_{3}^{-}, \mathrm{ClO}_{4}^{-}, \mathrm{CO}_{3}{ }^{2-}, \mathrm{OH}^{-}, \\
\mathrm{RNH}_{2}, \mathrm{CH}_{3} \mathrm{COO}^{-}, \mathrm{PO}_{4}{ }^{3-}, \\
\mathrm{N}_{2} \mathrm{H}_{4}, \mathrm{ROH}, \mathrm{RO}^{-}, \mathrm{R}_{2} \mathrm{O}, \\
\mathrm{RCO}_{2}{ }^{-} \text {, etc. }\end{array}$ \\
\hline Moles & $\begin{array}{l}\mathrm{Pd}^{2+}, \mathrm{Pt}^{2+}, \mathrm{Pt}^{4+}, \mathrm{Cu}^{+}, \mathrm{Ag}^{+}, \mathrm{Au}^{+}, \mathrm{Cd}^{2+}, \\
\mathrm{Hg}^{+}, \mathrm{Hg}^{2+}, \mathrm{CH}_{3} \mathrm{Hg}^{+}, \mathrm{Tl}^{+}, \mathrm{CH}_{2}, \mathrm{O}, \mathrm{Cl}, \\
\mathrm{Br}, \mathrm{I}, \mathrm{N}, \mathrm{RO}, \mathrm{RO}_{2} .\end{array}$ & $\begin{array}{l}\mathrm{H}^{-}, \mathrm{RSH}, \mathrm{CN}^{-}, \mathrm{SCN}^{-}, \mathrm{I}^{-} \\
\mathrm{R}_{3} \mathrm{P}, \mathrm{R}_{2} \mathrm{~S}, \mathrm{RS}^{-}, \mathrm{S}_{2} \mathrm{O}_{3}{ }^{2-}\end{array}$ \\
\hline
\end{tabular}

\subsection{Geometria molecular dos complexos}

As estruturas geométricas dos complexos metálicos podem ser determinadas de diversas maneiras. Quando se consegue obter monocristais, a difração de raios X é uma técnica muito eficiente, capaz de fornecer as formas, as distâncias e os ângulos. A ressonância magnética nuclear pode ser aplicada no estudo da geometria quando os 
complexos tem vida maiores do que microssegundos. A espectroscopia eletrônica e vibracional pode ser aplicada para o estudo da geometria de complexos de vida muito curta (poucos nano segundos). É possível inferir as geometrias de complexos com tempos de vida longos em solução analisando padrões de reação e isomeria [6].

Os complexos nos quais os ligantes estão ligados diretamente ao íon metálico central são denominamos de complexos de esfera interna. Os ligantes formam a esfera de coordenação primária do complexo, e o número de ligantes é chamado de número de coordenação do átomo metálico central. Porém, um íon metálico central poderá se associar ainda, eletrostaticamente a ligantes aniônicos (e por interações fracas às moléculas de solvente) sem deslocar as moléculas dos ligantes já presentes. O produto dessa associação é chamado de complexo de esfera externa. É importante lembrar que a maioria dos métodos utilizados para estudar o equilíbrio de complexação não são capazes de distinguir a formação de um complexo de esfera interna de outro de esfera externa. Porém sempre que o metal e os ligantes presentes no meio possuírem cargas opostas, haverá a possibilidade da formação de complexos de esfera externa [6].

Complexos de íons metálicos com número de coordenação quatro, cinco ou seis, constituem a classe mais importante de complexos. Eles incluem a grande maioria dos complexos presentes em solução e praticamente todos os complexos biologicamente importantes [6]. Sendo que a maioria dos complexos hexacoordenados é octaédrica ou tem formas que são pequenas distorções do octaedro [6]. Para complexos com um conjunto misto de ligantes, como os compostos de fórmula $\mathrm{MA}_{2} \mathrm{~B}_{4}$, onde $\mathrm{A}$ e $\mathrm{B}$ representam ligantes diferentes, pode ocorrer a formação de dois isômeros, o cis e o trans [13].

Quando os ligantes polidentados (formadores de quelatos), só permitem pequenos ângulos de mordidas (ângulos de ligação), causam distorções nos complexos hexacoordenados octaédricos para uma geometria prismática trigonal [6].

Para complexos metálicos tetracoordenados a geometria geral é tetraédrica. Complexos pentacoordenados são mais frequentemente encontrados nas formas trigonal bipiramidal ou pirâmide de base quadrada [13]. 


\subsection{Reatividade do íon metálico dentro de sua esfera de coordenação numa molécula orgânica}

São diversas as maneiras de como um íon metálico coordenado a uma molécula orgânica pode influenciar nas reações químicas envolvendo essa molécula. Como por exemplo:

- O metal pode servir como centro para a ligação e organização da molécula com um substrato.

- O metal pode polarizar um substrato tornando-o capaz de realizar reações incomuns para o mesmo.

- O metal pode mudar a conformação usual do ligante e consequentemente sua reatividade.

- O centro metálico pode apresentar atividade redox e ser capaz de reduzir ou oxidar o ligante. A capacidade dos metais de transição de apresentar variáveis estados de oxidação permite as chamadas reações de adição-oxidativa ou eliminação redutiva.

- O metal pode ter a energia dos seus orbitais de fronteira com os ligantes alterada e também os estados de spin (propriedades magnéticas).

- O íon metálico polariza a densidade eletrônica do ligante. O papel do metal é atual como eletrófilo e facilitar o ataque nucleófilo ao ligante.

Dessa forma a interação do metal sobre o ligante e do ligante sobre o metal é simbiótica [13]. 


\subsection{Importância dos equilíbrios envolvendo complexos}

Em consequência da facilidade com que os íons metálicos se combinam quimicamente com espécies ricas em elétrons (bases de Lewis) há a formação de inúmeros sistemas envolvendo íons metálicos e ligantes, constituindo-se num campo fundamental para estudo desses complexos bem como para diversas aplicações.

Para se obter informações químicas sobre as espécies presentes numa solução, faz-se necessário uma discussão sobre as constantes de estabilidade em termos termodinâmicos e estruturais de tais sistemas. A tentativa de explicação dos valores de tais constantes, considerando-se as diversas abordagens teóricas clássicas, leva a formação de modelos que permitem a explicação de dados experimentais. São muitas as áreas nas quais a pesquisa envolvendo sistemas com formação de complexos vem sendo desenvolvida e aplicada, dentre as quais citamos a química analítica, a medicina, a geoquímica, a fotografia e a poluição [14].

Dentre os processos biológicos que envolvem a presença de complexos metálicos pode-se citar a fotossíntese, onde o magnésio participa da clorofila, e respiração dos mamíferos, onde o ferro (II) $\mathrm{Fe}^{2+}$, através da hemoglobina, participa do transporte do oxigênio e gás carbônico entre os pulmões e as células. Na hemoglobina cada íon de $\mathrm{Fe}^{2+}$ liga-se a 4 átomos de nitrogênio podendo ainda se coordenar a uma molécula de oxigênio (Figura 3). Inclusive a toxidade das espécies $\mathrm{CN}^{1-}$ e $\mathrm{CO}$ deve-se ao fato do $\mathrm{Fe}^{2+}$ se coordenar mais facilmente com estas espécies do que com o $\mathrm{O}_{2}$ (Figura 3). A reação acontece conforme o seguinte equilíbrio equacionado a seguir:

$$
\left|\mathrm{Hb}-\mathrm{O}_{2}\right|+\mathrm{CO} \leftrightarrow|\mathrm{Hb}-\mathrm{CO}|+\mathrm{O}_{2} \mathrm{~K} \approx 3.10^{3} \text { a } 37^{\circ} \mathrm{C}[11]
$$




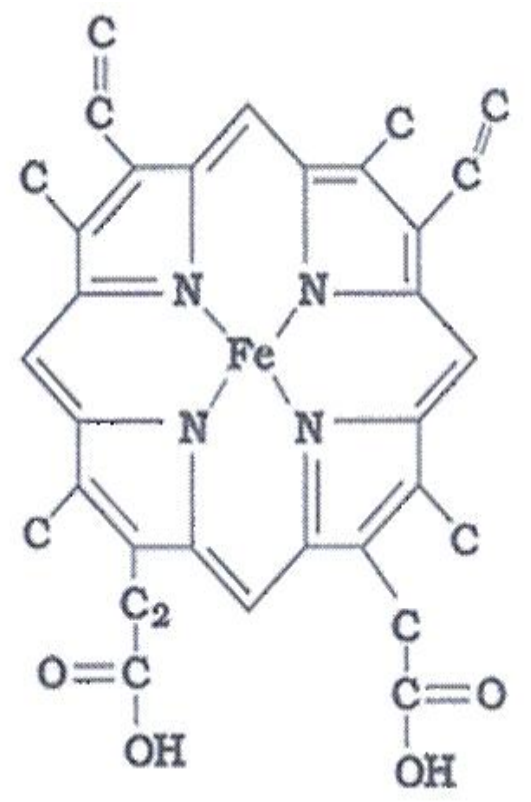

Figura 3 - Porção da hemoglobina responsável pelo transporte de oxigênio

\subsection{Efeito do pH sobre o equilíbrio metal-complexo}

São vários os fatores que contribuem para a formação de complexos de coordenação sendo um desses fatores o estabelecimento de uma situação de equilíbrio químico entre as diversas espécies químicas presentes no sistema [14].

Muitos agentes complexantes e quelantes são bases de Lewis e também bases de Brönsted (capazes de receber prótons), consequentemente, são afetados pelas mudanças no pH. A reação quelatométrica é influenciada pelo pH. Há ligantes livres em diferentes níveis de protonação, ou seja, os íons hidrogênio competem com o íon metálico na quelação [14].

Assim a formação de um complexo pode ser descrita pela equação em que M corresponde a um metal e $\mathrm{L}$ a um ligante que pode ou não originar um quelato:

$$
\mathrm{Mn}^{+}+\mathrm{H}_{\mathrm{y}} \mathrm{L}_{\mathrm{y}-\mathrm{m}} \leftrightarrow \mathrm{ML}_{\mathrm{n}-\mathrm{m}}+\mathrm{yH}^{+}
$$


Como resultado dessa basicidade (tendência a reagir com os prótons) que os íons ligantes L apresentam, a formação do complexo é dependente da variação do $\mathrm{pH}$.

\subsection{Alguns aspectos da química do EDTA e a influencia do pH no seu equilíbrio de deprotonação}

O EDTA (ácido etilenodiaminotetraacético) e seu sal dissódico dão origem a um ligante polidentado podendo fazer até seis ligações com o metal formando um complexo na proporção molar 1:1 e apenas uma equação de equilíbrio [15].

$$
\mathrm{M}+\mathrm{EDTA} \leftrightarrow \mathrm{MEDTA}
$$

O EDTA se comporta como um ácido tetraprótico fraco $\left(\mathrm{H}_{4} \mathrm{Y}\right)$, conforme os equilíbrios abaixo:

$$
\begin{array}{ll}
\mathrm{H}_{4} \mathrm{Y} \leftrightarrow \mathrm{H}^{+}+\mathrm{H}_{3} \mathrm{Y}^{-} & \mathrm{K}_{\mathrm{a} 1}=\left[\mathrm{H}^{+}\right]\left[\mathrm{H}_{3} \mathrm{Y}^{-}\right] /\left[\mathrm{H}_{4} \mathrm{Y}\right]=1,0 \times 10^{-2} \\
\mathrm{H}_{3} \mathrm{Y}^{-} \leftrightarrow \mathrm{H}++\mathrm{H}_{2} \mathrm{Y}^{2-} & \mathrm{K}_{\mathrm{a} 2}=\left[\mathrm{H}^{+}\right]\left[\mathrm{H}_{2} \mathrm{Y}^{2-}\right] /\left[\mathrm{H}_{3} \mathrm{Y}^{-}\right]=2,1 \times 10^{-3} \\
\mathrm{H}^{2} \mathrm{Y}^{2-} \leftrightarrow \mathrm{H}^{+}+\mathrm{HY}^{3-} & \mathrm{K}_{\mathrm{a} 3}=\left[\mathrm{H}^{+}\right]\left[\mathrm{HY}^{3-}\right] /\left[\mathrm{H}_{2} \mathrm{Y}^{2-}\right]=6,9 \times 10^{-7} \\
\mathrm{HY}^{3-} \leftrightarrow \mathrm{H}^{+}+\mathrm{Y}^{4-} & \mathrm{K}_{\mathrm{a} 4}=\left[\mathrm{H}^{+}\right]\left[\mathrm{Y}^{4-}\right] /\left[\mathrm{HY}^{3-}\right]=5,5 \times 10^{-11}
\end{array}
$$

Combinando-se por multiplicação, todas as equações acima, obtém-se:

$$
\mathrm{H}_{4} \mathrm{Y} \leftrightarrow 4 \mathrm{H}^{+}+\mathrm{Y}^{4-} \quad \mathrm{K}_{\mathrm{EDTA}}=\left[\mathrm{H}^{+}\right] 4\left[\mathrm{Y}^{4-}\right] /\left[\mathrm{H}_{4} \mathrm{Y}\right]
$$

ou:

$\mathrm{K}_{\text {EDTA }}=\mathrm{K}_{\mathrm{a} 1 \times} \times \mathrm{K}_{\mathrm{a} 2} \times \mathrm{K}_{\mathrm{a} 3} \times \mathrm{K}_{\mathrm{a} 4}=7,97 \times 10^{-22}$

onde, $\mathrm{K}_{\mathrm{EDTA}}$ é a constante de equilíbrio do EDTA. 
Portanto, em meio aquoso, o EDTA ioniza-se produzindo quatro espécies aniônicas $\left(\mathrm{H}_{3} \mathrm{Y}^{-} ; \mathrm{H}_{2} \mathrm{Y}^{2-} ; \mathrm{HY}^{3-} ; \mathrm{Y}^{4-}\right)$.

Em função do valor do $\mathrm{pH}$ as seguintes espécies de EDTA são predominantes:

$$
\begin{aligned}
& \mathrm{pH}<1 \quad \text { à } \mathrm{H}_{4} \mathrm{Y} \\
& \mathrm{pH} \approx 1-3 \quad \text { à } \mathrm{H}_{3} \mathrm{Y}^{-} \\
& \mathrm{pH} \approx 3-6 \quad \text { à } \mathrm{H}_{2} \mathrm{Y}^{2-} \\
& \mathrm{pH} \approx 7-10 \text { à } \mathrm{HY}^{3-} \\
& \mathrm{pH}>10 \text { à } \mathrm{Y}^{4-}
\end{aligned}
$$

Para valores de $\mathrm{pH}$ abaixo de 10, predominam as espécies protonadas de EDTA, ou sejam: $\mathrm{HY}^{3-}, \mathrm{H}_{2} \mathrm{Y}^{2-}, \mathrm{H}_{3} \mathrm{Y}^{-}$e $\mathrm{H}_{4} \mathrm{Y}$, justamente por causa da competição que acontece entre o íon $\mathrm{H}^{+}$e os íons $\mathrm{HY}^{3-}, \mathrm{H}_{2} \mathrm{Y}^{2-}, \mathrm{H}_{3} \mathrm{Y}^{-}$, conforme o $\mathrm{pH}$ da solução.

A figura 4, a seguir, mostra a variação das espécies $\mathrm{H}_{3} \mathrm{Y}^{-}, \mathrm{H}_{2} \mathrm{Y}^{2-}, \mathrm{HY}^{3-}$ e $\mathrm{Y}^{4-}$ em função do pH [15].

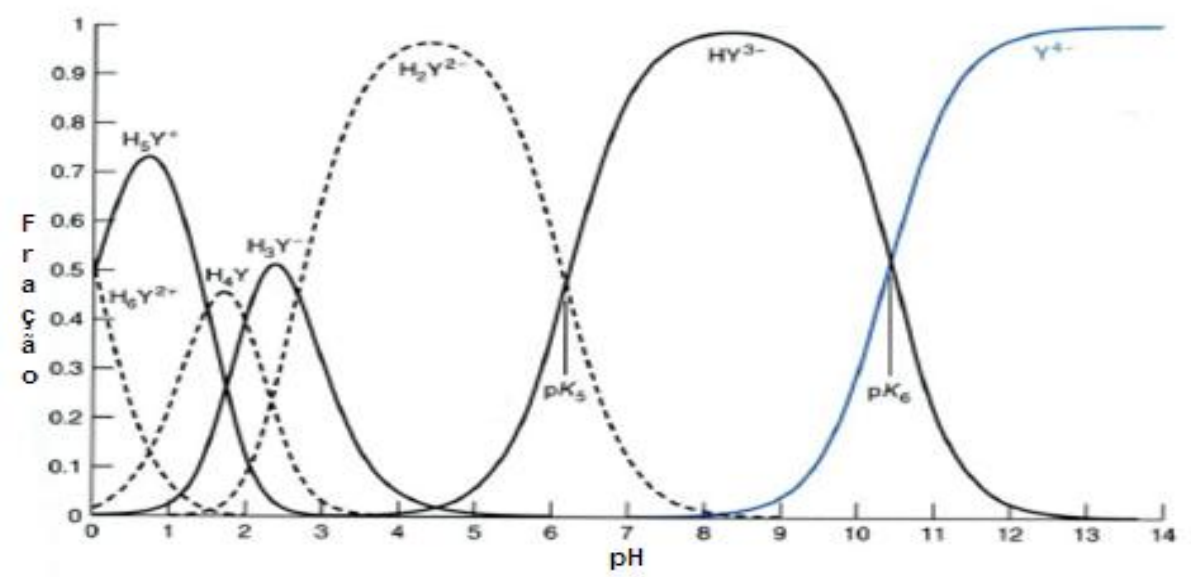

Figura 4 - Diagrama para a distribuição de espécies para o EDTA em solução aquosa em função do $\mathrm{pH}$ a $25^{\circ} \mathrm{C}$

Pela análise da figura 4, é possível prever a espécie derivada do EDTA mais abundante na solução para cada $\mathrm{pH}$. No presente trabalho, realizamos medidas nos $\mathrm{pH}$ 4,3 (da própria solução aquosa saturada do Etilenodiaminotetracetato de sódio - EDTA 
dissódico $\left(\mathrm{C}_{10} \mathrm{H}_{14} \mathrm{~N}_{2} \mathrm{O}_{8} \mathrm{Na}_{2} \cdot 2 \mathrm{H}_{2} \mathrm{O}\right)$, quando se prevê a formação do $\mathrm{M}-\mathrm{H}_{2} \mathrm{Y}^{2-}$ com mais de $90 \%$ de probabilidade; no $\mathrm{pH}$ 6,0, quando predominam no sistema as espécies $\mathrm{H}_{2} \mathrm{Y}^{2-}$ e $\mathrm{HY}^{3-}$ em proporção de aproximadamente $50 \%$ de cada, prevendo-se portanto a formação de dois quelatos nas mesmas proporções: o $\mathrm{M}-\mathrm{H}_{2} \mathrm{Y}^{2-}$ e o $\mathrm{M}-\mathrm{HY}^{3-}$ e no $\mathrm{pH}$ 10 quando predominam no sistema as espécies $\mathrm{HY}^{3-}$ e $\mathrm{Y}^{4-}$ em proporção de aproximadamente $50 \%$ de cada, prevendo-se portanto a formação de dois quelatos nas proporções correspondentes: o $\mathrm{M}-\mathrm{HY}^{3-}$ e o $\mathrm{M}-\mathrm{Y}^{4-}$.

\subsection{Alguns aspectos da química do fluoreto $\left(\mathrm{F}^{1-}\right)$}

O flúor apresenta configuração eletrônica $\mathrm{s}^{2} \mathrm{p}^{5}$ no seu nível mais externo, um elétron a menos que neônio que é o gás nobre mais próximo. Devido ao seu pequeno raio, a ausência de orbitais d de baixa energia no segundo nível e ao fato de ser o elemento mais eletronegativo do sistema periódico, o flúor sempre formará apenas uma ligação covalente normal e seu número de oxidação invariavelmente será 1-. O flúor é, portanto, um agente oxidante extremamente forte. Essa propriedade, combinada com seu pequeno raio, faz com que os elementos aos quais ele está ligado alcance seus estados de oxidação mais elevados [10].

O conhecimento destas propriedades destes ligantes são suficientes para a interpretação dos resultados obtidos neste trabalho. 


\section{CAPÍTULO 3}

\section{NÚCLEOS DE PROVAS}

Neste capítulo serão apresentadas algumas propriedades químicas dos núcleos de prova utilizados. Neste trabalho, dentre as propriedades dos elementos são destacadas a valência, o número de oxidação e a formação de complexos em meio aquoso.

\subsection{Núcleos de prova radioativos e suas propriedades}

No presente trabalho, quando se utiliza um dado radioisótopo como sonda CAP são levadas em consideração as propriedades químicas do isótopo-pai, e não às do isótopo-filho que irá decair pela cascata gama [16]. Isso por dois motivos: primeiro por que o ligante considerado irá estabelecer ligação química com o isótopo-pai e em segundo por que, tão logo o isótopo-filho (instável) seja formado, este emite imediatamente a cascata gama num tempo muito menor do que aquele que seria necessário para modificação do ambiente químico em adequação às propriedades químicas do isótopo-filho. Ou seja, o isótopo-filho emite a cascata gama que traz 
consigo informações do ambiente químico local (sitio) que se formou em torno no isótopo-pai. Por esse motivo a seguir destacaremos alguns aspectos fundamentais da química de alguns isótopos-pai utilizados como sondas CAP nesse trabalho.

\subsubsection{Alguns aspectos da química do índio $\left(\operatorname{In}^{3+}\right)$}

O elemento Índio faz parte do grupo 13 da Classificação Periódica e tem configuração $4 \mathrm{~d}^{10} 5 \mathrm{~s}^{2} 5 \mathrm{p}^{1}$, número de oxidação $3+$ e número de coordenação igual a $4 . \mathrm{O}$ $\mathrm{In}^{3+}$ apresenta propriedades químicas semelhantes às do $\mathrm{Al}^{3+}$ e do $\mathrm{Ga}^{3+}$, do mesmo grupo que o seu. As soluções aquosas dos sais de índio III são consideravelmente hidrolisadas. Dentre as propriedades do $\operatorname{In}^{3+}$ destacamos a hidrólise com a formação dos íons polinucleares do tipo $\operatorname{In}\left[(\mathrm{OH})_{2} \operatorname{In}\right] n^{+(3+n)}$. Neste caso de reações de hidrólise, a acidez (razão carga/tamanho) do cátion é tão grande (ácidos duros) que causa a ruptura das ligações H-O com a ionização do hidrato para produzir íons hidrônio [17].

Para baixas concentrações de $\operatorname{In}^{3+}$ tornam-se apreciáveis as espécies mononucleares $\operatorname{In}(\mathrm{OH})^{2+}$ e $\operatorname{In}(\mathrm{OH})_{2}^{+} \cdot \mathrm{O}$ índio forma complexos com halogênios e ácidos orgânicos em meio aquoso. Os halogenetos de índio formam com ligantes neutros, uma grande variedade de complexos. $\mathrm{O} \mathrm{InX}_{3} \mathrm{~L}_{3}$ é a estequiometria mais comum para complexos com ligantes que contêm $\mathrm{N}$ e $\mathrm{O}$ como doadores e são predominantemente hexacoordenados em estado sólido [17].

De acordo com BERTOTTI, existem muitas evidências de que o $\mathrm{In}^{3+}$ se apresenta em solução aquosa não complexante sob a forma de $\left|\operatorname{In}\left(\mathrm{H}_{2} \mathrm{O}\right)_{6}\right|^{3+}$ e que com números de coordenação 4 e 5 são conhecidos na química do $\operatorname{~In}^{3+}$ complexos formados especialmente com ligantes moles e/ou volumosos [14]. 


\subsubsection{Alguns aspectos da química do cádmio $\left(\mathrm{Cd}^{2+}\right)$}

O cádmio apresenta configuração $[\mathrm{Kr}] 4 \mathrm{~d}^{10} 5 \mathrm{~s}^{2}$ o que justifica a formação de compostos bivalentes característicos. O cádmio metálico pode ser atacado pelos ácidos sulfúrico e nítrico, liberando na solução resultante o íon $\mathrm{Cd}^{2+}$. Ele forma complexo com ligantes doadores de O, N e S e também com haletos. São conhecidos complexos desse elemento com número de coordenação de 2 a 8 , mas os mais comuns são tetracoordenados e tetraédricos. Existem ainda vários complexos octaédricos e hexacoordenados, como o íon complexo $\left[\mathrm{Cd}\left(\mathrm{H}_{2} \mathrm{O}\right)_{6}\right]^{2+}$ que é formado quando o $\mathrm{Cd}^{2+} \mathrm{se}$ encontra em meio aquoso[10].

\subsubsection{Alguns aspectos da química do Háfnio $\left(\mathrm{Hf}^{4+}\right)$}

Elemento metálico de transição, é prateado e brilhante. $Z=72$; configuração eletrônica: [Xe] $4 \mathrm{f}^{14} 5 \mathrm{~d}^{2} 6 \mathrm{~s}^{2}$ e $\mathrm{MA}=178,49 \mathrm{u}$. Por apresentar configuração $\mathrm{d}^{0}$, sem elétrons desemparelhados, seus compostos serão brancos ou incolores e diamagnéticos.

Em função da sua semelhança em tamanho e em propriedades com o zircônio, o háfnio é encontrado, na proporção de 1 a $2 \%$ em minérios de zircônio. E devido à semelhança de tamanho de seus íons a separação do háfnio do zircônio é muito difícil de ser realizada e para a maioria dos usos tal separação se faz desnecessária em função da semelhança entre as suas propriedades [10].

A maioria dos seus compostos são complexos de háfnio (IV), embora complexos menos estáveis de háfnio(III) também existam. O estado de oxidação (+IV) é o mais comum e estável. O háfnio metálico é pouco reativo nas condições ambientes, mas pode ser dissolvido em HF formando hexafluoro complexo conforme a reação:

$$
\mathrm{Hf}+6 \mathrm{HF} \leftrightarrow \mathrm{H}_{2}\left[\mathrm{HfF}_{6}\right]+2 \mathrm{H}_{2}[10]
$$


Segundo ALDOUS [18], também podem existir em meio aquoso, além do íon $\left[\mathrm{HfF}_{6}\right]^{2-}$, as seguintes estruturas em meio aquoso: o íon $\left[\mathrm{HfF}_{7}\right]^{3-}$. O íon que podem dimerizar formando os dímeros $\left[\mathrm{Hf}_{2} \mathrm{~F}_{14}\right]^{6-} .2 \mathrm{H}_{2} \mathrm{O}$ e $\left[\mathrm{Hf}_{2} \mathrm{~F}_{13}\right]^{5-}$ (figuras $5-\mathrm{A}$ e B).

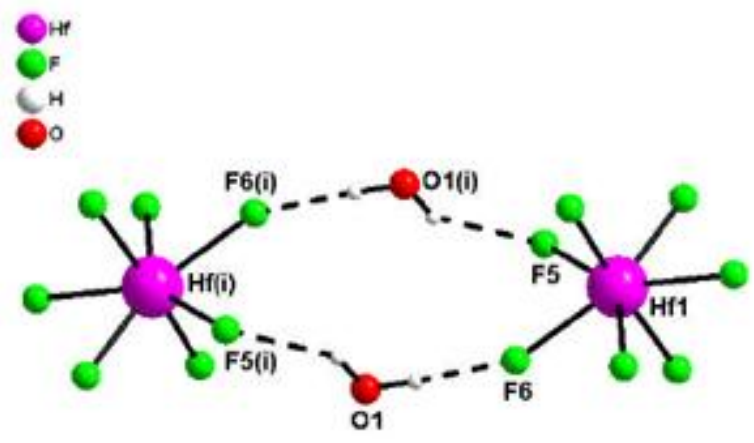

Figura 5- $\mathrm{A}-\left[\mathrm{Hf}_{2} \mathrm{~F}_{14}\right]^{6-} .2 \mathrm{H}_{2} \mathrm{O}$

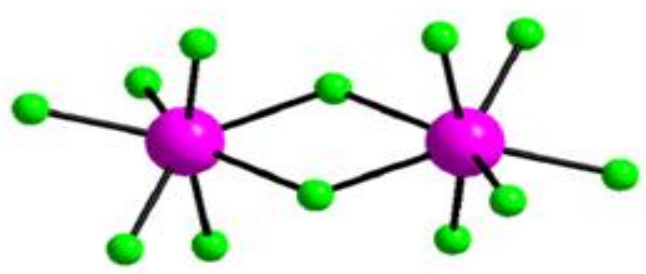

Figura 5- B - Dímero $\left[\mathrm{Hf}_{2} \mathrm{~F}_{13}\right]^{5-}$

$\mathrm{O}$ ligante $\mathrm{F}^{-}$, devido à sua elevada eletronegatividade, formará estruturas estáveis com o háfnio que se manterão mesmo na presença de outros ligantes.

Complexos de $\mathrm{Hf}^{4+}$ obedecem à regra dos 18 elétrons [13].

Os compostos de háfnio são notadamente similares aos de zircônio tanto química como estruturalmente. A origem dessa similaridade pode ser atribuída às configurações eletrônicas dos dois elementos;

$$
\begin{gathered}
{ }^{91,2} \mathrm{Zr}_{40}-[\mathrm{Kr}] \underline{4 d^{2}} 5 \mathrm{~s}^{2} \\
{ }^{178,5} \mathrm{Hf}_{72}-[\mathrm{Xe}] 4 \mathrm{f}^{14} \underline{5 d^{2}} 6 \mathrm{~s}^{2}
\end{gathered}
$$

A tabela 2 apresenta algumas das proximidades entre as características dos dois metais. 


\begin{tabular}{ccc}
\hline & Zircônio & Háfnio \\
\hline Raio atômico $(\mathrm{nm})$ & 0,1454 & 0,1442 \\
Raio iônico $\left(\mathrm{M}^{4+}\right)(\mathrm{nm})$ & 0.083 & 0.084 \\
Volume Atômico $(\mathrm{nm})$ & 1.397 & 1.342 \\
Eletronegatividade & 1.22 & 1.23 \\
\hline
\end{tabular}

Estes valores são indicativos da química, praticamente idêntica, apresentada pelos elementos zircônio e háfnio, explicando, portanto, a origem da similaridade entre seus compostos. Devido a esse comportamento, apresenta-se neste tópico apenas a química do zircônio, entendendo-se ser idêntica a do háfnio.

Os números de oxidação do zircônio são $+2,+3$ ou +4 , sendo esse último o mais característico. Sendo que, quanto maior a valência, maior será a estabilidade do composto considerado.

O zircônio não mostra preferências estereoquímicas e, devido a sua elevada razão carga/raio, exibe alto número de coordenação (6, 7 e 8), figurando como um típico complexante. Em ordem decrescente de tendência de formação de complexos com zircônio, os ligantes inorgânicos podem ser arranjados segundo a série [21]:

$$
\mathrm{OH}^{1-}>\mathrm{F}^{1-}>\mathrm{PO}_{4}{ }^{3-}>\mathrm{NO}_{3}{ }^{1-}>\mathrm{Cl}^{1-}>\mathrm{ClO}_{4}{ }^{1-}
$$

Outra importante consequência da elevada razão carga/raio exibida pelo zircônio, de acordo com ZARPELON [21], diz respeito ao fato de que sua química em solução aquosa é caracterizada por hidrólise, associada à tendência de formação de compostos poliméricos, nesse caso proporcionando a formação de partículas coloidais (sois) com diferentes cargas. Esse processo dependerá do $\mathrm{pH}$ e pode ser descrito pelo seguinte equilíbrio em solução aquosa:

$$
\mathrm{Zr}^{4+}+\mathrm{nH}_{2} \mathrm{O} \leftrightarrow \mathrm{Zr}(\mathrm{OH})_{n}^{4-n}+\mathrm{nH}^{1+}
$$


Ainda conforme ZARPELON [21], baixos valores de $\mathrm{pH}$ implicam na presença de íons $\mathrm{Zr}^{4+}$, enquanto a medida que o $\mathrm{pH}$ aumenta, aumenta também o número de hidroxigrupos em solução levando o $\mathrm{Zn}^{4+}$ a formar os complexos. Os estudos sobre hidrólise e polimerização indicam a existência de monômeros, $\mathrm{Zr}(\mathrm{OH}) \mathbf{n}^{(4 \mathbf{n})+}$, onde $\mathrm{n}=0,1,2,3$ ou 4, ou ainda, trimeros e tetrâmeros, os quais dependem da concentração de zircônio e acidez da solução. As espécies de zircônio que se formam em meio aquoso livre de ligantes dependem, além do $\mathrm{pH}$, da concentração da solução, evidenciando-se a ocorrência das formas hidratadas dos íons $\mathrm{ZrOOH}^{+}, \mathrm{ZrO}^{2+}, \mathrm{ZrOH}^{3+}, \mathrm{Zr}^{4+}$ e $\mathrm{Zr}_{\mathbf{4}}(\mathrm{OH})_{\mathbf{8}}{ }^{8+}$, em ordem crescente de acidez (tabela 3)

Tabela 3: Espécies de zircônio em solução na ausência de ligantes [19]

\begin{tabular}{cc}
\hline pH & Íons e moléculas \\
\hline$<0.0$ & $\mathrm{Zr}^{4+}, \mathrm{Zr}(\mathrm{OH})^{3+}($ monômeros $)$ \\
$0.0-1.0$ & $\mathrm{Zr}^{4+}, \mathrm{Zr}(\mathrm{OH})^{3+}, \mathrm{Zr}(\mathrm{OH})_{2}{ }^{2+}, \mathrm{Zr}(\mathrm{OH})_{3}{ }^{1+}, \mathrm{Zr}(\mathrm{OH})_{4}{ }^{0}$ (monômeros) \\
$1.0-1.5$ & $\mathrm{Zr}(\mathrm{OH})^{3+}, \mathrm{Zr}(\mathrm{OH})_{4}{ }^{0}$ (monômeros) \\
$1.5-4.0$ & $\mathrm{Zr}(\mathrm{OH})_{4}{ }^{0}(\mathrm{monômeros}),\left[\mathrm{Zr}(\mathrm{OH})_{\mathrm{x}}{ }^{4-\mathrm{x}}\right]$ (polímeros, pseudo-colóides) \\
$4.0-12.0$ & {$\left[\mathrm{Zr}(\mathrm{OH})_{4}\right]_{\mathrm{n}}(\mathrm{cristais}$ verdadeiros) } \\
$>12.0$ & $\mathrm{Zirconatos}$ \\
\hline
\end{tabular}

Estes comportamentos do $\mathrm{Zr}^{4+}$ serão considerados na interpretação dos resultados relativos ao $\mathrm{Hf}^{4+}$. 


\section{CAPÍTULO 4}

\section{INTERAÇÕES HIPERFINAS}

A interação dos momentos nucleares com os campos elétricos e magnéticos produzidos em sólidos ou meio aquoso pelas cargas eletrônicas e iônicas em torno do núcleo é chamada de interação hiperfina. Esta interação foi descoberta na espectroscopia atômica e seus efeitos nos espectros atômicos foram extensivamente estudados. Estas interações também são sensíveis aos núcleos tornando possível estudo dos campos internos em sólidos e em diferentes ambientes químicos, inclusive meios biológicos, sendo possível realização de medidas locais (da ordem de nanômetros) a partir das propriedades nucleares. Algumas das técnicas que permitem o estudo destas interações são: Efeito Mösbauer (EM), Ressonância Magnética Nuclear (RMN), Orientação Nuclear (ON) e Correlação Angular gama-gama Perturbada (CAP) [22].

Neste trabalho é apresentado o estudo de Interações Hiperfinas Elétricas, Gradiente de Campo Elétrico (GCE) para investigar a probabilidade de ligação de elementos metálicos na molécula de EDTA. Desta forma, neste capítulo são apresentados os fundamentos da técnica de CAP inclusive para realização de medidas e análise em meio aquoso. Complementando o capítulo são descritas algumas propriedades dos núcleos de prova utilizados para realização das medidas. 


\subsection{Correlação angular $\gamma-\gamma$}

Em 1940, DUNWORTH apontou a existência da correlação angular entre duas radiações gamas emitidas em cascata por um núcleo radioativo [23]. HAMILTON, também em 1940, publicou a primeira descrição teórica sobre o fenômeno da correlação angular [24]. Em 1946 GOERTZEL [25] sugeriu a possibilidade de perturbação da correlação angular gama-gama por campos extranucleares, sugestão esta, que foi estendida por ALDER como resultado da investigação do efeito de campos magnéticos externos [26]. Foram muitos os autores que aperfeiçoaram a teoria da correlação angular gama-gama perturbada (CAP), dentre os quais ABRAGAN end POUND [27], FRAUENFELDER e STEFFEN [28], de tal forma que, a teoria está bem estabelecida. Frauenfelder realizou, em 1951, o trabalho experimental pioneiro da correlação angular perturbada $[29,30]$.

A técnica PAC sofreu muitos avanços nas últimas décadas, a ponto de estar sendo aplicada para investigação nas áreas da química, da física nuclear, física do estado sólido entre outras [1]. A teoria que sustenta a técnica PAC também está bem estabelecida e a tecnologia para aquisição e tratamento dos dados está bem desenvolvida.

A seguir descreve-se os princípios básicos da correlação angular gama-gama não-perturbada e perturbada, das interações hiperfinas elétricas e das interações dinâmicas. 


\subsubsection{Correlação angular $\gamma-\gamma$ não perturbada}

A distribuição da intensidade das radiações- $\gamma$, provenientes dos estados nucleares excitados pertencentes a um conjunto de núcleos depende dos ângulos que as direções das emissões têm em relação às orientações dos "spins" nucleares. Como, num dado conjunto de núcleos, todas as orientações são equiprováveis, tal comportamento fica usualmente ocultado. Em decorrência disso, a detecção das radiações- $\gamma$, guardadas as eventuais flutuações experimentais, apresenta um padrão isotrópico de intensidade. Se fosse possível detectar aquelas radiações- $\gamma$ originárias de um subconjunto com orientação unidirecional dos "spins", o padrão anisotrópico da intensidade apareceria. O registro experimental desta orientação é realizado a partir de uma cascata de decaimento nuclear: a detecção da primeira radiação- $\gamma$ emitida, radiação- $\gamma_{1}$, naquela direção que permitiu sua detecção, implica que tenha se originado de um subconjunto de núcleos com uma certa orientação de "spin" (e assim, as demais radiações- $\gamma$ emitidas naquela direção serão necessariamente originárias do mesmo subconjunto de núcleos no que se refere ao alinhamento isodirecional dos seus "spins"). Na etapa seguinte deve-se detectar a radiação- $\gamma$ originada do estado intermediário desta cascata nuclear: por causa da exigência de conservação do momento angular total (composição vetorial entre os "spins" do estado nuclear excitado e da radiação- $\gamma$ emitida) a intensidade de emissão desta segunda radiação- $\gamma_{2}$ possuirá dependência angular com relação à direção de emissão da primeira radiação- $\gamma_{1}$. Para ter certeza de que ambas as radiações- $\gamma$ se originaram no mesmo núcleo, mantendo-se a coerência da informação experimental, um circuito eletrônico para registro de coincidências começa a operar quando da chegada do pulso eletrônico associado à radiação- $\gamma_{1}$, e só emite um pulso de saída para registro se durante um intervalo de tempo ajustado previamente [sempre em uma escala do nanosegundo (ns)] chegar um segundo pulso eletrônico, associado à radiação- $\gamma_{2}$. Desta maneira, com a observação das radiações- $\gamma_{1}$, é selecionado um subconjunto com orientação unidirecional de "spin"; registrando as coincidências entre a radiações- $\left(\gamma_{1^{-}}\right.$ $\gamma_{2}$ ), somente aquelas radiações- $\gamma_{2}$ emitidas por este mesmo subconjunto contribuem para este registro. O efeito da emissão com direção preferencial é conhecido como Correlação Angular (CA). A CA é caracterizada pelo parâmetro nuclear Anisotropia $\left(A_{k k}\right)$, aqui registrado a partir da taxa de contagem de coincidências entre as radiações 
$\left(\gamma_{1}-\gamma_{2}\right)$ como função do ângulo $(\theta)$ medido entre as direções da emissão seqüencial destas duas radiações [28,31].

$$
\mathrm{W}(\theta, \mathrm{t})=\sum_{\mathrm{k}} \mathrm{A}_{\mathrm{kk}} P_{\mathrm{k}}(\cos \theta)
$$

onde $\mathrm{k}$ é par e $0<\mathrm{k} \leq \min \left(2 \mathrm{I}, 2 \mathrm{~L}_{1}, 2 \mathrm{~L}_{2}\right)$, com $\mathrm{L}_{1}$ e $\mathrm{L}_{2}$ sendo respectivamente os momentos angulares de $\gamma_{1}$ e $\gamma_{2}, P_{k}(\cos \theta)$ o Polinomio de Legendre de ordem $k$.

\subsubsection{Correlação angular $\gamma-\gamma$ perturbada}

Quando o estado excitado intermediário da cascata nuclear (cuja desexcitação dá origem à radiação- $\gamma_{2}$ ) tem um vida média bem maior que o tempo de resolução do sistema instrumental em uso, a taxa de coincidências registrada apresenta uma função exponencial decrescente ao longo meia-vida deste estado.

Do ponto de vista do isótopo-sonda (figura 6), as interações hipefinas representam uma reorientação do "spin" nuclear durante a existência do seu estado quântico intermediário. Esta reorientação pode ser vislumbrada como uma precessão deste "spin", o que faz com que a probabilidade de emissão da radiação- $\gamma_{2}$ em uma determinada direção possa ser alterada em qualquer instante da existência daquele estado. Esta perturbação pode ser descrita por:

$$
\mathrm{W}(\theta, \mathrm{t})=\sum_{\mathrm{k}} \mathrm{G}_{\mathrm{kk}}(\mathrm{t}) \mathrm{A}_{\mathrm{kk}} P_{\mathrm{k}}(\cos \theta)
$$

onde $\mathrm{G}_{\mathrm{kk}}(\mathrm{t})$ é a função de perturbação cuja a estrutura depende do tipo de interação, magnética ou elétrica, e da simetria dos campos locais [28,31]. Um esquema simplificado pode ser observado na figura 7 . 


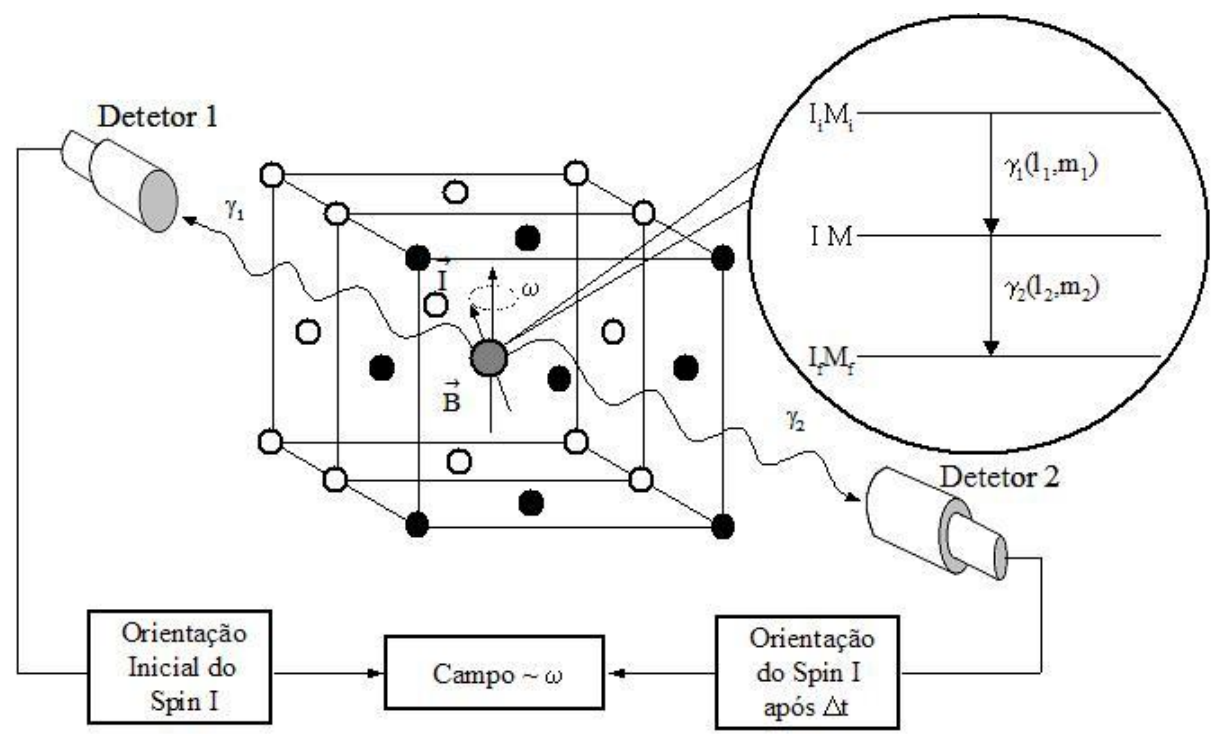

Figura 6 - Núcleo de prova no interior do cristal
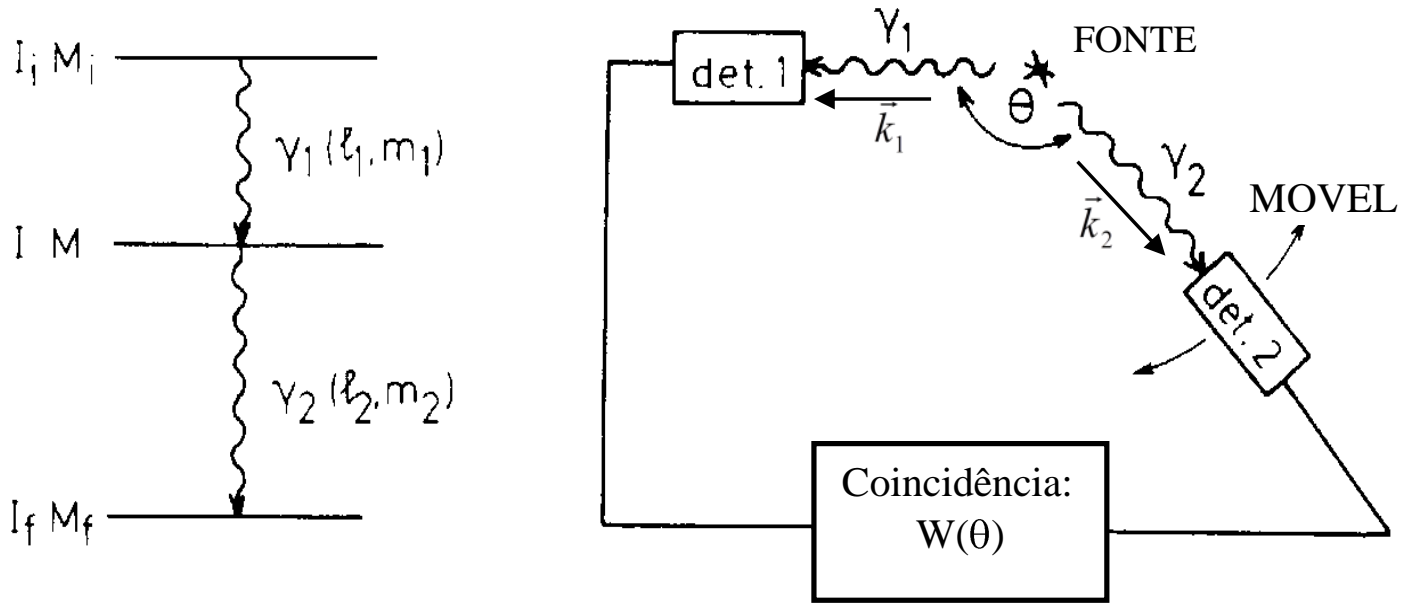

Figura 7 - Esquema simplificado de decaimento gama em cascata

Neste trabalho, o núcleo sonda se liga a uma molécula em meio aquoso, não havendo interação de natureza magnética. Sendo assim, descreve-se abaixo apenas os fundamentos teóricos de interação elétrica bem como a interação dinâmica que ocorre no meio devido ao seu estado físico. 


\subsection{Interação Elétrica}

É a interação entre o momento de quadrupolo nuclear Q e um tensor 3 X 3 do Gradiente de Campo Elétrico (GCE) $\mathrm{V}_{x, y}$ ( $x, y$ sendo as coordenadas cartesianas) que é dado pela derivada segunda do potencial elétrico $\mathrm{V}(\mathrm{r})$ no sítio do núcleo $(\mathrm{r}=0)$. Escolhendo um sistema de eixos para o qual $\mathrm{V}_{x, y}=0$ para $x \neq y$ o tensor gradiente de campo elétrico é simplificado e a Hamiltoniana da interação é dada por:

$$
H_{\mathbf{Q}}=\frac{\mathbf{e Q}}{4 \mathbf{I}(2 \mathrm{I}-1)}\left[\mathbf{V}_{\mathrm{zz}}\left(3 \mathbf{I}_{\mathrm{z}}^{2}-\mathbf{I}^{2}\right)+\frac{1}{2}\left(\mathbf{V}_{\mathbf{y y}}-\mathbf{V}_{\mathrm{xx}}\right)\left(\mathbf{I}_{\mathbf{y}}^{2}-\mathbf{I}_{\mathbf{x}}^{\mathbf{2}}\right)\right]
$$

onde e é a carga elementar.

No seu sistema de eixos principais o tensor GCE contém as 3 componentes $\mathrm{V}_{\mathrm{xx}}, \mathrm{V}_{\mathrm{yy}}$ e $\mathrm{V}_{\mathrm{zz}}$, que são expressas pela constante de acoplamento quadrupolar $v_{\mathrm{Q}}=$ $\mathrm{eQV}_{z z} / h$, que descreve a intensidade do tensor GCE, e pelo parâmetro de assimetria $\eta=$ $\left(\mathrm{V}_{\mathrm{xx}}-\mathrm{V}_{\mathrm{yy}}\right) / \mathrm{V}_{\mathrm{zz}}$ com $\left|\mathrm{V}_{\mathrm{xx}}\right| \leq\left|\mathrm{V}_{\mathrm{yy}}\right| \leq\left|\mathrm{V}_{\mathrm{zz}}\right|$ e $\mathrm{V}_{\mathrm{xx}}+\mathrm{V}_{\mathrm{yy}}+\mathrm{V}_{\mathrm{zz}}=0$, tal que $0 \leq \eta \leq 1$, que indica o desvio da simetria axial do GCE.

Portanto, apenas dois parâmetros são suficientes para caracterizar o tensor GCE: a sua maior componente $\mathrm{V}_{z z}$ e a diferença $\mathrm{V}_{\mathrm{yy}}-\mathrm{V}_{\mathrm{xx}}$, que são expressas pelo parâmetro de assimetria $\eta$. Deste modo a Hamiltoniana pode ser escrita em função de $V_{z z}, \eta$ e dos operadores de momento angular $I_{z}, I_{+}$e $\mathrm{I}$.

$$
H_{\mathrm{Q}}=\frac{\mathrm{eQV}_{\mathrm{zZ}}}{4 \mathrm{I}(2 \mathrm{I}-1)}\left[\left(3 \mathrm{I}_{\mathrm{Z}}^{2}-\mathrm{I}(\mathrm{I}+1)+\frac{\eta}{2}\left(\mathrm{I}_{+}^{2}+\mathrm{I}_{-}^{2}\right)\right]\right.
$$

Para $\eta=0$, os autovalores em energia da interação de quadrupolo elétrico são dados por: 


$$
E_{m}=\left[3 m^{2}-I(I+1)\right] \frac{e Q V_{z z}}{4 I(2 I-1)}
$$

que produz um desdobramento nos subníveis de energia, sendo que o espaçamento de energia entre eles é dado por :

$$
\Delta \mathbf{E}=\mathbf{E}_{\mathbf{m}}-\mathbf{E}_{\mathbf{m}^{\prime}}=\hbar \omega=\frac{3 \mathbf{e Q V}}{4 \mathbf{I Z}(2 \mathrm{I}-1)}\left|\mathbf{m}^{2}-\mathbf{m}^{\prime 2}\right|
$$

A menor frequência de transição entre os subníveis m é dada por:

$$
\begin{aligned}
& \omega_{0}=\frac{3 \mathbf{e Q V}_{\mathbf{Z Z}}}{\mathbf{4 I}(\mathbf{2} \mathbf{I}-\mathbf{1}) \hbar}=\mathbf{3} \omega_{\mathbf{Q}} \quad \text { para I=inteiro } \\
& \omega_{0}=\frac{6 \mathrm{eQV}_{\mathrm{zZ}}}{4 \mathrm{I}(2 \mathrm{I}-1) \hbar}=6 \omega_{\mathrm{Q}} \quad \text { para } \mathrm{I}=\text { semi-inteiro }
\end{aligned}
$$

onde $\omega_{Q}=\frac{\mathrm{eQV}_{\mathrm{zz}}}{4 \mathrm{I}(2 \mathrm{I}-1) \hbar}$ é a frequência de interação quadrupolar. Esta frequência independente do spin também é definida por:

$$
v_{\mathrm{Q}}=\frac{\mathrm{eQV}_{\mathrm{zz}}}{h}
$$


Para $\eta>0$ a Hamiltoniana deve ser diagonalizada para cada valor de $\eta$ pois os operadores de momento angular $\mathrm{I}_{ \pm}=\mathrm{I}_{\mathrm{x}} \pm \mathrm{iI}_{\mathrm{y}}$ projetam transições entre subestados $\mathrm{m}$ diferentes. Como consequência as frequências de transição $\omega_{n}$ mudam com o valor de $\eta$ como mostra a figura 8 .

Neste caso fator de perturbação dado por:

$$
\mathrm{G}_{\mathrm{kk}}(t)=\sum_{\mathrm{n}=0}^{\mathrm{n}_{\max }} \mathrm{S}_{\mathrm{kn}} \cos \left(\omega_{0 \mathrm{n}} t\right)
$$

onde os $S_{\mathrm{kn}}$, são as amplitudes das frequências de transição, que dependem diretamente do spin I do estado intermediário e são normalizados a 1. Seus valores são tabelados em função de $\eta$. Para o caso de spin $I=5 / 2$ e $\eta=0, k=2$ o fator de perturbação é dado por:

$$
G_{22}(t)=S_{20}+S_{21}+\cos \left(\omega_{01} t\right)+S_{22} \operatorname{Cos}\left(\omega_{02} t\right)+S_{23} \cos \left(\omega_{03} t\right)
$$

onde as frequências de transição são $\omega_{01}=\omega_{0}, \omega_{02}=2 \omega_{0} \varepsilon \omega_{03}=3 \omega_{0}$ é dada pela equação (11)

(a)

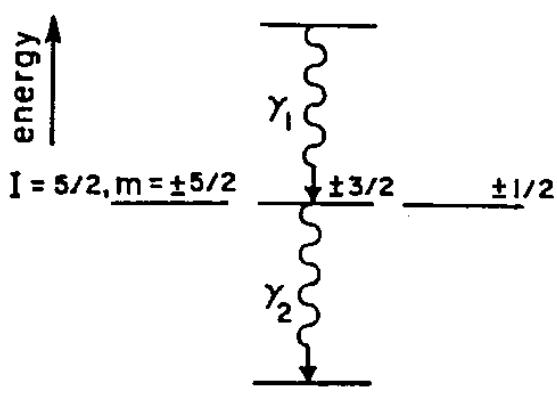

GCE ausente (b)

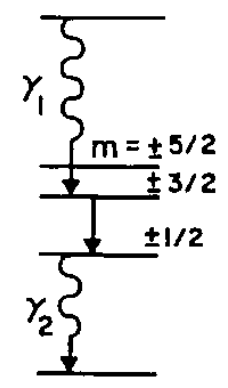

GCE presente

Figura 8 - Desdobramento de um estado nuclear causado por um gradiente de campo elétrico. 


\subsection{Interação Dinâmica}

As medidas de CAP com biomoléculas foram realizadas em solução, condição na qual sofrem o efeito da difusão rotacional que é representada pelo tempo de correlação rotacional $\tau_{\mathrm{C}}$, que descreve a mobilidade de uma molécula numa solução. Este tempo depende da viscosidade $\xi$, da temperatura absoluta $\mathrm{T}$ e do volume da molécula $\mathrm{V}$ e é definido por $\tau_{\mathrm{C}}=\mathrm{V} . \xi /\left(\mathrm{k}_{\mathrm{B}} \mathrm{T}\right)$, onde $\mathrm{k}_{\mathrm{B}}$ é a constante de Boltzmann. A influência da interação dinâmica é mais forte quando $\omega_{0} \tau_{\mathrm{C}} \approx 1$. Neste caso o efeito sobre a correlação angular será um rápido amortecimento da anisotropia como função do tempo. Há outras duas situações possíveis: Na primeira situação a flutuação da interação quadrupolar é rápida, definida por $\omega_{0} \tau_{\mathrm{C}}<<1$, ou seja quando o tempo de flutuação é curto comparado com a escala de tempo estabelecida pela interação quadrupolar caracterizada por $\omega_{0}$. Neste caso, o núcleo perde a coerência de fase e a função de perturbação se torna um simples decaimento exponencial: $G_{22}^{\text {din }}(t)=e^{-\lambda_{C} t}$. Na segunda, regime de flutuação da interação quadrupolar lenta, definida por $\omega_{0} \tau_{\mathrm{C}}>>1$, ou seja quando o tempo de flutuação é longo comparado com a escala de tempo estabelecida pela interação quadrupolar, o efeito sobre a correlação angular será um lento amortecimento da anisotropia e a função de perturbação é dada por: $G_{22}^{\text {din }}(t)=e^{-t / \tau_{C}} G_{22}(t)$. No limite $\tau_{\mathrm{C}} \rightarrow \infty$, a interação será puramente estática. Somente neste caso é possível determinar simultaneamente tanto $\omega_{0}$ (frequência angular) e $\eta$ (assimetria) que são os parâmetros hiperfinos relacionados com a estrutura local do sítio do núcleo de prova na biomolécula [1,27]. 


\subsection{O Índio e o "after-effects"}

O radioisótopo ${ }^{111}$ In decai por Captura Eletrônica para o ${ }^{111} \mathrm{Cd}$, que por sua vez, decai por meio de uma cascata de dois raios gama para o estado fundamental. A captura eletrônica deixa um buraco na camada $\mathrm{K}$ ou $\mathrm{L}$, iniciando uma emissão de elétrons-Auger. O processo de preenchimento do buraco na camada eletrônica do íonfilho, no caso o ${ }^{111 \mathrm{~m}} \mathrm{Cd}$, se desenvolve com uma cascata de vacâncias que se deslocam para o exterior da eletrosfera. Quando a vacância em cascata chega a camada mais externa do íon - filho, os átomos vizinhos começam a ser envolvidos no processo Auger e também ganham uma carga positiva [32].

Em decorrência da Captura Eletrônica é produzido o "after-effect" que pode causar uma forte perturbação no ambiente químico próximo da sonda utilizada gerando um tipo de interação hiperfina que pode observada pela técnica PAC. O after-effect é decorrente da difusão do buraco pela eletrosfera após a Captura Eletrônica corrida num radionuclídeo que esteja sendo utilizado como sonda PAC. A difusão do vazio ao longo da camada eletrônica ocorre num tempo muito curto (menor que $10^{-15} \mathrm{~s}$ ). Ao chegar na última camada, "o vazio" poderá ser "preenchido" por um elétron de condução presentes no ambiente químico vizinho evitando-se assim, uma perturbação elétrica no meio. Quando, porém, a sonda CAP está num ambiente em que não existem elétrons livres disponíveis, a ocupação do vazio da última camada do átomo que sofreu a captura $\mathrm{K}$ promove uma ionização que se propaga no meio originando uma série de espécies com diferentes gradientes eletrostáticos.

A possibilidade de desintegração da molécula de um complexo In - ligante orgânico em solução aquosa, causada pelo after-effect iniciado pelo processo Auger, foi discutido em Kulakov e outros [33] e posteriormente outro trabalho de Shpinkova e outros [34] o confirma, embora indiretamente, a hipótese de que o after-effect poderia causar a desintegração do complexo formado pela ligação entre o In e os ácidos dietilenotriaminopentaacético (DTPA) e nitrilotriacético (NTA). SHPINKOVA e outros [32] estudaram a possibilidade da degradação do complexo metal ligante em decorrência do after effect. Assim, com base nas referencias [32, 34], um fator a ser considerado ao se estudar complexos orgânicos de índio pela técnica CAP, diz respeito 
à possibilidade de desintegração do complexo In-ligante causada por efeitos pós Captura Eletrônica (pós-CE) iniciado pelo processo Auger .

\subsection{Núcleos de prova radioativos-algumas propriedades nucleares}

Além das propriedades químicas, um núcleo de prova radioativo ou ponta de prova, deve atender as exigências da técnica de correlação angular gama-gama perturbada como, decaimento em cascata gama-gama e vida-média do estado intermediário entre $2,5 \mathrm{~ns}$ e $1 \mu$ s [35]. Nesse trabalho foram utilizados os núcleos ${ }^{111}$ In $\rightarrow{ }^{111} \mathrm{Cd},{ }^{181} \mathrm{Hf} \rightarrow{ }^{181} \mathrm{Ta}$ e ${ }^{111 \mathrm{~m}} \mathrm{Cd} \rightarrow{ }^{111} \mathrm{Cd}$. A seguir são apresentadas mais algumas propriedades nucleares dos referidos radioisótopos.

${ }^{111}$ In $\rightarrow{ }^{111}$ Cd: $\mathrm{O}{ }^{111}$ In é obtido através da irradiação de ${ }^{109} \mathrm{Ag}$ com deuterons em um cíclotron com posterior separação química dos átomos de índio radioativos da matriz prata. Possui meia-vida de 2,3 dias e decai para os níveis excitados $7 / 2$ do ${ }^{111} \mathrm{Cd}$ por captura eletrônica populando o nível de $416,64 \mathrm{keV}$, que decai para o estado fundamental através da cascata gama $(172,3-245,4) \mathrm{keV}$. Seu nível intermediário possui meia-vida de $85 \mathrm{~ns}$, spin 5/2 e momento de quadrupolo elétrico $\mathrm{Q}=0,83(13) \mathrm{b}$. No LIH do IPEN, o ${ }^{111}$ In é utilizado na forma de solução de $\mathrm{InCl}_{3}$ e é importado da empresa MS Nordion do Canadá. Esta solução radioativa é adicionada nas amostras em pequenas quantidades, aproximadamente $0.5 \mu \mathrm{L}$. A figura 9 apresenta um esquema simplificado de alguns parâmetros nucleares do processo de decaimento ${ }^{111} \mathrm{In} \rightarrow{ }^{111} \mathrm{Cd}$ [36]. 


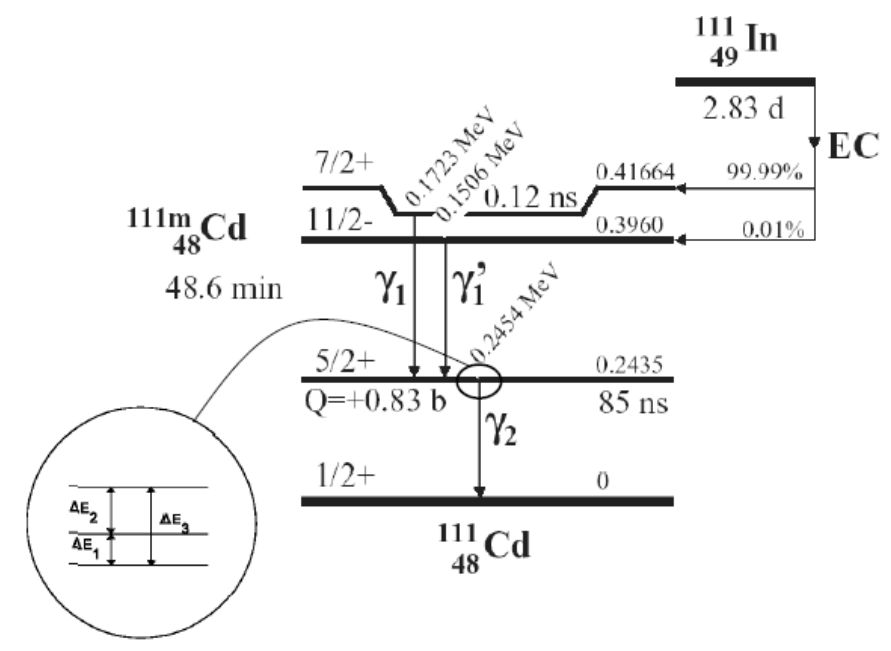

Figura 9: Decaimento do ${ }^{111} \mathrm{In}$ e ${ }^{111 \mathrm{~m}} \mathrm{Cd}$. A ampliação mostra os três possíveis níveis de energia do estado intermediário de spin $5 / 2$ devido a influência do gradientes de campo elétricos extranucleares.

${ }^{111 \mathrm{~m}} \mathrm{Cd} \rightarrow{ }^{111} \mathrm{Cd}: \mathrm{O}{ }^{111 \mathrm{~m}} \mathrm{Cd}$ foi obtido pela irradiação do cádmio natural por 2 horas num fluxo de nêutrons térmicos da ordem de $210^{13}$ nêutrons $/\left(\mathrm{cm}^{2} . \mathrm{s}\right)$ no reator IEA-R1 do IPEN. Após irradiado o ${ }^{111 \mathrm{~m}} \mathrm{Cd}$ foi dissolvido em $\mathrm{HNO}_{3}$ a $65 \%$.

O ${ }^{111 \mathrm{~m}} \mathrm{Cd}$ decai com uma meia-vida de 48,3 minutos, pela emissão $\gamma$ populando estados excitados do ${ }^{111} \mathrm{Cd}$ que decaem para o seu estado fundamental pela emissão de dois fótons $\gamma$ em cascata. A cascata gama utilizada foi $150-245 \mathrm{keV}$, passando por um nível intermediário com spin $\mathrm{I}=5 / 2^{+}$, meia-vida de $85 \mathrm{~ns}$ e momento de quadrupolo elétrico $\mathrm{Q}=0,883 \mathrm{~b}[36,37]$.

As propriedades do estado intermediário estão mencionadas da figura 10. 


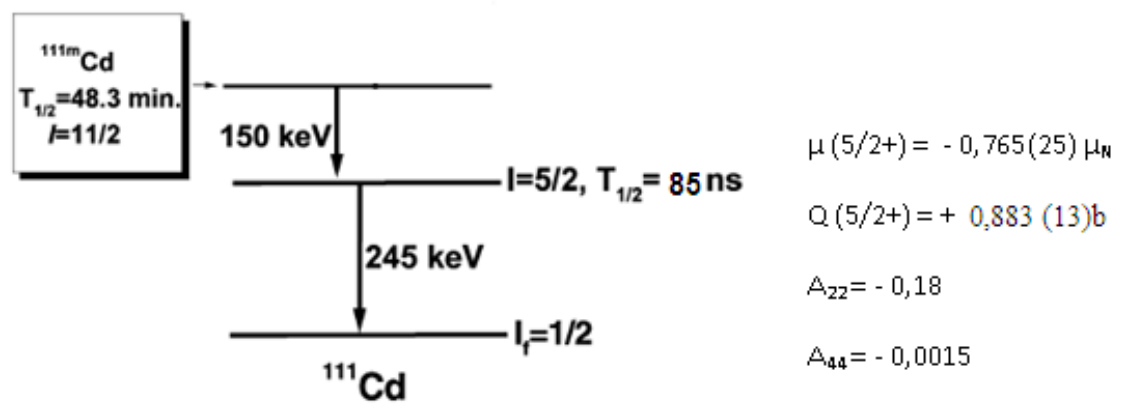

Figura 10 - Esquema de decaimento do ${ }^{111 \mathrm{~m}} \mathrm{Cd} \rightarrow{ }^{111} \mathrm{Cd}$

${ }^{181} \mathbf{H f} \rightarrow{ }^{181}$ Ta: $\mathrm{O}{ }^{181}$ Hf foi obtido a partir da irradiação do Hf natural por 60 horas num fluxo de nêutrons térmicos da ordem de $5.10^{13}$ nêutrons $/\left(\mathrm{cm}^{2}\right.$.s $)$ no reator IEA-R1 do IPEN. Após irradiado, o ${ }^{181} \mathrm{Hf}$ foi dissolvido em ácido fluorídrico concentrado resultando na solução-estoque 1 .

Outra maneira utilizada para a obtenção do núcleo de prova ${ }^{181} \mathrm{Hf}$ ativo foi pela irradiação do oxicloreto de háfnio dihidratado $\left(\mathrm{HfOCl}_{2} \cdot 2 \mathrm{H}_{2} \mathrm{O}\right)$ nas mesmas condições do Hf natural. Após irradiado, o oxicloreto de háfnio foi dissolvido em água deionizada formando uma solução contendo o ${ }^{181} \mathrm{Hf}^{4+}{ }_{(\mathrm{aq})}$ correspondendo à soluçãoestoque 2.

$\mathrm{O}{ }^{181} \mathrm{Hf}$ decai com uma meia-vida de 42,4 dias, pela emissão $\beta^{-}$populando estados excitados do ${ }^{181}$ Ta que decaem para o seu estado fundamental pela emissão de dois fótons $\gamma$ em cascata 137-482 keV, passando por um nível intermediário com spin I $=5 / 2^{+}$, meia-vida de $10,8 \mathrm{~ns}$ e momento de quadrupolo elétrico $\mathrm{Q}=2,36 \mathrm{~b}[37,38]$.

Os coeficientes de correlação angular gama-gama não perturbada para essa cascata gama são bem conhecidas, e seus valores são apresentados na figura 11 juntamente com o esquema simplificado do decaimento $[37,38]$. 


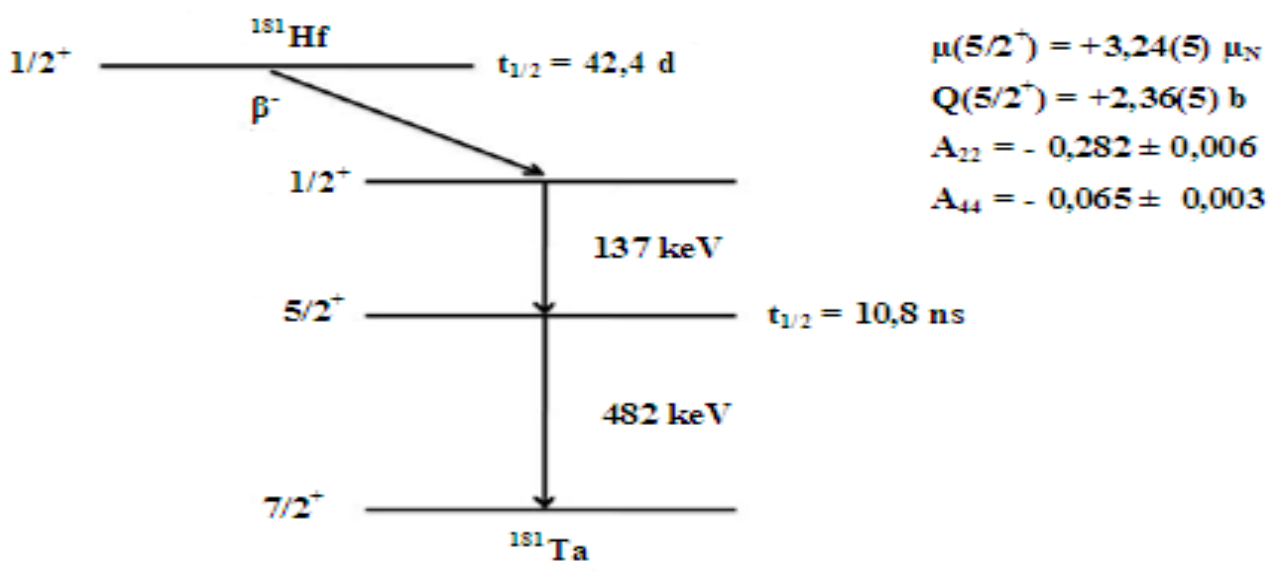

Figura 11- Esquema de decaimento do ${ }^{181} \mathrm{Hf} \rightarrow{ }^{181} \mathrm{Ta}$ 


\section{CAPÍTULO 5}

\section{ARRANJO EXPERIMENTAL E PROCEDIMENTOS}

Para que se possa realizar medidas de correlação angular perturbada é necessário introduzir o núcleo radioativo (ponta de prova) no material a ser estudado.

Neste capítulo são descritos os procedimentos utilizados na preparação das amostras estudadas, bem como as características do espectrômetro de correlação angular gama-gama perturbada do Laboratório de Interações Hiperfinas do IPEN, onde as medidas foram realizadas.

\subsection{Amostras utilizadas}

A preparação das amostras para as medidas foi realizada empiricamente já que ainda não existe uma metodologia específica de preparo para esse tipo de amostra. 
Para definir-se o melhor método de preparação dos compostos, foram utilizadas as seguintes soluções desenvolvidas neste trabalho:

- Solução aquosa de cloreto de índio.

- Solução saturada de EDTA (100g/L) - pH entre 4 e 5 (próprio da solução saturada de EDTA) + solução de cloreto de índio.

- Solução aquosa de cádmio previamente dissolvido em ácido nítrico 65\%..

- Solução de cádmio dissolvido em ácido nítrico a 65\% + solução saturada de EDTA

- Solução de cádmio dissolvido em ácido nítrico 65\% + EDTA (100g/L) em solução tampão $\left(\mathrm{HCO}_{3}{ }^{-} \leftrightarrow \mathrm{CO}_{3}{ }^{2-}+\mathrm{H}^{+}\right)-\mathrm{pH} 10$

- Solução aquosa de háfnio previamente dissolvido em ácido fluorídrico concentrado.

- Solução aquosa de háfnio previamente dissolvido em ácido fluorídrico concentrado + solução saturada de EDTA.

- Solução aquosa de oxicloreto de háfnio.

- Solução tampão $\left(\mathrm{HCO}_{3}{ }^{-} \leftrightarrow \mathrm{CO}_{3}{ }^{2-}+\mathrm{H}^{+}\right)-\mathrm{pH} 10+$ mais solução aquosa de oxicloreto de háfnio.

- Solução aquosa de oxicloreto de háfnio + EDTA (100g/L) em solução tampão $\left(\mathrm{HCO}_{3}{ }^{-} \leftrightarrow \mathrm{CO}_{3}{ }^{2-}+\mathrm{H}^{+}\right)-\mathrm{pH} 10$.

Abaixo são descritos as características e forma de aquisição dos núcleos de prova e posteriormente o processo de preparação de cada uma das soluções. 


\subsubsection{Preparo das soluções e confecção das amostras para medida}

De acordo com a especificidade, considerando-se a meia-vida do núcleo de prova, $\mathrm{pH}$ da solução e outras características físico químicas, inicialmente preparou-se a solução com os ligantes a serem investigados e a esta, posteriormente, foi adicionada a solução contendo o núcleo de prova.

\subsubsection{Confecção das amostras contendo ${ }^{111}$ In}

Amostra de ${ }^{111}$ In na forma de solução aquosa de cloreto de índio (amostra em branco): Uma alíquota de 5,0 $\mu \mathrm{L}$ da solução de cloreto de índio foi adiciona em $45 \mu \mathrm{L}$ de água destilada e separada para a realização das medidas CAP.

Amostra de ${ }^{111}$ In com EDTA em pH entre 4 e 5 (próprio da solução saturada de EDTA): Uma alíquota de solução de cloreto de índio (de 5 a $15 \mu \mathrm{L}$, dependendo da atividade) foi adicionada a $50 \mu \mathrm{L}$ de solução saturada de EDTA e separada para a realização das medidas CAP.

Amostra de ${ }^{111}$ In com EDTA em pH 10: Uma solução saturada de EDTA teve o pH ajustado pela adição de solução de $\mathrm{NaOH}$ a $20 \%$ até o pH 10 . Constituindo a solução estoque de EDTA. Uma alíquota de solução de cloreto de índio (de 5 a $15 \mu \mathrm{L}$, dependendo da atividade) foi acrescida de $50 \mu \mathrm{L}$ de solução estoque de EDTA e separada para a realização das medidas CAP. 


\subsubsection{Confecção da amostra de ${ }^{111 \mathrm{~m}} \mathrm{Cd}$}

Para confecção destas amostras, inicialmente uma massa de 5,0 mg de cádmio metálico natural foram irradiadas por 2 horas sob um fluxo de nêutrons térmicos da ordem de $510^{13}$ nêutrons/ $\left(\mathrm{cm}^{2} \mathrm{~s}\right)$ no reator IEA-R1 do IPEN. Em seguida, dissolveuse este material em $40 \mu \mathrm{L}$ da solução de ácido nítrico 65\%, acrescentou-se $10 \mu \mathrm{L}$ de hidróxido de sódio $20 \%$ e $60 \mu \mathrm{L}$ de água destilada. Esta foi a solução estoque do núcleo de prova.

Utilizando-se a solução radioativa, preparada como descrito acima, confeccionou-se diferentes amostras, para medidas no espectrômetro, conforme descrição abaixo:

Confecção da amostra de ${ }^{111 \mathrm{~m}} \mathrm{Cd}$ em meio aquoso: Acrescentou-se $10 \mu \mathrm{L}$ da solução estoque a $100 \mu \mathrm{L}$ de água destilada.

Confecção da amostra de ${ }^{111 \mathrm{~m}} \mathrm{Cd}+$ solução saturada de EDTA (pH entre 4 e 5): Acrescentou-se $10 \mu \mathrm{L}$ da solução estoque a $100 \mu \mathrm{L}$ da solução saturada de de EDTA.

Confecção da amostra de ${ }^{111 \mathrm{~m}} \mathrm{Cd}+$ EDTA em solução tampão a pH entre 9 e 10 : Acrescentou-se $10 \mu \mathrm{L}$ da solução estoque a $100 \mu \mathrm{L}$ da solução de EDTA $100 \mathrm{~g} / \mathrm{L}$ preparada em solução tampão. 


\subsubsection{Confecção da amostra contendo ${ }^{181} \mathrm{Hf}$ :}

$\mathrm{O} \mathrm{Hf}^{4+}$ foi obtido de duas maneiras diferentes, uma a partir do háfnio metálico e outra a partir do oxicloreto de háfnio. Nos itens a seguir são detalhados ambos procedimentos.

\subsection{Confecção da amostra contendo ${ }^{181} \mathrm{Hf}$ a partir do ${ }^{181}$ Hf metálico}

Confecção da amostra de ${ }^{181} \mathrm{Hf}$, a partir do háfnio metálico ativo dissolvido em ácido fluorídrico (Amostra em branco): $\mathrm{O}$ núcleo de prova foi obtido pela dissolução do háfnio metálico ativo em ácido fluorídrico concentrado. Como resultado dessa reação ocorre a formação do hexafluoro complexo conforme a reação:

$$
\mathrm{Hf}+6 \mathrm{HF} \leftrightarrow \mathrm{H}_{2}\left[\mathrm{HfF}_{6}\right]+2 \mathrm{H}_{2}[11]
$$

A solução resultante constituiu a solução-estoque 1 do núcleo de prova.

Uma alíquota de $5 \mu \mathrm{L}$ da solução-estoque 1 acrescida de $45 \mu \mathrm{L}$ de água destilada foi separada para a realização de medidas PAC.

Confecção da amostra de ${ }^{181} \mathrm{Hf}$ a partir do háfnio metálico dissolvido em ácido fluorídrico + EDTA: Medidas CAP foram realizadas em amostras preparadas a partir da adição de $5 \mu \mathrm{L}$ da solução-estoque 1 , acrescida de $45 \mu \mathrm{L}$ de solução saturada de EDTA (pH entre 4 e 5, próprio da solução saturada de EDTA). 


\subsection{Confecção da amostra contendo ${ }^{181}$ Hf a partir do oxicloreto de háfnio}

$\mathrm{O}$ oxicloreto de háfnio $\left(\mathrm{HfOCl}_{2} \cdot 8 \mathrm{H}_{2} \mathrm{O}\right)$ ativo (obtido conforme descrição no item 4.5) foi dissolvido em $2 \mathrm{~mL}$ de água destilada obtendo-se assim a solução-estoque 2 do núcleo de prova. Com esta solução radioativa confeccionou-se diferentes amostras, para medidas no espectrômetro, conforme descrição abaixo:

Confecção da amostra de ${ }^{181} \mathrm{Hf}$ a partir do oxicloreto de háfnio em solução aquosa (amostra em branco): Uma alíquota de $50 \mu \mathrm{L}$ da solução-estoque 2 foi separada para as medidas CAP.

Confecção da amostra de ${ }^{181} \mathrm{Hf}$ a partir do oxicloreto de háfnio + solução tampão a pH entre 9 e 10: Uma alíquota de $10 \mu \mathrm{L}$ da solução-estoque 2 foi acrescida em $50 \mu \mathrm{L}$ de solução tampão a pH entre 9 e 10.

Confecção da amostra de ${ }^{181}$ Hf a partir do oxicloreto de háfnio + solução de EDTA a pH entre 9 e 10: Uma alíquota de $10 \mu \mathrm{L}$ da solução-estoque 2 , foi acrescentada em $50 \mu \mathrm{L}$ de solução tamponada de EDTA 100g/L com pH entre 9 e 10.

\subsection{Espectrômetro de Correlação Angular gama-gama}

O espectrômetro onde foram realizadas as medidas é composto de 4 detectores cintiladores de fluoreto de bário $\left(\mathrm{BaF}_{2}\right)$ associados a um sistema eletrônico para medidas de coincidências $\gamma-\gamma$ atrasadas. O sistema eletrônico associado utiliza a configuração lento-rápido, possibilitando a obtenção de 12 espectros de coincidência em tempo, sendo quatro espectros com detectores segundo o ângulo de $180^{\circ}$ e 8 espectros 
para ângulos de $90^{\circ}$. Cada um dos detectores produz sinais de saída para as radiações $\gamma_{1}$ e $\gamma_{2}$. O esquema da configuração da eletrônica "lento-rápido" está representado na figura 12.

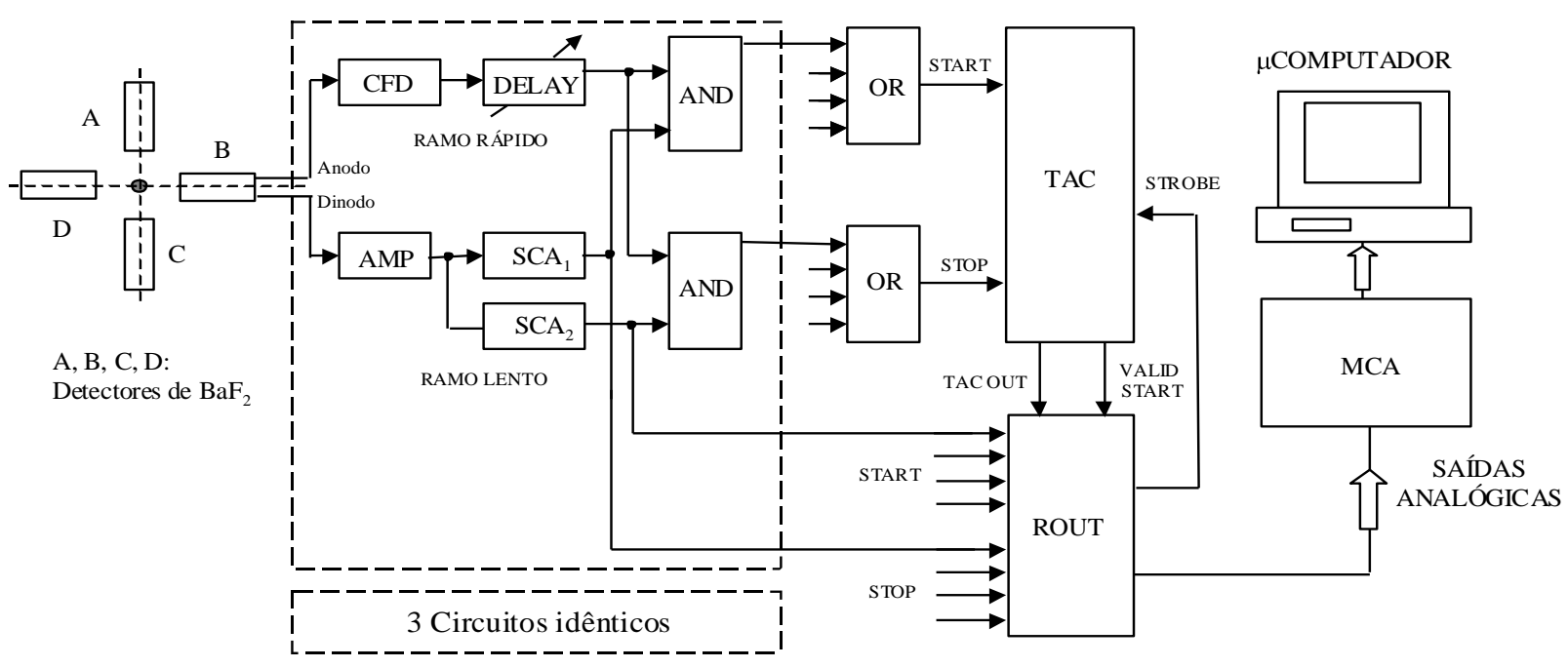

Figura 12 - Esquema simplificado do espectrômetro com quatro detectores.

Na saída dos detectores há um dinodo, que fornece um pulso positivo proporcional a energia dos raios gama e um anodo, que produz um sinal que carrega informações relativas ao tempo de chegada dos fótons no detector.

Os pulsos relacionados a estes dois tipos de informação são analisados em dois ramos distintos do sistema eletrônico, o ramo de energia (lento) e o ramo de tempo (rápido) para cada detector do espectrômetro.

No ramo lento o sinal de energia extraído do dinodo passa inicialmente por um pré-amplificador (PRE) seguido de um amplificador de espectroscopia (AMP). O sinal de saída é então transmitido a dois analisadores monocanais (TSCA) onde são selecionadas as energias da região de interesse do espectro. Assim, cada detector pode dar origem a um sinal de "start" ou "stop" conforme a detecção do primeiro ou segundo gama da respectiva cascata. 
No ramo rápido o sinal de tempo vindo do anodo da fotomultiplicadora é processado pelo discriminador de fração constante (CFD), que gera um pulso correlacionado com o instante em que o raio gama é detectado.

A partir dos pulsos gerados nos dois ramos são feitas as coincidências entre o sinal rápido e o sinal lento. Mas, antes de serem feitas as coincidências, o sinal do ramo rápido é atrasado através de um DELAY de modo a compensar o intervalo de tempo necessário para a análise do sinal em energia.

O pulso resultante da coincidência entre o sinal lento e o sinal rápido (AND) é então designado como "start" se corresponder à primeira radiação da cascata $\left(\gamma_{1}\right)$, ou "stop" se corresponder à segunda radiação da cascata $\left(\gamma_{2}\right)$. Os sinais são então enviados a um conversor de tempo em amplitude (TAC), onde o pulso de saída é proporcional à diferença de tempo entre a chegada dos pulsos de "start" e "stop".

O sinal de saída do TAC é então enviado ao roteador, que envia para uma das 12 entradas multicomplexas do analisador multicanal (MCA) de acordo com a combinação dos detectores que originaram a coincidência gama. É realizada então a conversão do sinal analógico em digital (ADC) e seu resultado é armazenado em uma região de memória do MCA. Os dados armazenados em memória dão origem aos 12 espectros de coincidência gama-gama atrasados que depois serão processados para a obtenção dos parâmetros relativos à interação hiperfina [40,41].

\subsection{Tratamento dos dados}

Os 12 espectros, experimentais, são obtidos pela combinação de detectores nos quais são armazenados tanto coincidências verdadeiras como coincidências acidentais (provenientes de fótons que não tem origem no núcleo de prova, mas que atingem o detector dentro do tempo de resolução. Estes espectros são tratados pelo software TDPAC [42] que gera uma curva de $\mathrm{A}_{22} \mathrm{G}_{22}(\mathrm{t})$, dada por uma combinação dos espectros $\mathrm{W}(\theta, \mathrm{t})$ : 


$$
A_{22} G_{22}(t)=2\left[\bar{W}\left(180^{\circ}, t\right)-\overline{\mathrm{W}}\left(90^{\circ}, t\right)\right] /\left[\overline{\mathrm{W}}\left(180^{\circ}, t\right)+2 \overline{\mathrm{W}}\left(90^{\circ}, t\right)\right]
$$

Onde os termos $\overline{\mathrm{W}}\left(180^{\circ}, \mathrm{t}\right)$ e $\overline{\mathrm{W}}\left(90^{\circ}, \mathrm{t}\right)$ são respectivamente:

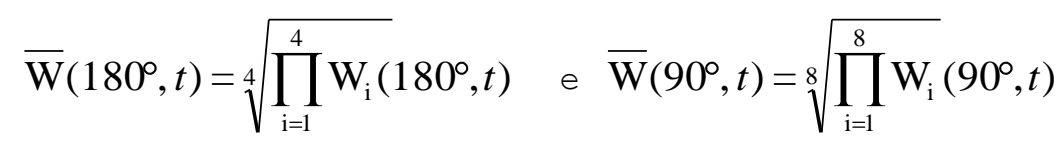

sendo $\mathrm{W}_{\mathrm{i}}(\theta, t)$ os espectros de coincidências para as diversas combinações de detectores nos ângulos $\theta=90^{\circ}, 180^{\circ}$ subtraídos os efeitos devidos a eventos de coincidências acidentais $\mathrm{W}_{\mathrm{A}}(\mathrm{t}): \mathrm{W}_{\mathrm{i}}(\theta, \mathrm{t})=\mathrm{W}_{\mathrm{i}}(\theta, \mathrm{t})-\mathrm{W}_{\mathrm{A}}(\mathrm{t})[43]$.

A partir da curva de $\mathrm{A}_{22} \mathrm{G}_{22}(\mathrm{t})$ é possível obter as frequências de transição $\omega_{\mathrm{i}}$ correspondentes ao desdobramento em energia do nível intermediário da cascata gama do núcleo de prova devido à presença do gradiente de campo elétrico originado pela vizinhança eletrônica [36]. 


\section{CAPÍTULO 6}

\section{RESULTADOS E DISCUSSÕES}

Neste capítulo são apresentados e discutidos os resultados das medidas de Correlação Angular $\gamma-\gamma$ Perturbada (CAP) para as diferentes amostras utilizadas. Em todos os casos o nuclídeo pai foi considerado para as interpretações de caráter químico. Foi considerado também cada uma das possíveis espécies formadas pela ligação química do núcleo de prova com os possíveis ligantes presentes no sistema como sendo um "sítio", ou seja, um "local" de onde a ponta de prova forneceu as informações traduzidas nos espectros de correlação angular. Para todas as amostras foram realizadas medidas de Correlação Angular Perturbada a temperatura ambiente (295 K) e resfriada (77K). 


\subsection{Amostras com adição de ${ }^{111}$ In $\rightarrow{ }^{111} \mathrm{Cd}$ como núcleo de prova}

Na figura 13 são apresentados os espectros de correlação angular perturbada do ${ }^{111} \mathrm{Cd}$ em meio aquoso, a 295K (A) e $77 \mathrm{~K}$ (B). Na figura 14 são apresentados os espectro de correlação angular perturbada do ${ }^{111} \mathrm{Cd}$ com EDTA em pH entre 4 e 5 (A) a 295K e (B) a 77K e na figura 15 observa-se espectro de correlação angular perturbada para o ${ }^{111}$ In mais solução saturada de EDTA em pH estre 9 e 10 (pH ajustado com solução de $\mathrm{NaOH}$ ) (A) a $295 \mathrm{~K}$ e (B) a $77 \mathrm{~K}$.

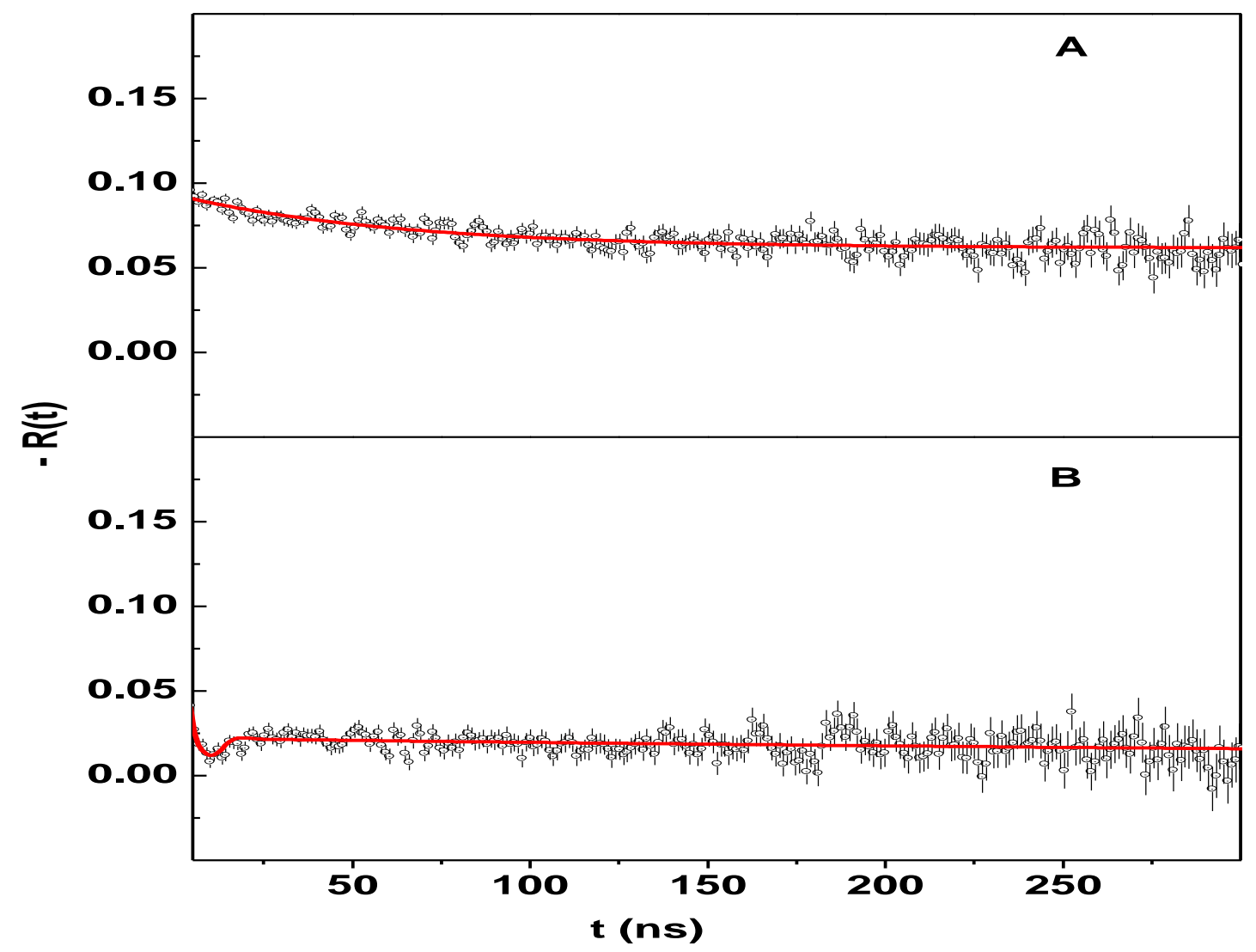

Figura 13- Espectro de correlação angular perturbada do ${ }^{111} \mathrm{Cd}$ em solução aquosa (Amostra em branco): A) a $295 \mathrm{~K}$ e B) a $77 \mathrm{~K}$. 


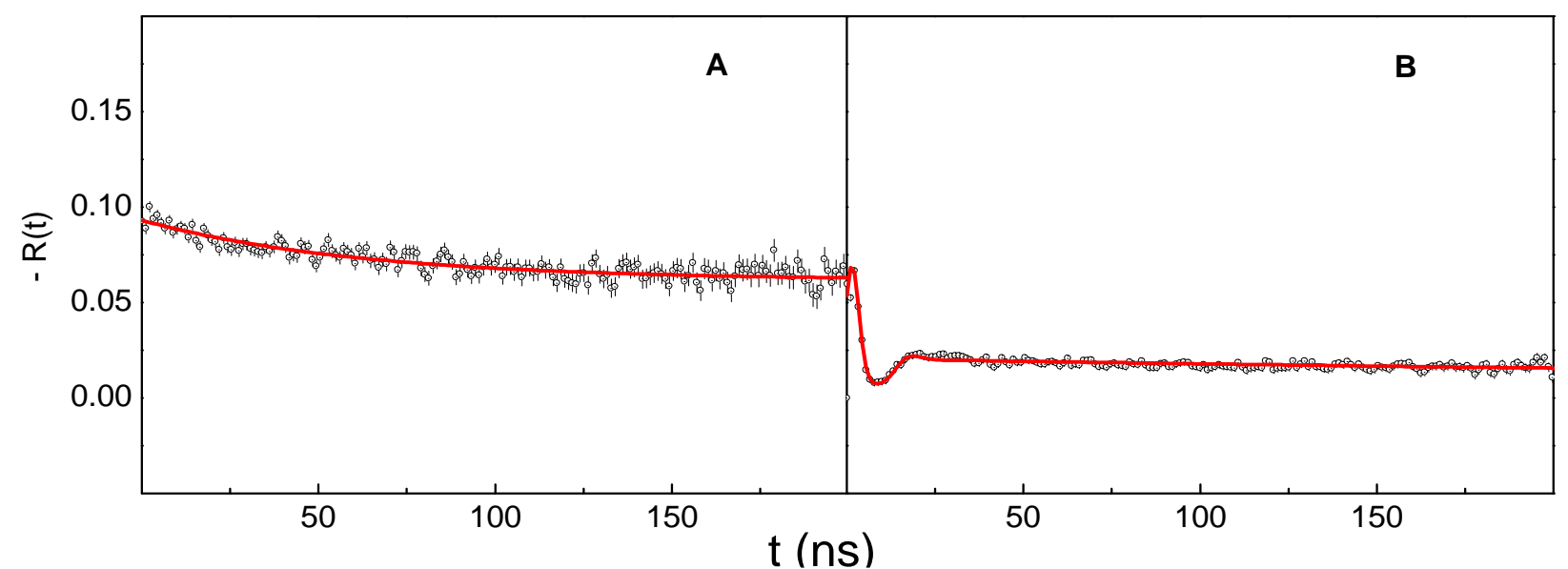

Figuras 14 - Espectro de correlação angular perturbada do ${ }^{111} \mathrm{Cd}$ com EDTA em pH entre 4 e 5 (da própria solução saturada de EDTA): A) a $295 \mathrm{~K}$ e B) a $77 \mathrm{~K}$.

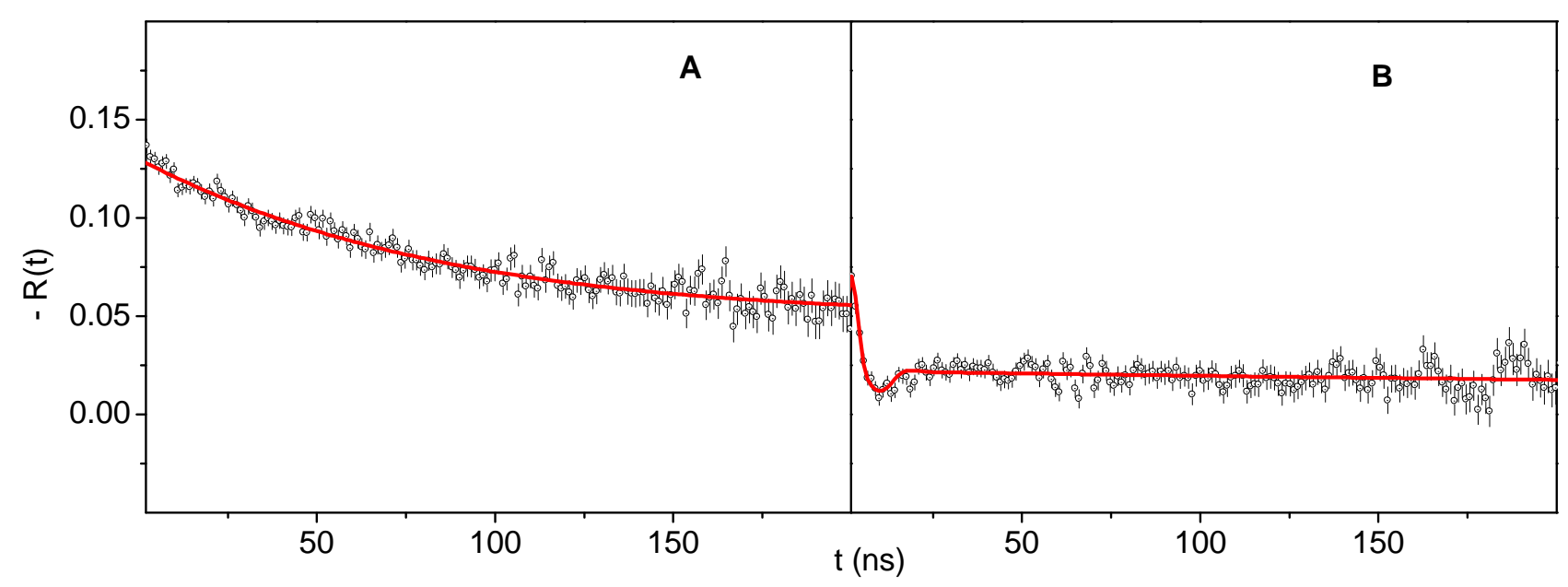

Figuras 15 - Espectro de correlação angular perturbada do ${ }^{111} \mathrm{Cd}$ com EDTA em pH entre 9 e 10 (Ajustada com solução de $\mathrm{NaOH}$ ): A) a $295 \mathrm{~K}$ e B) a $77 \mathrm{~K}$.

A Tabela 4 apresenta os parâmetros hiperfinos obtidos a partir do núcleo de prova ${ }^{111} \mathrm{Cd}$ em meio aquoso, com EDTA em pH entre 4 e 5 e com EDTA em pH entre 9 e 10. 
Tabela 4. Parâmetros Hiperfinos obtidos do núcleo de prova ${ }^{111}$ Cd em solução aquosa, com EDTA em pH entre 4 e 5 e com EDTA em pH entre 9 e 10.

\begin{tabular}{|c|c|c|c|c|c|c|c|c|}
\hline Amostra & Sitio & Temp.(K) & Fração(\%) & $v_{\mathrm{Q}}(\mathrm{MHz})$ & $\eta$ & $\lambda(\mathrm{MHz})$ & $\delta$ & Fig \\
\hline \multirow{2}{*}{$\begin{array}{l}\text { Amostra de }{ }^{111} \text { In na forma de solução aquosa de } \\
\text { cloreto de índio (amostra em branco) }\end{array}$} & 1 & 77 & 100 & $67,0 \pm 3,0$ & $0.70 \pm 0,00$ & & $0.60 \pm 0,02$ & \multirow[b]{2}{*}{13} \\
\hline & 1 & 295 & 100 & & & $19,0 \pm 4,0$ & & \\
\hline \multirow{3}{*}{$\begin{array}{c}\text { Amostra de }{ }^{111} \text { In com EDTA em pH entre } 4 \text { e } 5 \\
\text { (próprio da solução saturada de EDTA }\end{array}$} & 1 & \multirow{2}{*}{77} & 94 & $216,4 \pm 3,0$ & $0,18 \pm 0,00$ & & $0,80 \pm 0,02$ & \multirow{3}{*}{14} \\
\hline & 2 & & 6 & $7,4 \pm 3,0$ & $1,00 \pm 0,00$ & & 0,1 & \\
\hline & 1 & 295 & 100 & & & $15,0 \pm 0,5$ & & \\
\hline \multirow{3}{*}{ Amostra de ${ }^{111}$ In com EDTA em pH entre 9 e 10} & 1 & \multirow{2}{*}{77} & 52 & $155,0 \pm 3,0$ & $0,5 \pm 0,03$ & & $0,07 \pm 0,02$ & \multirow{3}{*}{15} \\
\hline & 2 & & 48 & $128,0 \pm 6,0$ & $0,3 \pm 0,1$ & & $0,13 \pm 0,02$ & \\
\hline & 1 & 295 & 100 & & & $10,5 \pm 0,5$ & & \\
\hline
\end{tabular}


A presença de frequência de natureza dinâmica de $19 \mathrm{MHz}$ para a amostra de índio em meio aquoso a 298 K (figura 13 - A) aponta para a formação de complexos decorrentes da hidrólise do índio em meio aquoso conforme [17].

Observando os espectros das amostras de In com EDTA em pH entre 4 e 5 (pH próprio da solução saturada de EDTA) e em pH 10 ajustado com solução de hidróxido de sódio, percebe-se que, em ambos os casos, pode-se afirmar que o In estabeleceu ligação. Esta afirmação pode ser feita pela evidência de correlação rotacional com flutuação de tempo de correlação longo (Figuras 14 A e 15 A).

A medida a 77K (temperatura do nitrogênio líquido- figura 14 B e 15 B) foi realizada para reduzir a mobilidade das moléculas. Nestas condições, analisando os gráficos, observa-se que não ocorre o comportamento exponencial característico da interação dinâmica [1].

Os dados apresentados na tabela 4 podem ser avaliados considerando-se o seguinte: O EDTA comporta-se como um ácido tetraprótico fraco $\left(\mathrm{H}_{4} \mathrm{Y}\right)$. Portanto, em meio aquoso, o EDTA ioniza-se produzindo quatro espécies aniônicas $\left(\mathrm{H}_{3} \mathrm{Y}^{-} ; \mathrm{H}_{2} \mathrm{Y}^{2-}\right.$; $\left.\mathrm{HY}^{3-} ; \mathrm{Y}^{4-}\right)$. Para valores de $\mathrm{pH}$ abaixo de 10 , predominam as espécies protonadas de EDTA, ou sejam: $\mathrm{HY}^{3-}, \mathrm{H}_{2} \mathrm{Y}^{2-}, \mathrm{H}_{3} \mathrm{Y}^{-}$e $\mathrm{H}_{4} \mathrm{Y}$ enquanto para valores de $\mathrm{pH}$ maiores que 10, predomina a espécie desprotonada $\mathrm{Y}^{1-}$. Em pH entre 4 e 5 tem-se uma mistura de espécies com predominância maior que $90 \%$ da espécie $\mathrm{H}_{2} \mathrm{Y}^{2-}$ (condição em que se encontra o Etilenodiaminotetracetato de sódio - EDTA dissódico $\left(\mathrm{C}_{10} \mathrm{H}_{14} \mathrm{~N}_{2} \mathrm{O}_{8} \mathrm{Na}_{2} .2 \mathrm{H}_{2} \mathrm{O}\right)$ em solução), enquanto em $\mathrm{pH} 10$ tem-se uma mistura aproximadamente equimolar das espécies $\mathrm{HY}^{3-}$ e $\mathrm{Y}^{1-}[15]$.

É possível afirmar que ocorreu a ligação entre o In e o EDTA, considerando-se, primeiramente, os valores das frequências de quadrupolo medidas (216 MHz para o In mais EDTA saturado e $128 \mathrm{MHz}$ e $155 \mathrm{MHz}$ para as duas frações medidas para o In mais EDTA em pH 10 ) diferentes daquela medida para a amostra em branco que foi de $67 \mathrm{MHz}$, e também considerando-se as frações das espécies presentes no sistema em função do $\mathrm{pH}$ das amostras. De acordo com o diagrama de distribuição das espécies para o EDTA em meio aquoso nos diferentes pH (Figura 4), temos que num $\mathrm{pH}$ entre 4 e 5 existe predominantemente uma espécie no sistema $\left(\mathrm{H}_{2} \mathrm{Y}^{2-}\right)$ com mais de $90 \%$. Essa espécie reage com o In formando um quelato In $-\mathrm{H}_{2} \mathrm{Y}^{2-}$. Esse 
quelato é visto como sendo um sítio com fração de 94\% (tabela 4). Para o In mais EDTA em tampão a pH 10, de acordo com o mesmo diagrama mostrado na figura 4, tem-se duas espécies provenientes do EDTA, o íon $\mathrm{HY}^{3-}$ e o íon $\mathrm{Y}^{4-}$ com aproximadamente $50 \%$ de cada um. Essas espécies reagem com o EDTA formando os quelatos $\mathrm{In}-\mathrm{HY}^{3-} \mathrm{e} \mathrm{In}-\mathrm{Y}^{4-}$ responsáveis pelas frequências medidas e que aparecem na última linha da tabela 4.

\subsection{Amostras com adição de ${ }^{111 \mathrm{~m}} \mathrm{Cd} \rightarrow{ }^{111} \mathrm{Cd}$ como núcleo de prova}

Na figura 16 são apresentados os espectros de correlação angular perturbada do ${ }^{111 \mathrm{~m}} \mathrm{Cd}$ em meio aquoso, a $295 \mathrm{~K}$ (A) e $77 \mathrm{~K}$ (B). Na figura 17 são apresentados os espectro de correlação angular perturbada do ${ }^{111 \mathrm{~m}} \mathrm{Cd}$ com solução saturada de EDTA em pH entre 4 e 5 (pH da própria solução saturada de EDTA) a 295K (A) e 77K (B). Na figura 18 são apresentados os espectro de correlação angular perturbada do ${ }^{111 \mathrm{~m}} \mathrm{Cd}$ com solução com EDTA em pH entre 9 e 10 (tamponada) a 295K (A) e 77K (B).

A Tabela 5 apresenta os parâmetros hiperfinos obtidos a partir do núcleo de prova ${ }^{111 \mathrm{~m}} \mathrm{Cd}$ em meio aquoso e com solução saturada de EDTA em pH entre 4 e 5.

Observando os espectros das amostras de ${ }^{111 \mathrm{~m}} \mathrm{Cd}$ em solução aquosa a $295 \mathrm{~K}$ (figuras 16 - A, 17 - A e 18 - A), não se vê nenhuma interação, o que sugere duas possíveis hipóteses: a primeira que o íon $\mathrm{Cd}^{2+}$, por ser um ácido mole, não reagiu com as espécies $\mathrm{NO}_{3}{ }^{1-}$ (proveniente do ácido nítrico utilizado para dissolver o cádmio metálico), não reagiu com as espécies provenientes do tampão (os íons $\mathrm{CO}_{3}{ }^{2-} \mathrm{e}^{\mathrm{HCO}_{3}}{ }^{{ }}$) e nem com as espécies provenientes do EDTA presentes no sistema que correspondem a bases duras [11,12] e a segunda hipótese é a de que o íon $\mathrm{Cd}^{2+}$, por estar no sistema em concentração relativamente elevada, tenha formado clusters de geometria simétrica, que resistiram às variações do $\mathrm{pH}$ e à presença dos ligantes existentes no sistema. Ao se 


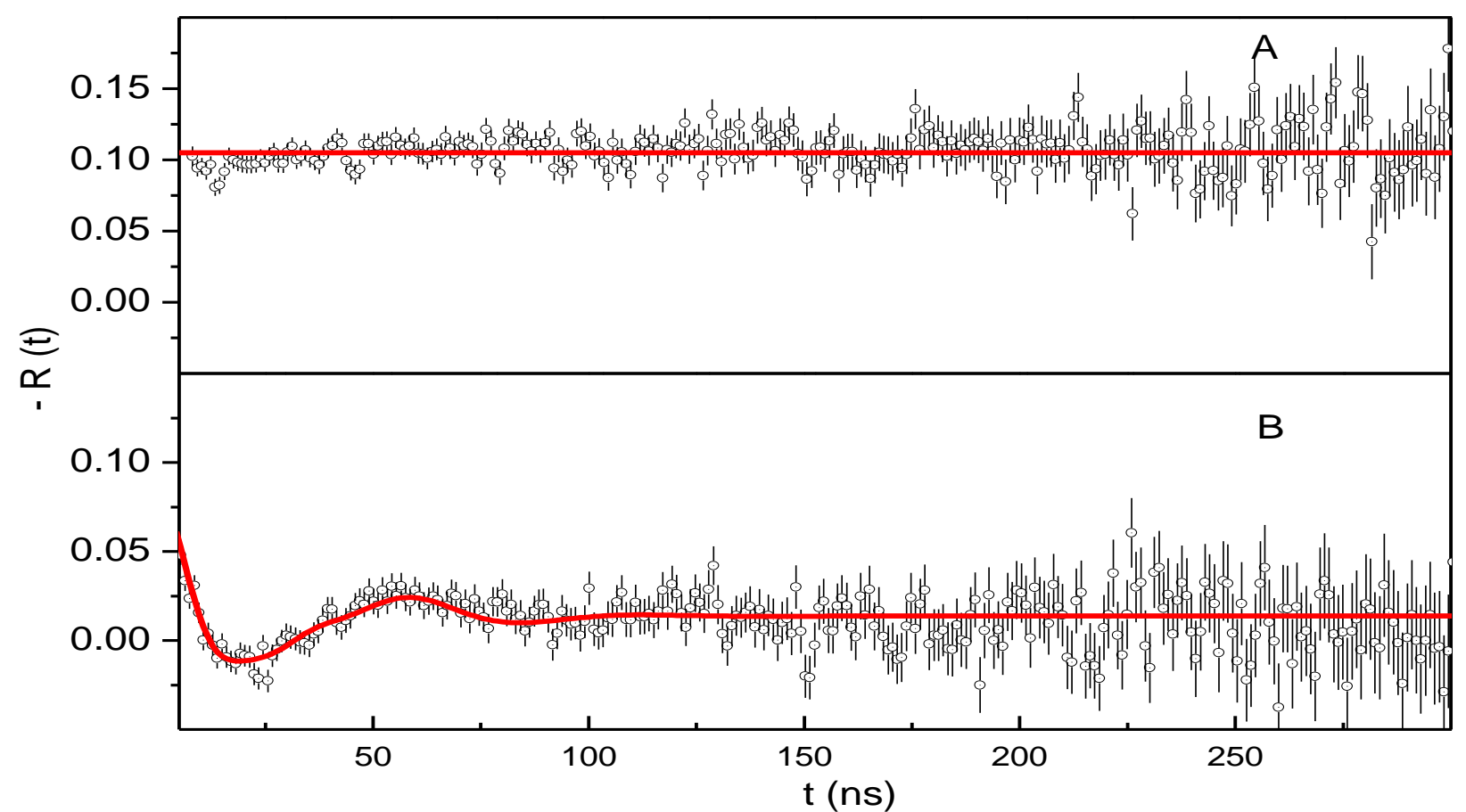

Figuras 16 - Espectro de correlação angular perturbada do ${ }^{111 \mathrm{~m}} \mathrm{Cd}$ em solução aquosa: A) a $295 \mathrm{~K}$ e B) a $77 \mathrm{~K}$.

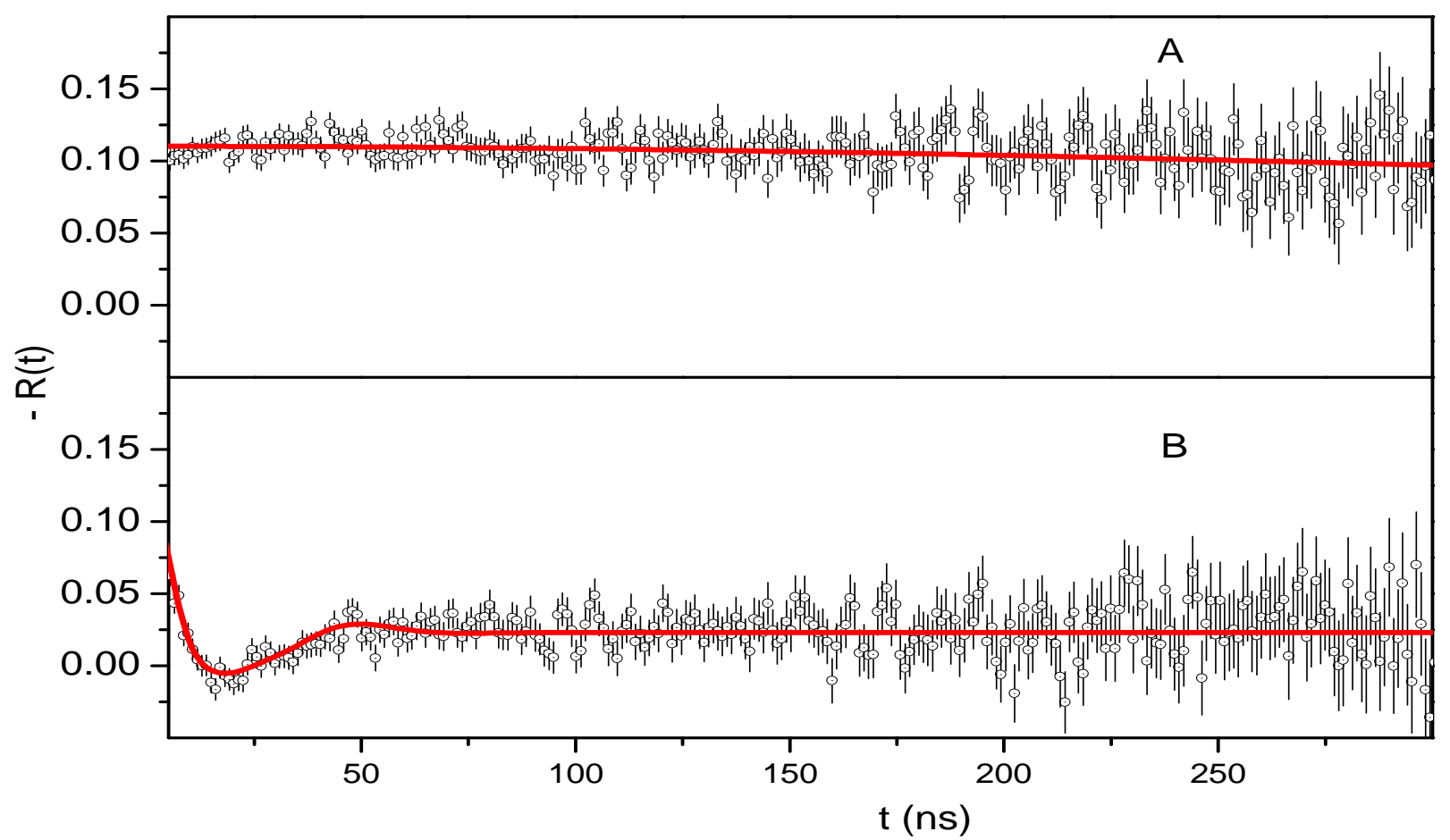

Figuras 17 - Espectro de correlação angular perturbada do ${ }^{111 \mathrm{~m}} \mathrm{Cd}$ com solução saturada de EDTA em pH entre 4 e 5 (pH da própria solução saturada de EDTA) a 295K (A) e 77K (B) 


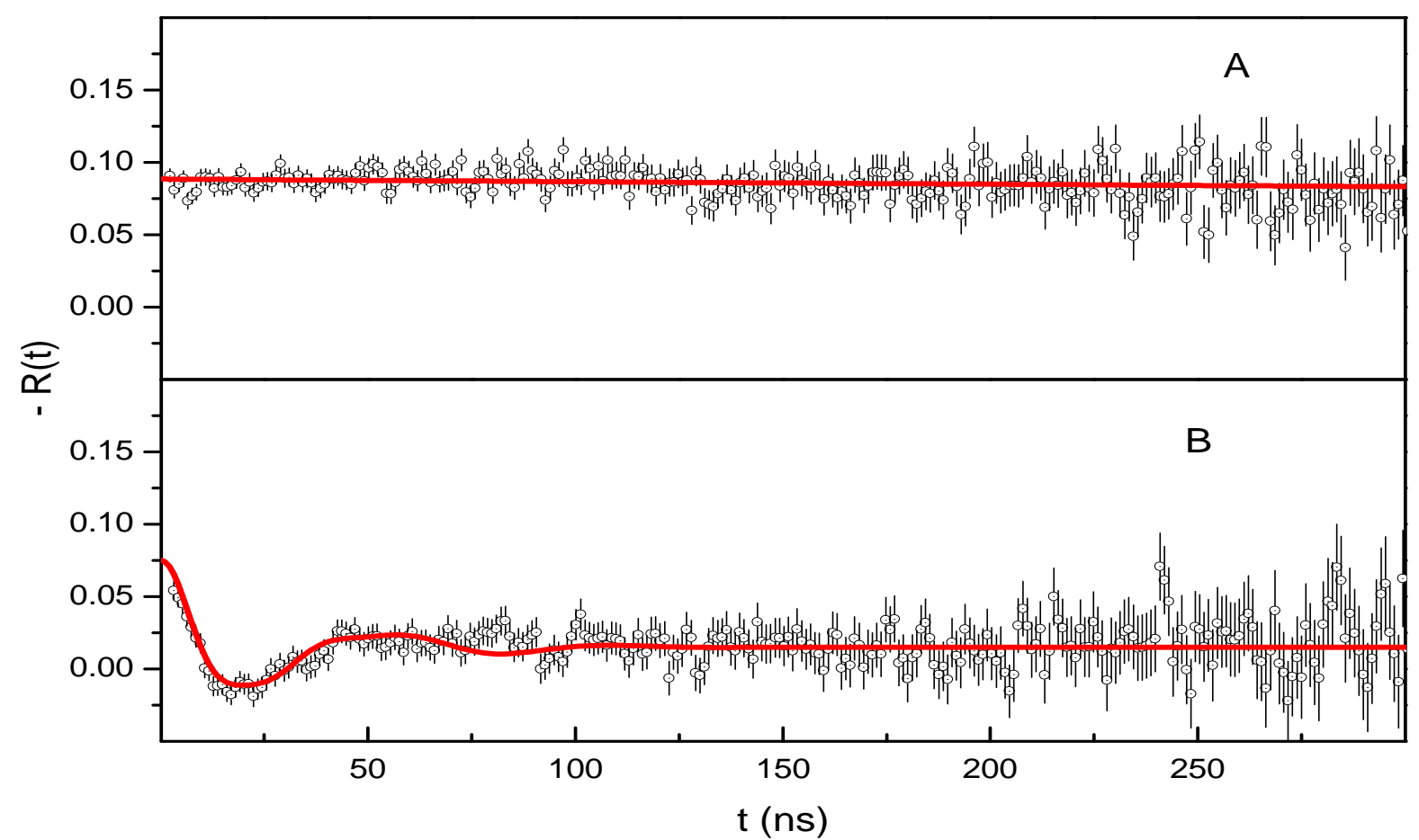

Figuras 18 - Espectro de correlação angular perturbada do ${ }^{111 \mathrm{~m}} \mathrm{Cd}$ com EDTA em pH entre 9 e 10 (EDTA em solução tampão) a 295K (A) e 77K (B).

Tabela 5. Parâmetros Hiperfinos obtidos do núcleo de prova ${ }^{111 \mathrm{~m}} \mathrm{Cd}$ em solução aquosa e com solução saturada de EDTA em pH entre 9 e 10 a temperatura de 77K.

\begin{tabular}{c|c|c|c|c}
\hline \multicolumn{1}{c|}{ Amostra } & $v_{\mathrm{Q}}(\mathrm{MHz})$ & $\eta$ & $\delta$ & Fig. \\
\hline${ }^{111 \mathrm{~m} C d \text { em meio aquoso }}$ & $108,0 \pm 3,0$ & $0,30 \pm 0,05$ & $0,30 \pm 0,02$ & 16 \\
\hline \hline${ }^{111 \mathrm{~m} C d \text { EDTA em pH entre 4 e 5 }}$ & $109,0 \pm 5,0$ & $0,30 \pm 0,07$ & $0,30 \pm 0,03$ & 17 \\
\hline \hline${ }^{111 \mathrm{~m} C d \text { com EDTA em pH entre } 9 \text { e } 10}$ & $108,0 \pm 5,0$ & $0,30 \pm 0,04$ & $0,30 \pm 0,03$ & 18 \\
\hline
\end{tabular}


resfriar a amostra, porém, é medida uma frequência de quadrupolo de $108 \mathrm{MHz}$, de 109 $\mathrm{MHz}$ e $109 \mathrm{MHz}$ respectivamente para as amostras de $\mathrm{Cd}^{\mathrm{m}}$ em meio aquoso, com solução saturada de EDTA em pH entre 4,0 e 5,0 e com solução de EDTA (100g/L) tamponada em pH entre 9 e 10 (tabela 5). Este fato apoia a hipótese da formação dos clusters, pois temos a mesma espécie sendo formada nas três amostras e o resfriamento apenas distorce a simetria dos clusters de cádmio fazendo com que apareça a frequência de quadrupolo.

\subsection{Amostra de ${ }^{181} \mathrm{Hf} \rightarrow{ }^{181}$ Ta como núcleo de prova.}

Como já descrito (itens 5.1.1.3.1 e 5.1.1.3.2) as amostras onde adicionou-se háfnio, e portanto, contendo tântalo como núcleo de prova, foram obtidas de duas formas: A partir de Hf metálico irradiado e dissolvido em ácido fluorídrico concentrado e a partir da irradiação oxicloreto de háfnio dissolvido em água.

Para cada um dos processos foram realizadas medidas em solução aquosa para verificar a ligação de Hf com HF (figura 19), Hf com água (figura 22), e Hf com solução tampão (figura 23) e Hf com EDTA (figura 24).

A partir do Hf metálico, realizou-se medidas em solução saturada de EDTA e para essa mesma amostra cristalizada. Os espectros de correlação angular perturbada estão apresentados nas figuras 20 e 21 . Já os resultados obtidos a partir do oxicloreto de háfnio estão apresentados na figura 22, 23 e 24 sendo respectivamente oxicloreto em água, em solução tampão e em solução contendo EDTA (100g/L) tamponada.

Os parâmetros hiperfinos obtidos do ajuste das curvas de correlação angular das amostras contendo o núcleo de prova ${ }^{181}$ Ta estão apresentados na tabela 6 , e abaixo estão listadas e discriminadas cada uma das amostras estudadas:

Amostra 1: ${ }^{181} \mathrm{Hf}$ obtida a partir da dissolução do háfnio metálico em HF concentrado: amostra em solução aquosa a 77K. (figura 19) 
Amostra 2: de ${ }^{181} \mathrm{Hf}$ obtida a partir da dissolução do háfnio metálico em HF concentrado: amostra com solução saturada de EDTA em pH entre 4,0 e 5,0 (pH da própria solução saturada de EDTA) a 295K e a 77K (figura 20).

Amostra 3: ${ }^{181} \mathrm{Hf}$ obtida a partir da dissolução do háfnio metálico em HF concentrado: amostra com solução saturada de EDTA em pH entre 4,0 e 5.0 (pH da própria solução saturada de EDTA) cristalizada a 295K e a 77K (figura 21).

Amostra 4: ${ }^{181} \mathrm{Hf}$ obtido a partir do $\mathrm{HfOCl}_{2}$ : Solução aquosa de $\mathrm{HfOCl}_{2}$ (amostras em branco) a $295 \mathrm{~K}$ e a $77 \mathrm{~K}$ (figura 22).

Amostra 5: ${ }^{181} \mathrm{Hf}$ obtido a partir do $\mathrm{HfOCl}_{2}$ : Solução aquosa de $\mathrm{HfOCl}_{2}$ tamponada em $\mathrm{pH}$ entre 9 e 10 a $295 \mathrm{~K}$ e a $77 \mathrm{~K}$ (figura 23 ).

Amostra 6: ${ }^{181} \mathrm{Hf}$ obtido a partir do $\mathrm{HfOCl}_{2}$ : Solução aquosa de $\mathrm{HfOCl}_{2}$ mais EDTA $(100 \mathrm{~g} / \mathrm{L})$ tamponada em $\mathrm{pH}$ entre 9 e 10 a $295 \mathrm{~K}$ e a $77 \mathrm{~K}$ (figura 24 ).

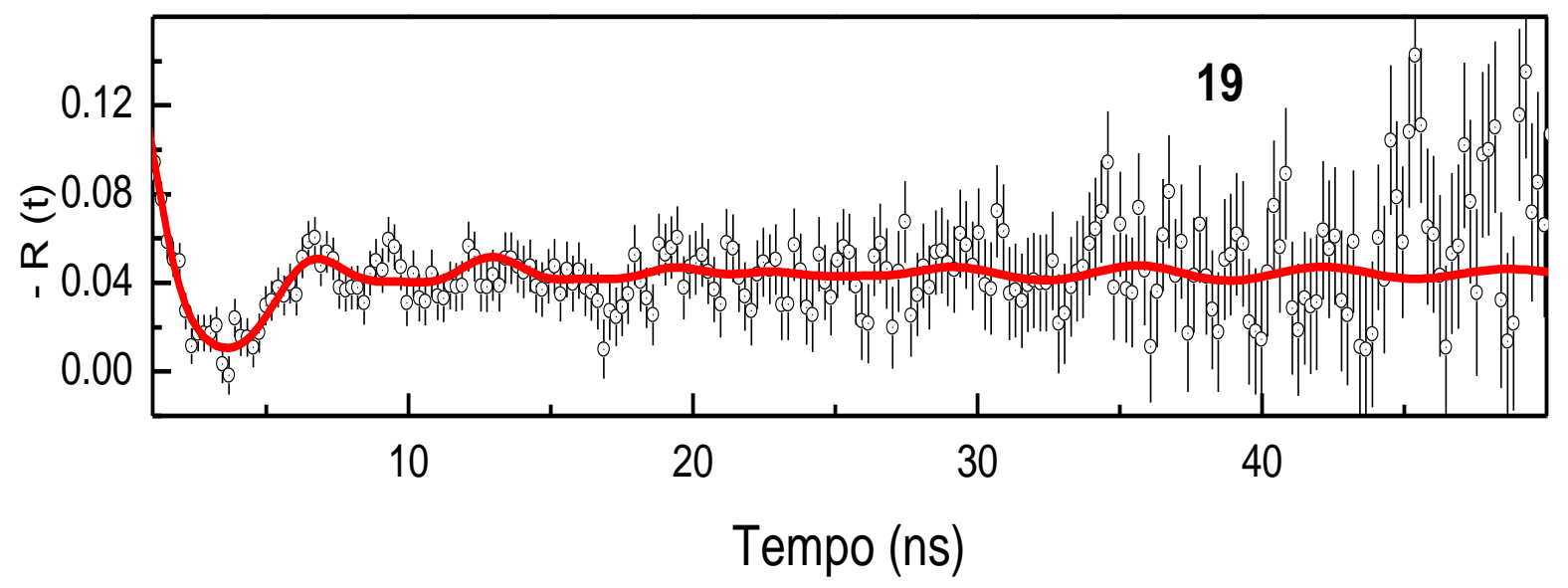

Figura 19- Espectro de correlação angular perturbada para solução aquosa do ${ }^{181} \mathrm{Hf}$ a $77 \mathrm{~K}$ 


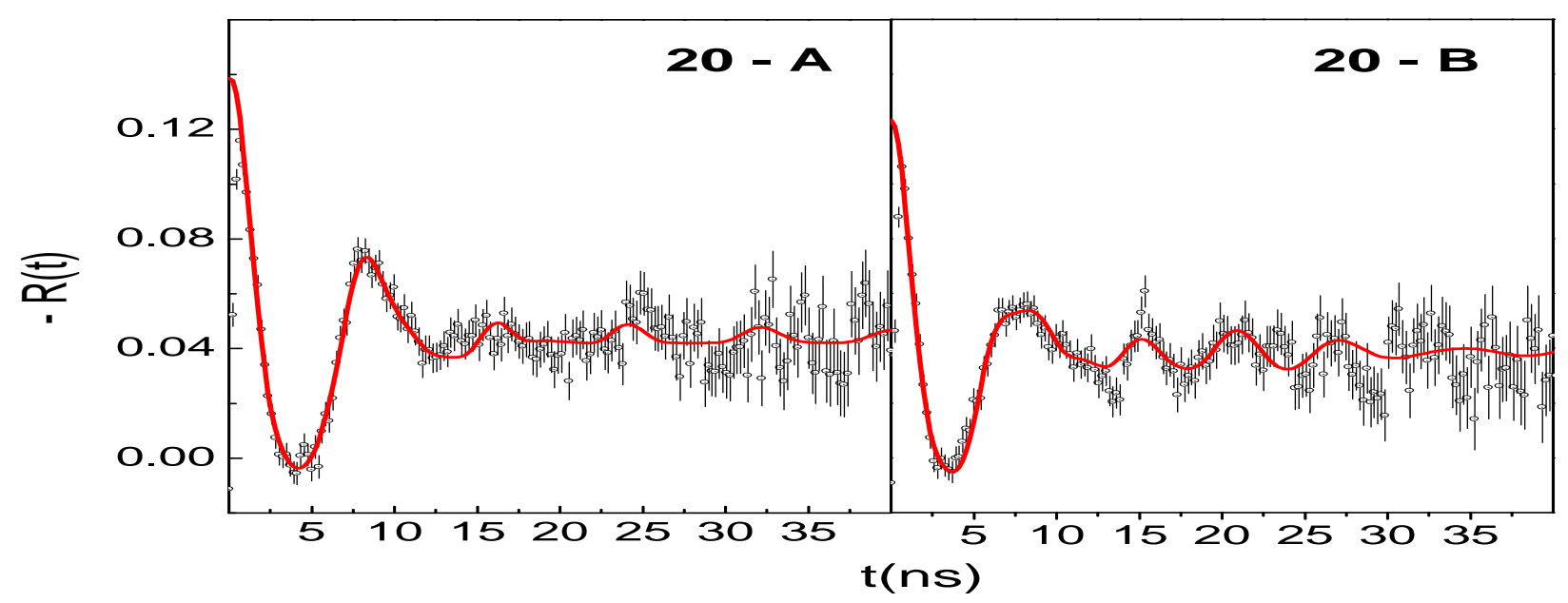

Figura 20 - Espectro de correlação angular perturbada para o ${ }^{181} \mathrm{Hf}$ a mais solução saturada de EDTA: a 295 (A) e a 77K (B) pH entre 4,0 e 5,0.

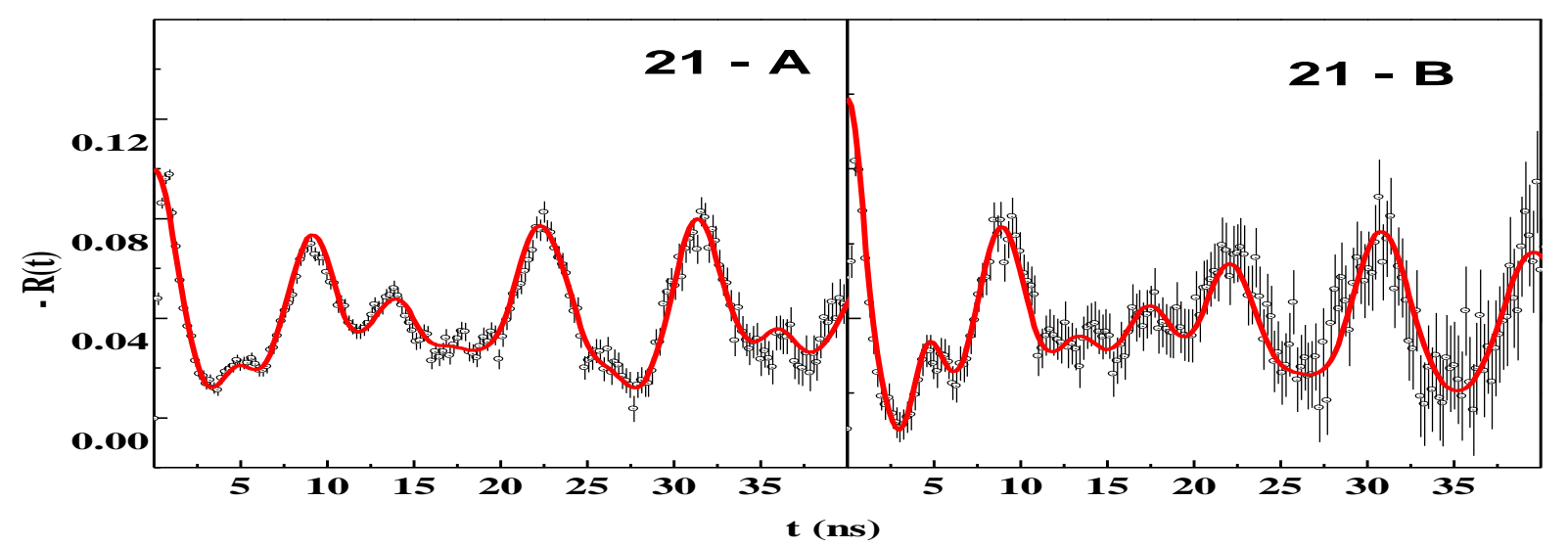

Figura 21- Espectro de correlação angular perturbada para o ${ }^{181} \mathrm{Hf}$ mais solução saturada de EDTA (cristalizado): a 295 (A) e a $77 \mathrm{~K}$ (B) pH entre 4,0 e 5,0. 


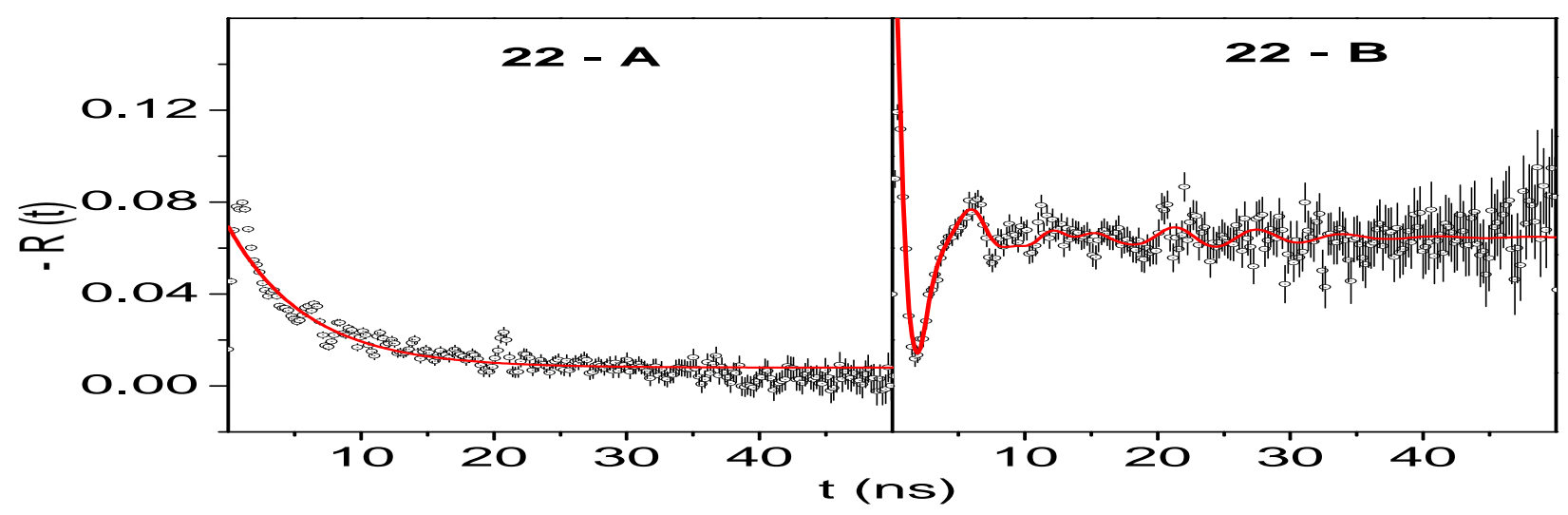

Figura 22 - Espectros de correlação angular perturbada para a amostra de $\mathrm{HfOCl}_{2} \mathrm{em}$ solução aquosa a $295(\mathrm{~A})$ e a $77 \mathrm{~K}$ (B)

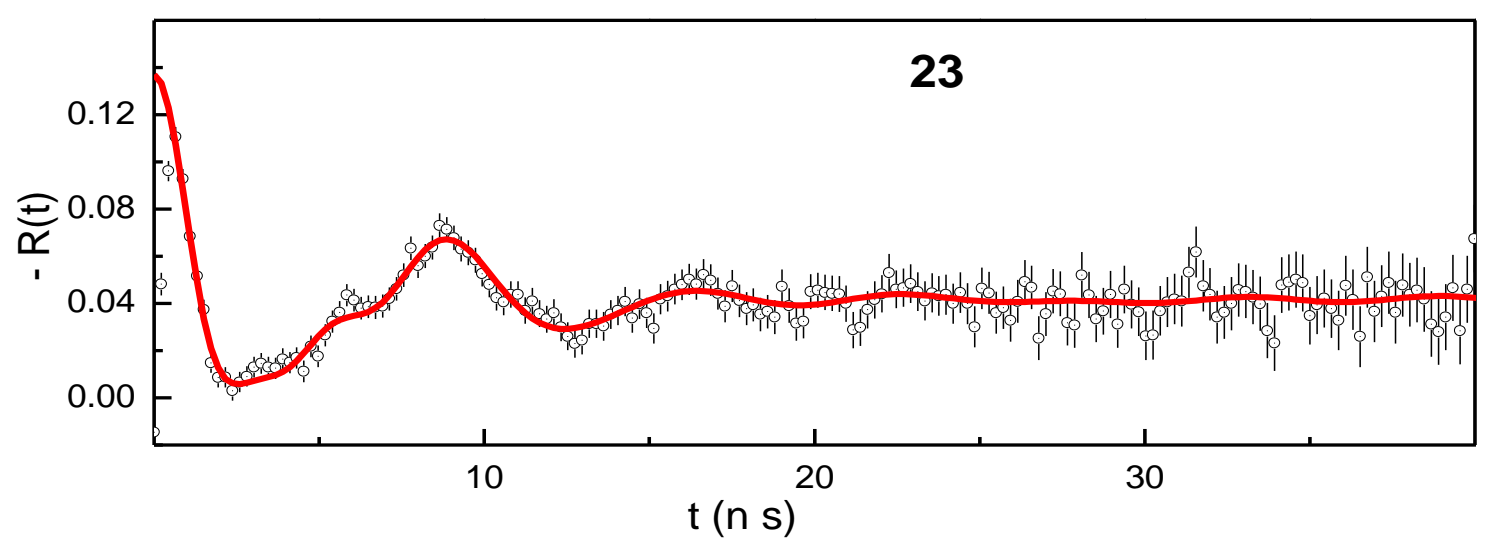

Figura 23 - Espectros de correlação angular perturbada para as amostras de $\mathrm{HfOCl}_{2}$ em solução tampão a pH 10 a $77 \mathrm{~K}$

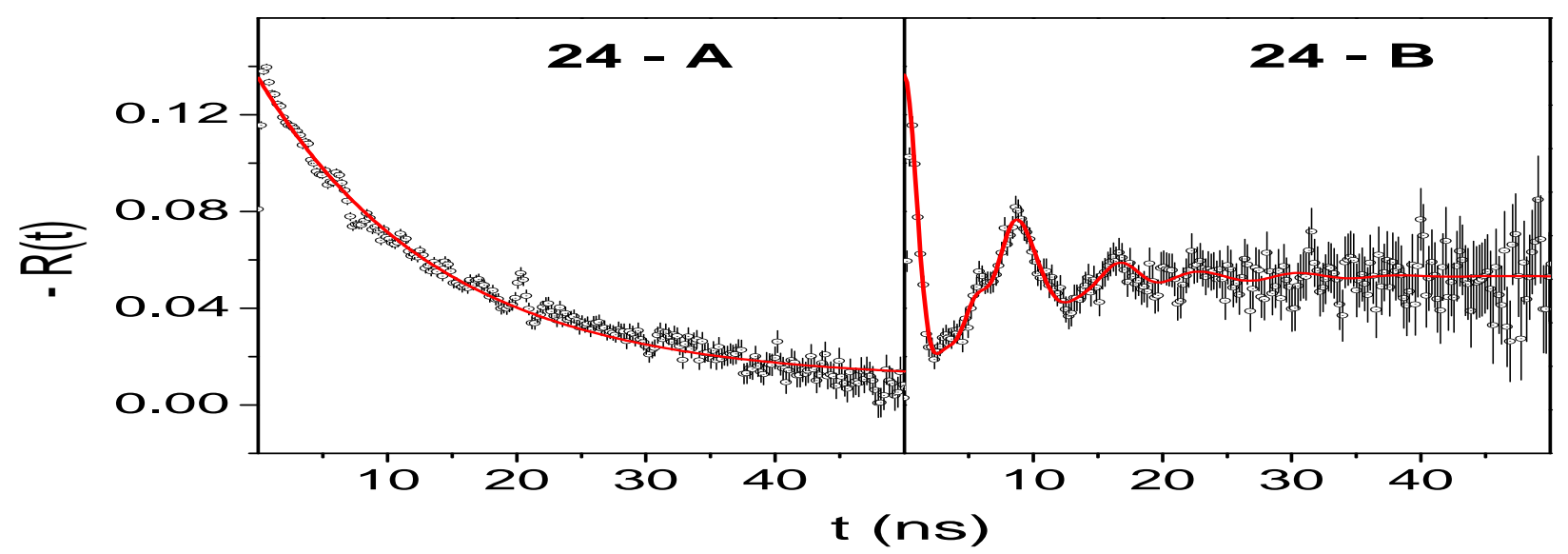

Figura 24 - Espectro de correlação angular perturbada para a solução de $\mathrm{HfOCl}_{2}+\mathrm{EDTA}$ em tampão pH 10: a 295K(A) e a77K (B) 
Tabela 6. Parâmetros Hiperfinos obtidos do núcleo de prova ${ }^{181}$ Ta em solução aquosa, em solução tampão com EDTA em pH entre 4 e 5 e com EDTA em pH entre 9 e 10.

\begin{tabular}{|c|c|c|c|c|c|c|c|c|}
\hline Amostra & Sitio & $\begin{array}{l}\text { Temp. } \\
\text { (K) }\end{array}$ & $\begin{array}{l}\text { Fração } \\
(\%)\end{array}$ & $v_{\mathrm{Q}}(\mathrm{MHz})$ & $\eta$ & $\lambda(\mathrm{MHz})$ & $\delta$ & $\begin{array}{l}\text { Amostra/ } \\
\text { Figura }\end{array}$ \\
\hline \multirow{2}{*}{${ }^{181}$ Ta em solução aquosa (amostra em branco) } & 1 & \multirow{2}{*}{77} & 80 & $957,0 \pm 45,0$ & $0,60 \pm 0,10$ & - & $0,10 \pm 0,10$ & \multirow{2}{*}{$1 / 19$} \\
\hline & 2 & & 20 & $545,0 \pm 10,0$ & $0,20 \pm 0,10$ & - & $0,06 \pm 0,10$ & \\
\hline \multirow{4}{*}{${ }^{181}$ Ta mais solução de EDTA em pH entre 4 e 5} & 1 & \multirow{2}{*}{77} & 87 & $517,5 \pm 20,0$ & $0,60 \pm 0,10$ & - & $0,2 \pm 0,10$ & \multirow{4}{*}{$2 / 20$} \\
\hline & 2 & & 13 & $678,0 \pm 15,0$ & $0,60 \pm 0,10$ & - & $0,03 \pm 0,10$ & \\
\hline & 1 & \multirow{2}{*}{295} & 89 & $457,0 \pm 30,0$ & $0,70 \pm 0,10$ & - & $0,2 \pm 0,10$ & \\
\hline & 2 & & 11 & $802,0 \pm 55,0$ & $0,20 \pm 0,10$ & - & $0,01 \pm 0,10$ & \\
\hline \multirow{4}{*}{$\begin{array}{l}{ }^{181} \text { Ta mais solução de EDTA em } \mathrm{pH} \text { entre } 4 \text { e } 5 \\
\text { cristalizada }\end{array}$} & 1 & \multirow{2}{*}{77} & 78 & $458,0 \pm 20,0$ & $0,60 \pm 0,10$ & - & $0,03 \pm 0,10$ & \multirow{4}{*}{$3 / 21$} \\
\hline & 2 & & 22 & $818,0 \pm 30,0$ & $0,80 \pm 0,10$ & - & $0,02 \pm 0,10$ & \\
\hline & 1 & \multirow{2}{*}{295} & 85 & $458,0 \pm 20,0$ & $0.60 \pm 0,10$ & - & $0,03 \pm 0,10$ & \\
\hline & 2 & & 15 & $722,0 \pm 50,0$ & $0,80 \pm 0,10$ & - & $0,02 \pm 0,10$ & \\
\hline \multirow{4}{*}{${ }^{181} \mathrm{Ta}\left(\mathrm{HfOCl}_{2}\right)$ em solução aquosa } & 1 & \multirow{2}{*}{77} & 89 & $1035,0 \pm 51,0$ & $0,50 \pm 0,10$ & - & $0,3 \pm 0,10$ & \multirow{4}{*}{$4 / 22$} \\
\hline & 2 & & 11 & $656,0 \pm 62,0$ & $0,70 \pm 0,10$ & - & $0,06 \pm 0,10$ & \\
\hline & 1 & \multirow{2}{*}{295} & \multirow{2}{*}{100} & \multirow{2}{*}{ 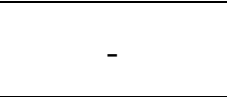 } & \multirow{2}{*}{-} & \multirow{2}{*}{$168,0 \pm 15,0$} & \multirow{2}{*}{-} & \\
\hline & 2 & & & & & & & \\
\hline \multirow{2}{*}{$\begin{array}{l}{ }^{181} \text { Ta }\left(\mathrm{HfOCl}_{2}\right) \text { solução aquosa + solução tampão a } \\
\text { pH } 10\end{array}$} & 1 & \multirow{2}{*}{77} & 20 & $723,0 \pm 34,0$ & $0,30 \pm 0,10$ & - & $0,1 \pm 0,10$ & \multirow{2}{*}{$5 / 23$} \\
\hline & 2 & & 80 & $832,0 \pm 11,0$ & $0,60 \pm 0,10$ & - & $0,1 \pm 0,10$ & \\
\hline \multirow{3}{*}{${ }^{181} \mathrm{Ta}\left(\mathrm{HfOCl}_{2}\right)+$ EDTA em tampão a pH 10} & 1 & \multirow{2}{*}{77} & 47 & $957,0 \pm 45,0$ & $0,60 \pm 0,10$ & - & $0,1 \pm 0,10$ & \multirow{3}{*}{$6 / 24$} \\
\hline & 2 & & 53 & $545,0 \pm 10,0$ & $0,20 \pm 0,10$ & - & $0,1 \pm 0,10$ & \\
\hline & 1 & 295 & 100 & - & - & $71,5 \pm 18,0$ & - & \\
\hline
\end{tabular}


Nestas condições, é possível a realização de análise através dos resultados obtidos pela técnica de correlação angular perturbada.

Os espectros das amostras 1 e 2 tanto a $295 \mathrm{~K}$ como a $77 \mathrm{~K}$ (figuras 19 e 20) demonstram que não há difusão rotacional devido ao tempo de correlação longo em relação ao tempo de interação do estado intermediário no decaimento do ${ }^{181}$ Ta. Entretanto, observa-se através dos espectros e dos resultados obtidos que o ${ }^{181} \mathrm{Hf}$ está ligado. O espectros da amostra do ${ }^{181} \mathrm{Hf}$ dissolvido em HF (amostra em branco) a $77 \mathrm{~K}$ demonstra que não há difusão rotacional e que efetivamente o ${ }^{181} \mathrm{Hf}$ se ligou fortemente ao íon fluoreto proveniente do ácido fluorídrico utilizado na dissolução do háfnio. Uma das possíveis estruturas formadas é o íon complexo $\left[\mathrm{HfF}_{6}\right]^{2-}[10]$ (figura $25-\mathrm{A}$ ). Segundo ALDOUS [18], também podem existir em meio aquoso, além do íon $\left[\mathrm{HfF}_{6}\right]^{2-}$, o íon $\left[\mathrm{HfF}_{7}\right]^{3-}$. O íon $\left[\mathrm{HfF}_{6}\right]^{2-}$ pode dimerizar formando o dímero $\left[\mathrm{Hf}_{2} \mathrm{~F}_{12}\right]^{4-}$ (figura $25-$ B), enquanto o íon $\left[\mathrm{HfF}_{7}\right]^{3-}$ pode formar os dímeros $\left[\mathrm{Hf}_{2} \mathrm{~F}_{13}\right]^{5-}$ e $\left[\mathrm{Hf}_{2} \mathrm{~F}_{14}\right]^{6-} \cdot 2 \mathrm{H}_{2} \mathrm{O}$ [17] (figuras $25-\mathrm{C}$ e D).

A presença de duas frequências, uma de $957 \mathrm{MHz}$ e outra de $545 \mathrm{MHz}$ (tabela 6) pode estar associada primeiro, à possibilidade do íon $\left[\mathrm{HfF}_{6}\right]^{2-}$ formado assumir estruturas diferentes no espaço (octaedro ou prisma trigonal) em função do íon central apresentar número de coordenação 6 (considerando o $\mathrm{Hf}^{4+}$ como íon central). A coordenação octaédrica é a mais comum [6, 10 e 44]. Em segundo lugar à possibilidade de formação dos dímeros dos íons $\left[\mathrm{HfF}_{6}\right]^{2-}$ e $\left[\mathrm{HfF}_{7}\right]^{3-}$ (figuras $25-\mathrm{A}, 25-\mathrm{B}, 25-\mathrm{C}$ e $25-\mathrm{D})$.

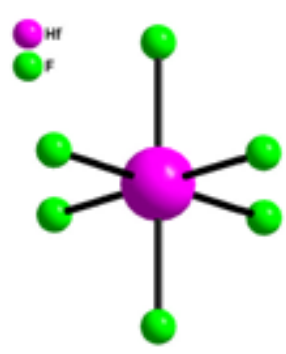

Figura 25-A - Monômero $\left[\mathrm{HfF}_{6}\right]^{2-}$

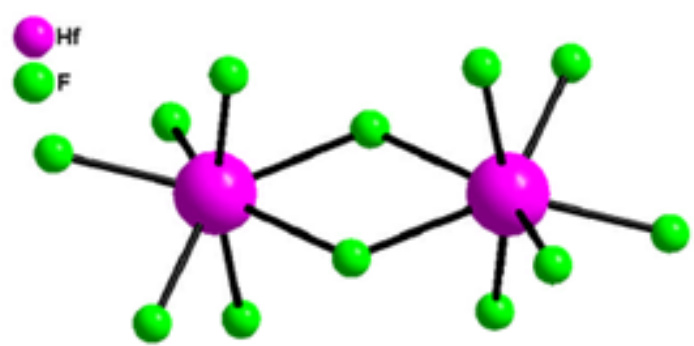

Figura $25-\mathrm{B}-$ dimero $\left[\mathrm{Hf}_{2} \mathrm{~F}_{12}\right]^{4-}$ 
Os dados para as amostras contendo EDTA (amostra 2) apontam também para a existência de dois sítios de ligação, porém não há qualquer evidência de que o EDTA tenha se ligado diretamente ao núcleo de prova e este fato concorda com o estudo desenvolvido por CHAIN E PASQUEVICH [45]. Como as duas frequências de quadrupolo encontradas para a amostra com EDTA são diferentes daquelas apresentadas pela amostra em branco, provavelmente o EDTA ligou-se aos dímeros $\left[\mathrm{Hf}_{4} \mathrm{~F}_{12}\right]^{4-}$ e $\left[\mathrm{Hf}_{2} \mathrm{~F}_{14}\right]^{2-}$ através de pontes de hidrogênio a semelhança do que acontece com dímero $\left[\mathrm{Hf}_{2} \mathrm{~F}_{12}\right]^{4-}$ - trietilenotetramina representado na figura 26 [18]. A molécula de EDTA ligada aos dímeros provocaria uma mudança na carga redundando na mudança de frequência quadrupolar (Tabela 6).

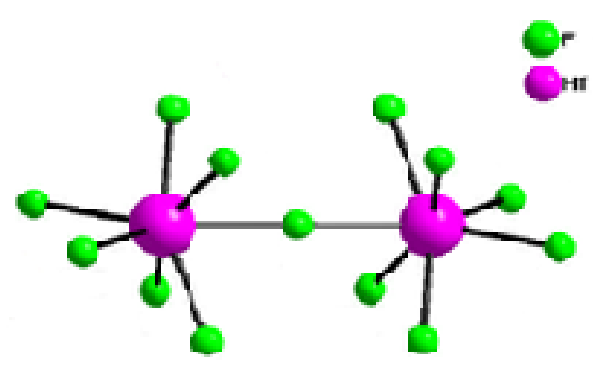

Figura $25-\mathrm{C}-$ Dimero $\left[\mathrm{Hf}_{2} \mathrm{~F}_{13}\right]^{5-}$

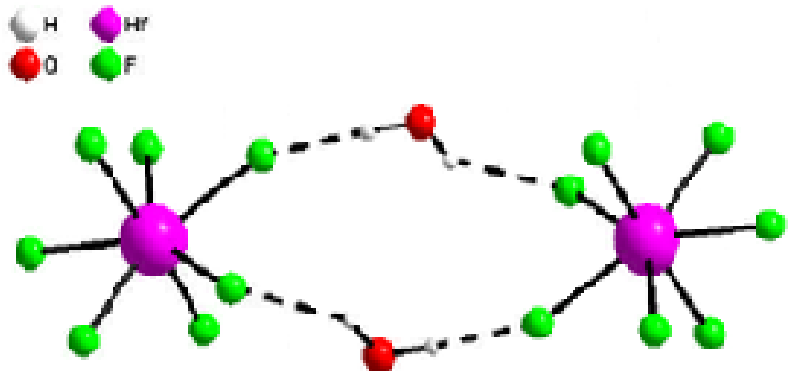

Figura $25-\mathrm{D}$ - Dimero $\left[\mathrm{Hf}_{2} \mathrm{~F}_{14}\right]^{6-} \cdot 2 \mathrm{H}_{2} \mathrm{O}^{-}$

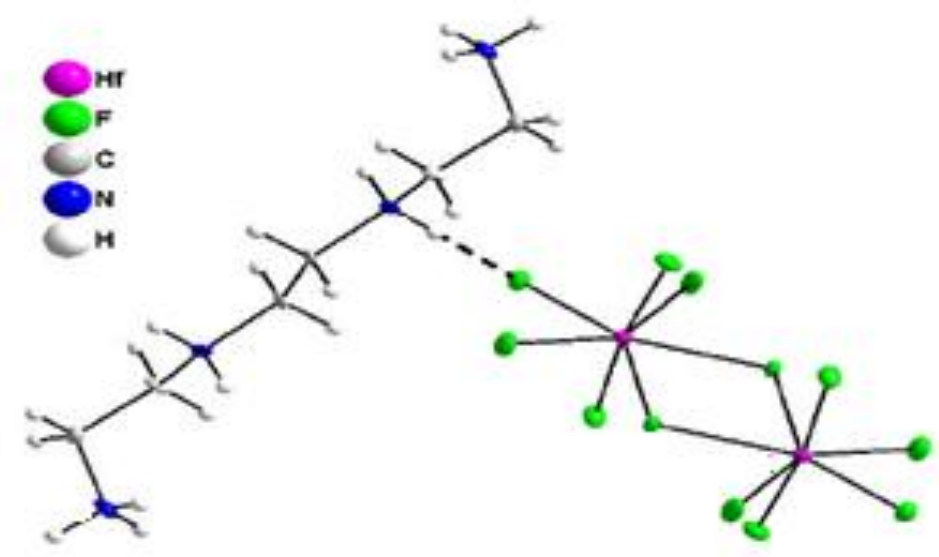

Figura 26 - Estrutura da molécula de trietilenotetramina ligada ao dímero $\left[\mathrm{Hf}_{2} \mathrm{~F}_{12}\right]^{4}$

Ao cristalizar a solução (amostra3) por meio da vaporização da água, os íons sódio provenientes do EDTA, provavelmente se aproximaram dos dímeros 
$\left[\mathrm{Hf}_{2} \mathrm{~F}_{13}\right]^{5-}$ e $\left[\mathrm{Hf}_{2} \mathrm{~F}_{14}\right]^{6-}$ formando os compostos $\mathrm{Na}_{3} \mathrm{Hf}_{7}$ e $\mathrm{Na}_{5} \mathrm{Hf}_{2} \mathrm{~F}_{13}$ [44] responsáveis pelas alterações nos parâmetros hiperfinos listados na tabela 6. Comparando os dados para as amostras a temperatura ambiente e resfriado a temperatura do nitrogênio líquido, pode-se perceber que as estruturas se mantiveram praticamente inalteradas.

Na figura 22-A (amostra 4), onde é mostrado o espectro de correlação angular para a solução do oxicloreto de háfnio, observa-se que há difusão rotacional evidenciando a existência da ligação do núcleo de prova. Como o ambiente está livre de ligantes além da água, a ligação do háfnio seria justificada pela a hidrólise com a consequente formação de aquao-complexos de háfnio [34] que seriam responsáveis pelas frequências de quadrupolo medidas para a amostra resfriada e que estão apresentadas na tabela 6 .

A elevação do $\mathrm{pH}$ a presença de novos ligantes $\left(\mathrm{CO}_{3}{ }^{2-}\right.$ e $\left.\mathrm{HCO}_{3}{ }^{-}\right)$provocada pela presença da solução tampão levou a formação de novas espécies evidenciadas pelo espectro mostrado na figura 23 (amostra 5) e pelos parâmetros apresentados na tabela 6 e este fato concorda com a referência [34].

Na presença do ligante EDTA (amostra 6), o Hf liga-se ao mesmo formando um complexo Hf-EDTA como fica evidente pela presença da difusão rotacional mostrado nos espectros de correlação angular (figura 24-A) e pela presença dos parâmetros hiperfinos que são diferentes daqueles apresentados pela amostra sem EDTA (tabela 6). 


\section{CAPÍTULO 7}

\section{CONCLUSÕES E PERPECTIVAS}

As medidas de interações hiperfinas incluindo seu caráter dinâmico, por meio da técnica de Correlação Angular Perturbada realizadas neste trabalho, permitiram uma primeira análise do comportamento dinâmico e dos parâmetros hiperfinos em função da temperatura e do $\mathrm{pH}$ para as amostras analisadas. Abaixo descrevemos as conclusões de acordo com as argumentações apresentadas no capítulo anterior para cada um dos casos.

\subsection{Conclusões e Perspectivas}

O conhecimento da estrutura molecular de compostos bioinorgânicos tem sido objeto de muitos estudos nos últimos anos por se tratar de um aspecto muito importante para a compreensão dos mecanismos químicos que os envolvem principalmente nos organismos vivos. No entanto a investigação das estruturas desses 
compostos não é uma tarefa fácil por se tratarem de moléculas grandes como as proteínas e por se apresentarem em sistemas aquosos como os citoplasmas celulares. No presente trabalho realizou-se a investigação de Interações Hiperfinas elétricas e incluindo seu caráter dinâmico em amostras de soluções contendo ligantes como o $\mathrm{F}^{-}$, $\mathrm{OH}^{-}$e o EDTA a $295 \mathrm{~K}$ e $77 \mathrm{~K}$ utilizando-se o ${ }^{111} \mathrm{In},{ }^{111 \mathrm{~m}} \mathrm{Cd}$ e o ${ }^{181} \mathrm{Hf}$.como pontas de provas.

\subsubsection{Amostras com ${ }^{111}$ In $\mathrm{e}^{111 \mathrm{~m}} \mathrm{Cd}$ como pontas de prova}

A 295K foi observado claramente interações de natureza dinâmica para as amostras de solução saturada de EDTA contendo o ${ }^{111}$ In como ponta de prova tanto em pH da própria solução saturada de EDTA como em pH entre 9 e 10 ajustado com $\mathrm{NaOH}$, o que indica que o Indio-111, isótopo-pai utilizado, efetivamente se ligou ao EDTA formando um complexo In-EDTA. Em pH mais elevado a ligação se torna facilitada pela desidrogenação do EDTA.

Para a amostra o ${ }^{111 \mathrm{~m}} \mathrm{Cd}$ em solução aquosa não foi observada nenhuma interação o que indica que em meio aquoso, nas condições em que foram realizadas as medidas o $\mathrm{Cd}$, provavelmente formou clusters simétricos que resistiram à presença dos ligantes presentes no meio $\left(\mathrm{NO}_{3}{ }^{1-}, \mathrm{OH}^{1-}\right.$ além das espécies provenientes do EDTA).

Nas amostras contendo o ${ }^{111} \mathrm{In}$ e ${ }^{111 \mathrm{~m}} \mathrm{Cd}$ mais EDTA a $77 \mathrm{~K}$ verifica-se a predominância de interação de natureza estática. 


\subsubsection{Amostras com ${ }^{181} \mathrm{Hf}$ como ponta de prova}

Nas amostras contendo ${ }^{181} \mathrm{Hf}$ como ponta de prova obtido a partir da dissolução háfnio metálico em ácido fluorídrico concentrado, não se observa interação de natureza dinâmica mesmo para as amostras a 295K, o que indica a formação de íons complexos de fluoretos de háfnio (núcleo-pai) com diferentes estequiometrias. Estas estruturas de fluoretos de háfnios permanecem inalteradas mesmo na presença do quelante EDTA.

Para as amostras contendo o ${ }^{181} \mathrm{Hf}$ obtido a partir da solução do oxicloreto de háfnio, verifica-se interações de natureza dinâmica para as amostras medidas a 295K, forte evidência de que o $\mathrm{Hf}^{4+}$ (núcleo-pai) se liga ao EDTA. Em solução tampão verifica-se a hidrólise do háfnio com a consequente formação de aquao-complexos de háfnio, mas que na presença do EDTA como ligante, estes complexos se desfazem e quelatos de háfnio são formados.

Assim, com o presente trabalho, podemos concluir que:

- A técnica de Correlação Angular Gama-gama Perturbada mostra-se eficiente para a investigação de Interações Hiperfinas incluindo sua natureza dinâmica em compostos mesmo em meio aquoso e a temperatura ambiente.

- $\mathrm{O}{ }^{181} \mathrm{Hf}$ proveniente do háfnio metálico dissolvido em HF concentrado não é indicado, pois a ligação entre ${\mathrm{o} \mathrm{Hf}^{4+}}^{4} \mathrm{~F}^{1-}$ é muito forte o que impede qualquer outro ligante de se ligar ao $\mathrm{Hf}^{4+}$.

- Admitindo-se a metodologia empregada nesse trabalho, o $\mathrm{Cd}-111 \mathrm{~m}$ não se mostrou adequado, primeiro por não apresentar afinidade química com os ligantes empregados e também, devido a elevada concentração do $\mathrm{Cd}^{2+}$ no sistema o que possibilita a formação de clusters.

- O ${ }^{111}$ In pode ser aplicado como sonda em investigações dessa natureza embora seja necessário a investigação das possíveis consequências do "aftereffects". 
- $\mathrm{O} \mathrm{HfOCl} 2$ é adequado para fornecer o $\mathrm{Hf}^{4+}$ como ponta de prova para ligação com o EDTA.

\subsection{Perspectivas}

Como perspectivas para futuros trabalhos pode-se confrontar a técnica CAP com outras técnicas como a difração de raios $\mathrm{X}$ para amostras cristalizadas $\mathrm{e}$ espectroscopia de infravermelho para a investigação das estruturas em meio aquoso.

Pode-se ainda aprimorar a metodologia de preparação de amostras para o

${ }^{111 \mathrm{~m}} \mathrm{Cd}-{ }^{111} \mathrm{Cd}$ para que possa se eliminar a eventual presença do efeito pós captura eletrônica presente quando se utiliza o ${ }^{111} \mathrm{In}-{ }^{111} \mathrm{Cd}$ como ponta de prova embora não tenha sido possível, no presente trabalho, estabelecer uma relação entre os parâmetros hiperfinos obtidos e o efeito pós captura eletrônica decorrente da desexcitação do índio. 


\section{BIBLIOGRAFIA}

[1] HEMMINGSEN, L.; SAS, K.N.; DANIELSEN,E. Biological Applications of Perturbed Angular Correlations of $\gamma$-Ray Spectroscopy. Chem. Rev., 104, p. 4027-4061, 2004

[2] LEIPERT, T. K; BALDESCHWIELER, J. D and SHIRLEY, D. A. Applications of gamma ray angular correlations to the study of biological macromolecules in solutions. Nature. 200, p. 907-909, 1968

[3] KARLSSON, E.; MATthiAS, E.; SIEGBAHN, S. Perturbed Angular Correlation, North-Holland, Amsterdam, 1965.

[4] BENITE, Ana Maria Canavarro, MACHADO, Sergio de Paula, BARREIRO, Eliezer .; Uma visão da química bioinorgânica medicinal. Quim. Nova, Vol. 30, No. 8, p. 2062-2067, 2007.

[5] O’CONNOR, Rod; Fundamentos de Química. São Paulo: Harbra, 1977.

[6] SHRIVER, D.F; ATKINS, P. W.; OVERTON, T.L.; ROURKE, J.P.;WELLER,M.T.;ARMSTRONG, F.A. Química Inorgânica. $4^{\text {a }}$ edição. Porto Alegre, Bookman, 2008.

[7] OLIVEIRA, Ótom Anselmo de. Fundamentos da Química de Coordenação In. FARIAS, Robson Fernandes de. Química de Coordenação - fundamentos e atualidades. Campinas: Editora Átomo, 2005, p. 19-86.

[8] ATKINS, Peter,JONES, Loretta; Princípios de Química - questionando a vida moderna e o meio ambiente. Porto Alegre: Bookman, 2001. 
[9] FARIAS, Robson Fernandes de, OLIVEIRA, Ótom Anselo de. Breve Histórico da Química de Coordenação In. FARIAS, Robson Fernandes de. Química de Coordenação - fundamentos e atualidades. Campinas: Editora Átomo, 2005, p. 9-18

[10] LEE, J.D. Química Inorgânica Não Tão Concisa. $5^{\mathrm{a}}$ Ed. São Paulo: Edgard Blucher, 1999.

[11] MAIA, Elene Cristina Pereira; DEMICHELI, Cynthia Peres. Química de Coordenação em sistemas Biológicos. In. FARIAS, Robson Fernandes de. Química de Coordenação - fundamentos e atualidades. Campinas: Editora Átomo, 2005, p. 157-193.

[12] AYALA, José Danilo. Química Inorgânica - Definições de Ácidos e Bases. Disponível em: http://qui.ufmg.br/ ayala/matdidatico/acidobase.pdf. Acesso em $18 / 04 / 2011$

[13] CHISHOM, Malcolm. A vestimenta dos íons metálicos: a química de coordenação na virada do milênio. In.HALL, Nina. Neoquímica. Porto Alegre: Bookman, 2004, p. 105-120.

[14] BERTOTTI, M. Estudos Potenciométricos Sobre a Formação de Complexos Entre Indio (III) e Azoteto, em Meio Aquoso. 1986. Dicertação (Mestrado) Instituto de Química da Universidade de São Paulo, São Paulo.

[15] OLIVEIRA, A.F. Equilíbrios em solução aquosa orientados à aplicação Sistemas Ácido-base de Bronsted e outros equilíbrios. Campinas: Editora Átomo, 2009.

[16] F. FALK, A. LINNFORS and J. E. THUN. A Search for After-effects of the ${ }^{111}$ In EC decay on the ${ }^{111} \mathrm{Cd} \gamma \gamma$ correlation. Nuclear Physics A152 (1970), p. 305316; North-Holland Pubfishiny Co., Amsterdam.

[17] FERREIRA, Elizabeth de Magalhães Massena. Uso de Espuma de Poliuretano na Extração de Índio de Meio Iodeto, 2003. Tese (Doutorado) - Pontifícia Universidade Católica do Rio de Janeiro, Rio de Janeiro. 
[18] ALDOUS, David W. Solvothermal chemistry of early transition metal fluorides. 2008. Thesis Submitted for the Degree of $\mathrm{PhD}$ at the University of St. Andrews, Escócia.

[19] ELISON, S. V. \& PETROV, K. I. Analytical chemistry of zirconium and hafnium. London, Ann Arbor, 1969.

[20] WANG, J.; LI, H.P.; STEVENS, R. Hafinia and hafinia-toughned ceramics. J. Mater. Sci., 21:p. 5397 - 5430, 1992.]

[21] ZARPELON, L. M. C. Contribuição ao Estudo da Separação Zircônio/Háfnio no Sistema MIBK-HSCN-HCI. 1995. Tese (Doutorado) - Instituto de Pesquisas Energéticas e Nucleares, São Paulo.]

[22] LAPOLLI, A.L. Estudo de Interações Hiperfinas em compostos intermetálicos Gd(Ni,Pd)In, Dy(Ni,Pd)In e Ho(Ni,Pd)In. 2006. Tese (Doutorado) - Instituto de Pesquisas Energéticas e Nucleares, São Paulo].

[23] DUNWORTH, J.W. The application of the coincidence counting to experiments in nuclear physics. Nucl. Instrum. Meth., v. 11, p. 167-80,1940]

[24] HAMilton, D. R. On directional of sucessive quanta. Phys. Rev., v. 58, p.122$131,1940]$

[25] GOERTZEL, G. Angular correlação of gamma-rays. Phys. Rev., v. 70, p.897909, 1946

[26] AlDER, K.; ALVERSSCHONBERG, H.; HEER, E. ; NOVEY, T. B. The measurement of nuclear moments of excited states by angular correlation methods. Helverica. Phys. Acta, v. 26, p. 761-784, 1953.

[27] ABRAGAM, A. and POUND, R. V., Influence of electric and magnetic fields on angular correlations. Phys. Rev. 92, p. 943-962, 1953.

[28] FRAUENFELDER, H.; STEFFEN, R. M.; de GROOT, S.R.; TOLHOEK, H.A. HUISKAMP, W.J. Angular distribuition of nuclear radiation. In SIEGBAHN,K. (Ed.). Alfa, beta-gamma Ray spectroscopy, North-Holland, Amsterdan, $5^{\text {a Ed, }}$ v. 2, p. 997-1198, 1968. 
[29] FRAUENFELDER, H. Influence of the atomic shell on nuclear angular correlation. Phys. Rev. v.82, p. 549-550, 1951.

[30] AEPPLI, H. ; BISHOP, A.S. ; FRAUENFELDER, H.; WALTER,M. ; ZUNTI. W., Influence of the atomic Shell on nuclear angular correlation in ${ }^{111} \mathrm{Cd}$. Phys. Rev. V.82, p. 550-551, 1951.

[31] SAITOVITCH, Henrique; SILVA, Paulo R. J. Interações hiperfinas em catalisadores metálicos. Quim. Nova, Vol. 28, No. 3, p. 529-534, 2005].

[32] SHPINKOVA L.G., CARBONARI, A.W., NIKITIN, S.M., MESTNIK-FILHO, J., Influence of electron capture after-effects on the stability of ${ }^{111} \operatorname{In}\left({ }^{111} \mathrm{Cd}\right)$ complexes with organic ligands, Chemical Physics 279 255-263, 2002.

[33] V.N. Kulakov, S.M. Nikitin, T.N. Babushkina, A.N.Shirokov, A.A. Sorokin, B.A. Komissarova, L.G. Shpinkova, G.K. Ryasny, Koordinatsionnaya Khimiya 23 (1997) 883.

[34] L.G. Shpinkova, V.N. Kulakov, A.A. Sorokin, G.K. Ryasny, B.A. Komissarova, S.M. Nikitin, Z. Naturforsch. 53a (1998) 630.

[35] RINNEBERG, H.H. Aplication of pertubed angular correlations to chemistry and related áreas of solid state physiscs. Atomic Energy Rev., v. 17: p. 477-595, 1979]

[36] SHCATZ, G; WEIDINGER, A. Nuclear Condensed Matter Physics: Nuclear, Methods end Aplications. Ed. J. Wiley e Sons, 1992.

[37] MACGONWAN, F.K. Angular correlations of gamma rays in 181Ta. Phys. Rev., 93: 471-7, 1961.;

[38] GRABOWKI, Z.; PETTERSSON, B.G.; GERHOLM, T. R.; THUM, J.E. Penetration matrix elements and nuclear structure effects in 181Ta. Nucl. Phys., 24: 251-68, 1961.

[39] HASS, H., CORREIA, J. G. The quadrupole moments of Zn and Cd isotopes - an update. Hyperfine Interactions, v. 198, p. 133-137, 2010. 
[40] BLOCHL, P.E. Projector augmented-wave method. Phys. Rev. B 50, 17953, 1994

[41] DOMIENIKAN, C. Uma interface eletrônica para Aquisição de 12 Espectros de Coincidências Gama-Gama Atrasadas. 2001. Tese (Mestrado), Instituto de Pesquisas Energéticas e Nucleares, São Paulo.

[42] MESTNIK F. J. Tratamento de Dados de Correlação Angular Perturbada, comunicação privada, 2002

[43] ARENDS, A. Data reduction methodology of Perturbed Angular Correlation experiments. Hiperfine Interactions, v.8, p. 191-213, 1980.

[44] JONES, Chris J. A Química dos Elementos dos Blocos d e f, Porto Alegre, Editora Bookman, 2002

[45] CHAIN, Cecília Y., PASQUEVICH, A.F: On hafnium chelation by EDTA and DTPA for TDPAC experiments. Hyperfine Interact. Published online: 13 January 2011. 